\title{
A new polycotylid plesiosaur with extensive soft tissue preservation from the early Late Cretaceous of northeast Mexico
}

Eberhard Frey, Eric W.A. Mulder, Wolfgang Stinnesbeck, Héctor E. Rivera-Sylva, José Manuel Padilla-Gutiérrez, Arturo Homero González-González

Eberhard Frey

dinofrey@aol.com

Staatliches Museum für Naturkunde Karlsruhe, Geowissenschaftliche Abteilung, Erbprinzenstraße 13, 76133 Karlsruhe, Germany.

\section{Eric W. A. Mulder}

Museum Natura Docet Wonderryck Twente, Oldenzaalsestraat 39, 7591 GL Denekamp, the Netherlands.

\section{Wolfgang Stinnesbeck}

Universität Heidelberg, Institut für Geowissenschaften, Im Neuenheimer Feld 234-236, 69120 Heidelberg, Germany.

Héctor E. Rivera-Sylva José Manuel Padilla-Gutiérrez Arturo Homero González-González Museo del Desierto, Carlos Abedrop Dávila 3745, Centro Metropolitano, Parque Las Maravillas, 25022 Saltillo, Mexico.

BOL. SOC. GEOL. MEX. 2017

VOL. 69 NO. 1

P. $87-134$

\begin{abstract}
A nearly complete skeleton of a polycotylid plesiosaur is described from the early Late Cretaceous laminated limestones at Vallecillo, northeast Mexico. It shows extensive soft tissue preservation. In some exceedingly well preserved areas there are transversely elongate rectangular to trapezoid millimetric scale-like structures arranged in longitudinal rows. The trailing edge skin flap preserves fibers and scale rows perpendicular to the trailing edge. A thick layer of subdermal tissue is present, especially along the tail base. It was responsible for the hydrodynamic drop-shaped body contour, with the body and tail forming a single unit. The body shape determined from the preserved soft tissues suggests a swimming speed similar to extant leatherback turtles. Based on the unique osteology of the palate, which is intermediate between Dolichorhynchops and Trinacromerum, and according to the unique morphology of the girdles and propodials as well as the medially converging gastralia, the new specimen is placed in a new genus and species of Polycotylidae, Mauriciosaurus fernandezi gen. et sp. nov.
\end{abstract}

Keywords: Vertebrate palaeontology, Plesiosauria, Polycotylidae, Late Cretaceous, northeast Mexico, soft tissue preservation, palaeoecology.

\section{RESUMEN}

Se describe el esqueleto casi completo de un nuevo plesiosaurio polycotílido. El ejemplar procede de las calizas laminares de Vallecillo del noreste de México y fue asignada estratigráficamente a la parte temprana del Cretácico Tardio. En las porciones mejor preservadas de las partes blandas se identificaron estructuras milimétricas, alargadas transversalmente de forma rectangular a trapezoidal, y con orden longitudinal. En la solapa, el borde posterior de la piel preserva fibra y escamas, ordenadas en filas y perpendiculares al borde de salida. Se identificó una capa de tejido subdermal, la que es particularmente gruesa en la base de la cola y debe haber contribuido al contorno hidrodinámico en forma de gota del animal, formándose una entidad entre el cuerpo y la cola. De acuerdo con el contorno y los tejidos blandos, se presume que la velocidad del animal debe de haberse aproximada a la de una tortuga laúd. La enigmática osteología del paladar, intermedio entre Dolichorhynchops y Irinacromerum, la morfología única de los cinturones y propodiales, igual que las vértebras gastrales medialmente convergentes, permiten asignar el nuevo espécimen a un nuevo género y especie de los Polycotilidae, Mauriciosaurus fernandezi gen. et sp. nov.

Palabras clave: Paleontología de vertebrados, Plesiosauria, Polycotylidae, Cretácico Tardío, noreste de México, preservación de partes blandas, paleoecología. 


\section{Introduction}

Plesiosauria are one of the dominant groups of Mesozoic marine reptiles. Besides the enigmatic Pistosaurus and its allies of Middle to late Triassic age, two 'suborders' are distinguished in traditional systematics, the either long- or short-necked Plesiosauroidea and the exclusively short-necked Pliosauroidea (Carpenter, 1997; Druckenmiller and Russell, 2008; Ketchum and Benson, 2010; O'Keefe, 2001). A body with a rounded triangular or oval cross-section and a tail, whose length is shorter than the body, are the main features that characterize all Plesiosauria. Plesiosaurs swam with four hydrofoil-shaped flippers of almost equal size with dorsoventrally flattened limb bones, a unique pattern of aquatic locomotion. Among Plesiosauria, flipper size varies with respect to body size (Ellis, 2003; Hampe, 1992). The skeletal anatomy of these predatory marine reptiles is known from numerous excellently preserved specimens, and much is known about their life style, but little about their reproduction and ontogeny (Noé, 1999; O’Keefe and Carrano, 2005; O’Keefe and Chiappe, 2011; Taylor, 1986). The diet of elasmosauroids and pliosauroids is evidenced by rare fossil stomach contents and the body cavity of some specimens also contains gastroliths, the role of which is still debated (Brown, 1904; Cicimurri and Everhart, 2001; Cope, 1872; Martill, 1992; McHenry et al., 2005; Taylor, 1993). While subaqueous flight is generally accepted as the main mode of locomotion, the mode of flipper operation remains debated as the role of the tail (Frey and Riess, 1982; Godfrey, 1984; Halstead, 1989; Lingham-Soliar, 2000; Robinson, 1975; Sanders et al., 2004; Taylor, 1981). Reconstructions of plesiosaurs with a tail fin are based on a single specimen of Seeleyosaurus guilelmïmperatoris (Dames, 1895) from the Early Jurassic of Holzmaden (South Germany). This specimen shows a black expanded substance dorsal to the posterior quarter of the posterior vertebral column. However, Großmann (Großmann, 2006) states that after a detailed study of the specimen that this tail fin is likely to have been fabricated. There is discussion on whether plesiosaurs could crawl on land, as do sea turtles and pinnipeds, and on how fast they could swim (Taylor, 1986). The discovery of a pregnant female of a polycotylid plesiosauroid, a longirostrine group of Late Cretaceous plesiosaurs, provides evidence that Plesiosauria were viviparous and did not need to emerge on land for the purpose of egg laying (O'Keefe and Chiappe, 2011 ).

Despite numerous complete and fully articulated skeletons being available, there is a lack of soft tissues in the fossil record of Plesiosauria. Even in localities where soft tissue preservation is well known from other vertebrates in the assemblage there is no unequivocal record of soft tissue for plesiosaurs. In one single Holzmaden specimen of Hydrorion brachypterygius in the collection of the Geologisch-Paläontologisches Institut at Tübingen, Germany (GPIT/RE/3185), a black substance trailing the proximal half of the posterior margin of the front fins is preserved suggesting a skinny flexible trailing edge (Großmann, 2006; Robinson, 1975). Besides the tail fin (Dames, 1895) this represents the only record of soft tissue preservation in plesiosaurs. Information on the body shape of plesiosaurs and the surface structure of their skin remains a mystery.

Polycotylid plesiosaurs are a cosmopolitan taxon with a temporal range extending from the Early Aptian to the Late Maastrichtian (Druckenmiller and Russell, 2009). One of the currently oldest representatives, the Australian Umoonasaurus demoscyllus (Kear et al., 2006), is no longer referred to Polycotylidae by most authors (Druckenmiller and Russell, 2009). The same is true for Edgarosaurus muddi from the Late Albian Thermopolis Shale of the United States which, according to many authors, lies outside Polycotylidae (Albright III et al., 2007a; Benson et al., 2013; Schumacher, 2007; Schumacher et al., 2016) Two specimens, AM 6206-6298 and SAM P36356, both from the Aptian or Albian Bulldog shale of Australia (Kear, 2006), have not been formally named. The earliest polycotylid from North America, TMP 95.87.01, comes from the Albian Clearwater For- 
mation of Alberta, Canada, and is also unnamed. Thus, the earliest named polycotylids are those reported from the Cenomanian of North America [Eopolycotylus rankini, (Albright III et al., 2007a), Palmulasaurus quadratus, (Albright III et al., 2007a, b), Pahasapasaurus haasi, (Schumacher, 2007)] and Morocco [Thililua longicollis, (Bardet et al., 2003)]. The geologically youngest polycotylid has no formal name or collection number and comes from New Zealand (Kear, 2006: p. 847, Figure 2E). The geologically youngest named species, Sulcusuchus erraini comes from near the Campanian/Maastrichtian boundary of Argentina (Gasparini and Fuente, 2000).
This report describes a new genus and species of polycotylid plesiosaur (collection number INAH CPG RFG 2544 P.F.1) from the Late Cretaceous of northeast Mexico. The specimen comes from laminated limestones cropping out around the town of Vallecillo $\left(26^{\circ} 39^{\prime} \mathrm{N} 99^{\circ} 59^{\prime} \mathrm{W}\right)$, about 100 $\mathrm{km}$ north of the City of Monterrey, Nuevo León (Figure 1). The skeleton is complete, fully articulated and represents the first plesiosaur preserving dermal surface structures in fine detail. The specimen was discovered in summer 2011 by a group of workmen in an active limestone quarry in the vicinity of Vallecillo.

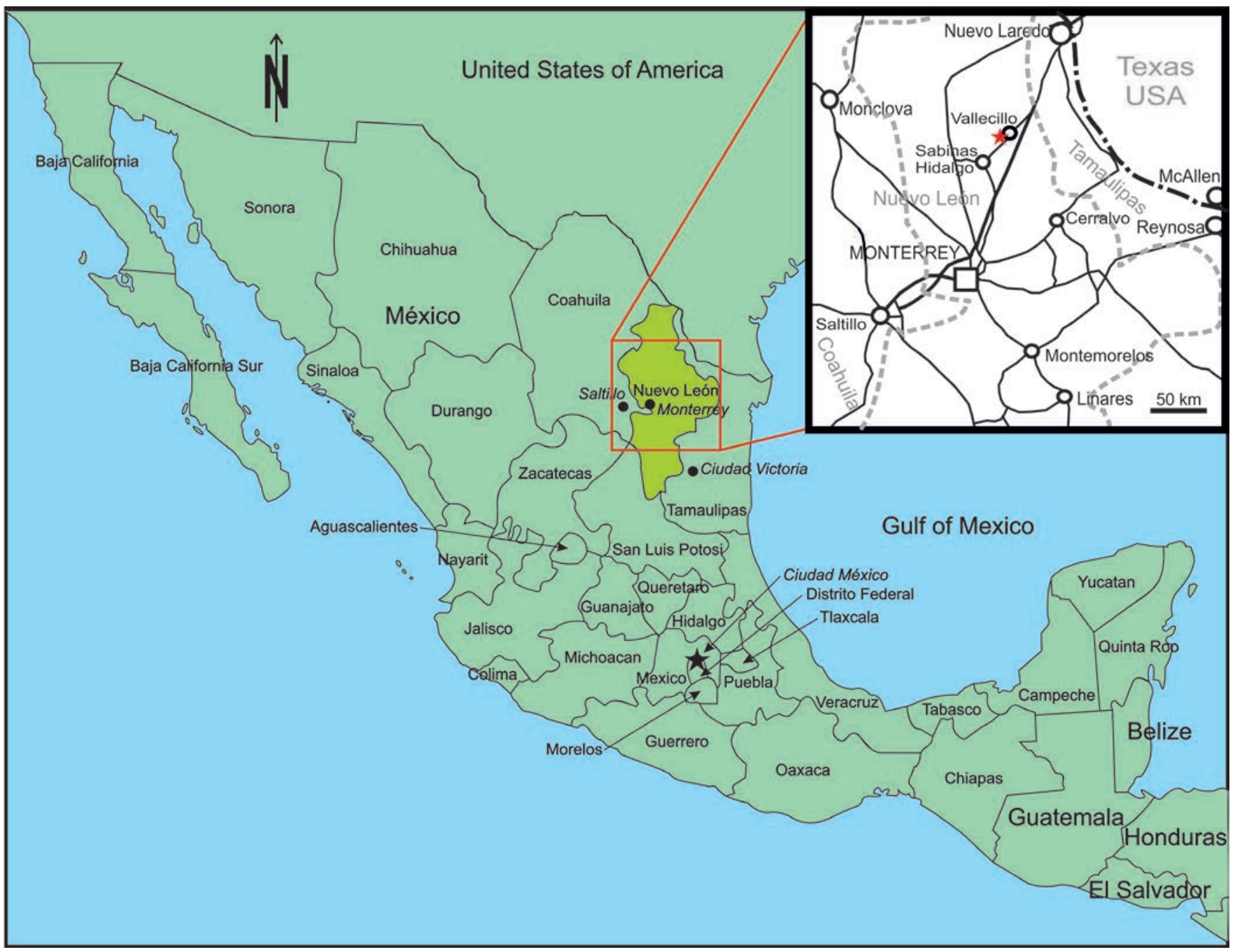

Figure 1 Geographical position of the town of Vallecillo. The new polycotylid comes from the quarry field in the close vicinity of Vallecillo. The exact quarry of provenance cannot be reconstructed, because the slabs were already loaded on a truck. 


\section{Material and method}

The material comprises a single specimen preserved in finely laminated, micritic limestone. Photographs were taken with an Olympus TG 1 ("Tough") and an Olympus E 620 with a Zuiko Digital $14-42 \mathrm{~mm}$ lens, 1:3.5 - 5.6 and a Zuiko Digital Macro $35 \mathrm{~mm}$ lens, 1:3.5. Low angle light photography was performed with an infrared controlled Olympus Electronic Flash FL 36R. Photographs were traced with CorelDraw X6. The drawings were designed using the same program. The specimen was investigated under natural and artificial low angle illumination.

\section{Geological setting}

The new specimen comes from the Cenomanian to Turonian Agua Nueva Formation, a dominantly carbonate unit comprising thick sequences of cyclic limestone and shale that are widely distributed in northeastern Mexico. These strata were deposited in a moderately deep shelf of low relief, which were developed along the western coast of the Gulf of Mexico extending as far as the Western Interior of the United States of America and Gulf of Mexico Basin (Goldhammer and Johnson, 2001; Ifrim, 2006; Muir, 1936; Sohl et al., 1991).

The Agua Nueva Formation is generally poor in macrofossils (Sohl et al., 1991), but it includes a unit of thin-bedded laminated limestone and marl (plattenkalk) with abundant and exquisitely preserved vertebrates of latest Cenomanian to earliest Turonian age. The fauna includes a diverse assemblage of fishes (selachians, crossopterygians, pycnodontiforms, aspidorhynchiforms, teleosts) and marine reptiles (Mosasauroidea and Chelonia). Many of the fossils exhibit soft tissue preservation (Buchy et al., 2007; Ifrim et al., 2005). Until now, Plesiosauria are represented by a single tooth (Blanco-Piñón et al., 2005; Blanco-Piñón and Alvarado-Ortega, 2007; Blanco and Alvarado-Ortega, 2006; Blanco and Cavin, 2003; Buchy et al., 2005; Giersch, 2014; Ifrim, 2006). This assemblage is known mainly from around the small town of Vallecillo, but similar coeval lithologies and fossiliferous horizons are known from other areas in northeastern Mexico, including Monterrey, Arteaga and Ciudad Victoria (Ifrim et al., 2008; Stinnesbeck and Frey, 2014). The Vallecillo-type plattenkalk is thus widespread and covers an area of at least 10000 square kilometers. It formed on an open shelf environment under anoxic conditions caused by global Oceanic Anoxic Event 2 OAE 2 (Ifrim et al., 2011, 2008; Ifrim and Stinnesbeck, 2008; Schlanger and Jenkyns, 1976). The polycotylid presented here is the first virtually complete plesiosaur of the Late Cretaceous of Vallecillo, and the first complete polycotylid from Mexico.

At Vallecillo, the plattenkalk section of thin-bedded and millimetrically laminated platy marl is 7.7 $\mathrm{m}$ thick and contains abundant planktic foraminifera, inoceramid bivalves, ammonites and crustaceans (Stramentum) which provide a precise and detailed biostratigraphic zonation from the latest Cenomanian Inoceramus pictus pictus Zone to late Early Turonian (Mammites nodosoides Vascoceratid - Mytiloides kossmati assemblage) (Ifrim and Stinnesbeck, 2008). The invertebrate assemblage, the biostratigraphy, as well as sedimentological aspects, have been described in detail by Ifrim (2006). The slab containing the polycotylid plesiosaur described here is associated with a specimen of Mammites nodosoides, indicating that it is from the late Early Turonian interval of the Vallecillo section.

The Vallecillo plattenkalk is a Konservat-Lagerstätte deposited in an open marine environment several hundred kilometres from the North American coastline, near the southern opening of the Western Interior Seaway into to the Paleogulf of Mexico (Figure 2). The excellent preservation of vertebrate fossils is explained by the absence of traction currents and storm waves on the sea floor, combined with dysoxic to anoxic conditions on the substrate resulting in the absence of carnivores, scavengers, and infaunal benthos. Inoceramids are the only abundant benthic element in the macro- 


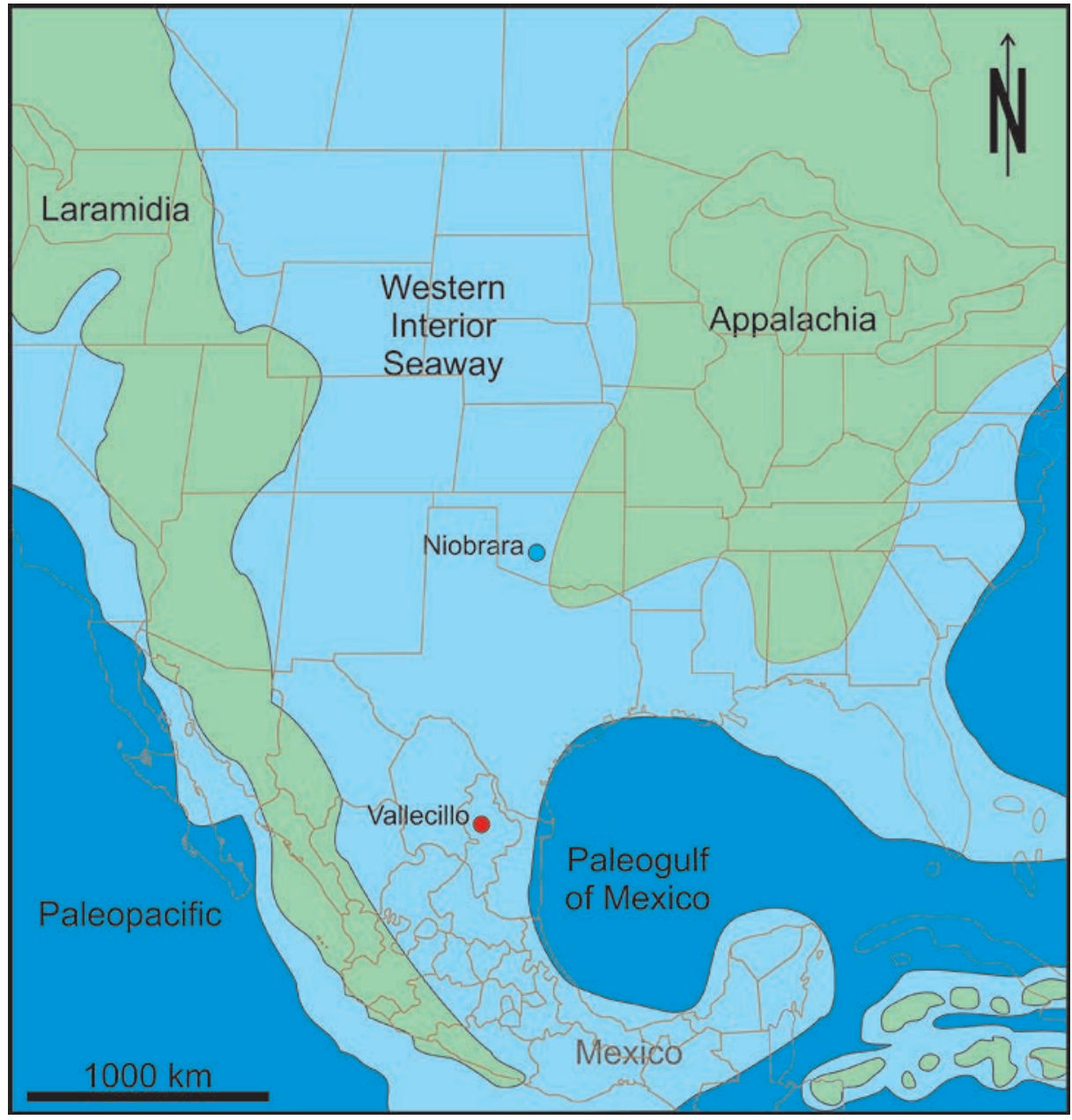

Figure 2 Geographical position of Vallecillo N.L. during the Turonian. Note that the Western Interior Seaway is connected with the Paleogulf of Mexico (modified from Bhattacharya and MacEachern, 2009).

and microfauna and may have adapted to the hostile low-oxygen conditions by sheltering chemoautotrophic microbes as symbionts (e.g. Fischer and Bottjer, 1995; Ifrim et al., 201 1; MacLeod and Hoppe, 1992).

\section{Preservation}

The complete and fully articulated polycotylid plesiosauroid, is accessible through the Museo del Desierto, Saltillo, Coahuila Mexico under the INAH (Instituto Nacional de Antropología e Historia) collection number CPG RFG 2544 P.F.1. It is preserved on 28 slabs that fit closely together (Figure 3). The specimen has a length of 1.9 me- ters, a flipper span of 1.15 meters and is exposed in ventral aspect. Besides a substantial part of the left coracoid, only small sections of the skeleton are missing: a slab immediately craniomedially to the left pubic plate, the distal half of the right fore flipper, the distal third of the left hind flipper, a segment of the mid part of the right hind flipper and the tip of the tail (Figure 3A). These elements were lost when the quarry workmen excavated the specimen. The propodials and all girdle bones show slight impaction and/or deformation cracks. The vertebrae, mandible, epipodials, metapodials and phalanges are somewhat deformed due to compaction.

The postcervical vertebral column is nearly straight, but the neck is strongly curved to the 
right such that the skull is orientated at an angle of about $85^{\circ}$ to the long axis of the trunk and tail skeleton (Figure 3). The skull is exposed in ventral aspect with the mandible in articulation (Figures 3, 4 A, B). The mandibular rami have been distorted because the left is positioned vertically with only its ventral edge visible, while the right ramus shows its ventrolateral aspect. The palate is exposed between the mandibular rami and shows only minor compaction fractures. The cranium and mandible are slightly twisted sinistrally whereby the mandible was sheared to the left by about $5^{\circ}$ against the long axis of the cranium but with the jaw articulations remaining in contact. Fifteen teeth are visible on the right side of the rostrum, two of which likely belong to the premaxilla. Nine teeth are preserved on the left side, of which two belong to the premaxilla. However, tooth positions can only be positively identified on the right maxilla, the alveolar flange of which is fully exposed. Only a few fragments of the left maxilla are visible medially adjacent to the left splenial and lateral to the left margin of the mandible (Figure 4 A, B). The enamel of all preserved teeth as well as some apices of the crowns has been largely scratched away during preparation.

All vertebrae posterior to the atlas-axis system are seen in ventrolateral view such that the neural spines are visible in lateral aspect (Figures 3, 5, 6). The anterior and posterior margins of the neural spines contact each other and define the neck curvature. The neural spines have been distorted dextrally at their bases due to compression. The torsion of the cervical series begins immediately posterior to the atlas-axis, which is slightly disarticulated but is still in contact with the occipital condyle (Figures 3, 4 A, B). This torsion persists to the cervicothoracic transition at the base of the neck.

The ribcage has collapsed posteriorly and the ventral termini of the ribs overlie each other (Figures $3,8)$. There is no trace of a lateral movement of the ribs, implying that vertebrocostal articulation must was maintained on burial. The gastralia are only slightly disarticulated in a few places but the entire gastral basket has been flattened by compaction so that the ventral termini of the gastralia now extend beyond the ribcage and protrude beyond the lateral margin of the preserved skin on

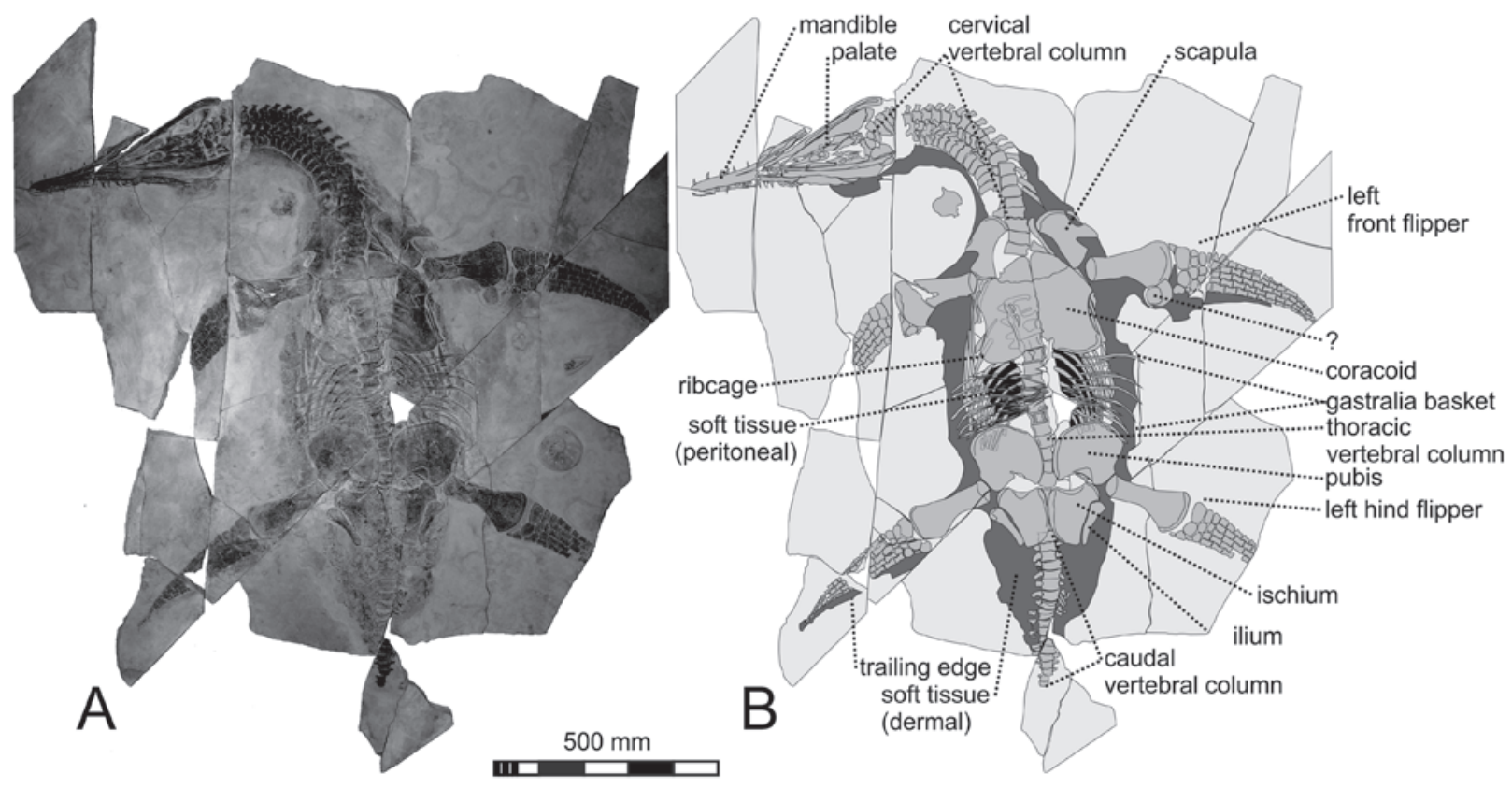

Figure 3 : Mauriciosaurus fernandezi INAH CPC RFG 2544 P.F.1. A) Photograph of the specimen after preparation, B) interpretative line drawing. Note the massive tail base and the dorsal skin preserved between the ribs. 

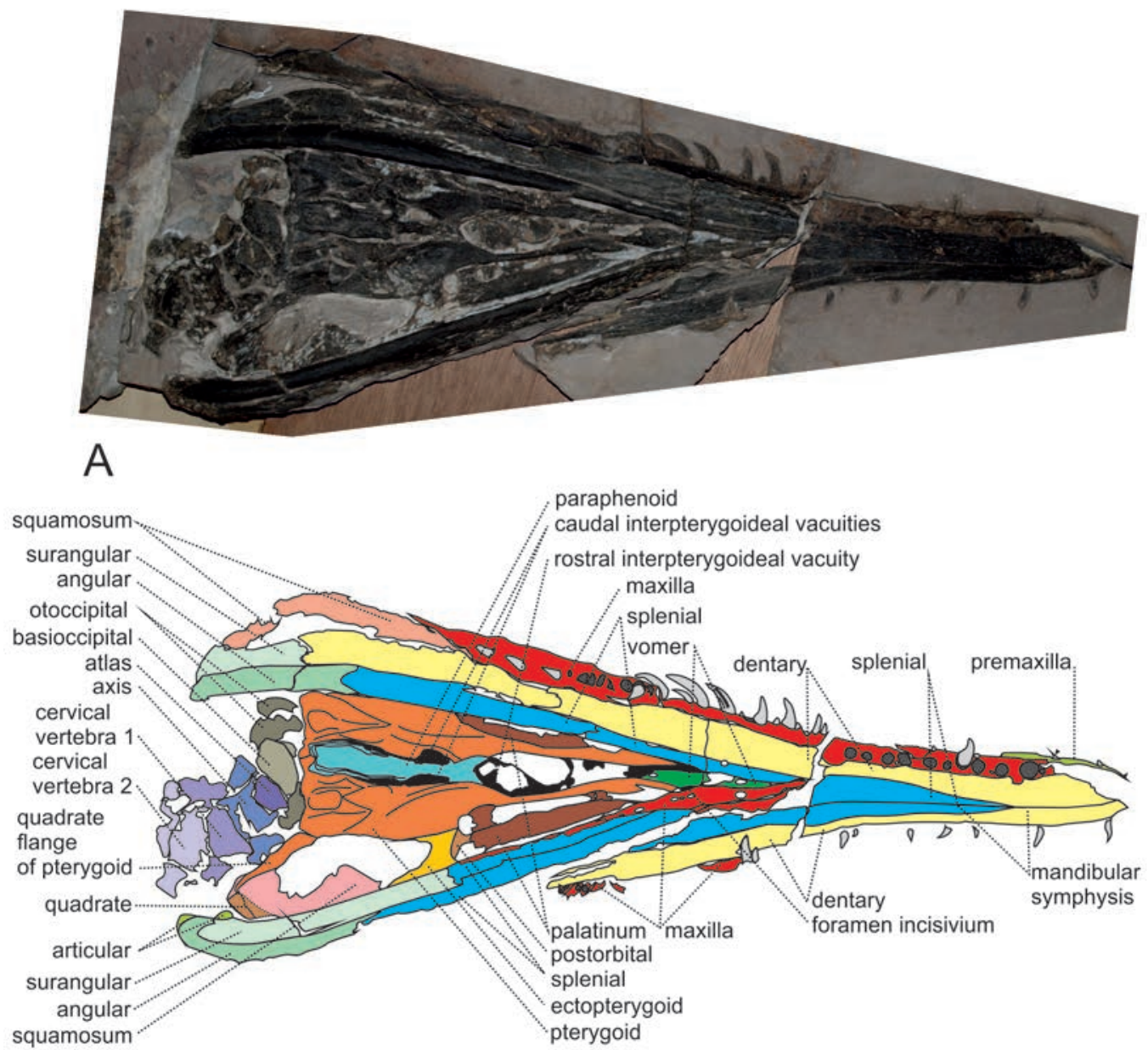

B

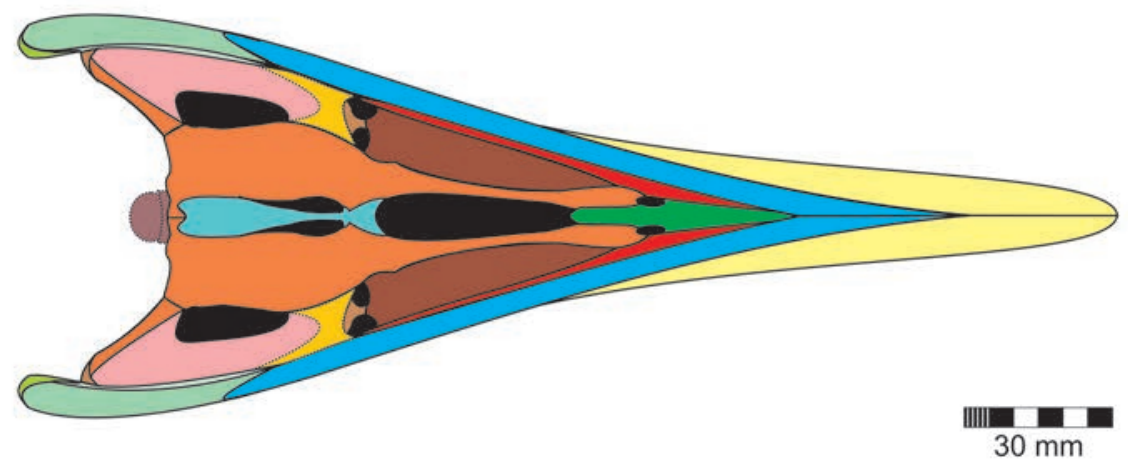

C

$30 \mathrm{~mm}$

Figure 4 : Mauriciosaurus fernandezi INAH CPC RFG 2544 P.F.1. A) skull as preserved in ventrolateral aspect, B) interpretative line drawing, $C$ ) reconstruction of the skull in ventral aspect.

the left side of the trunk (Figure 6).

Like the gastralia, the ventral bones of both girdles lie flat in one plane (Figures 3, 8). While the median suture of the coracoids, as far as preserved, is in tight contact, the pubic symphysis has slightly separated, but the ischia maintain their in situ contact. The dorsal elements of both girdles are disarticulated but still lie close to their original in situ position (Figures 3, 8). The ventral elements of both girdles have been deformed around the underlying bones (Figure 6). Both scapulae, the external face of which is exposed, have symmetrical- 
ly rotated anterolaterally but retain contact with the coracoids with their anteroproximal corner at the glenoid fossa (Figures 3, 8). The anteromedial corners of both scapulae lie adjacent to the cervical vertebrae. The scapular processes of both scapulae face laterally. Both ilia have rotated posteriorly at the posterior acetabular contact. They lie along the lateral margin of the ischia with their medial face exposed (Figures 3, 8).

All four flippers extend laterally. While both humeri face laterally at an angle of $\sim 90^{\circ}$ to the long axis of the trunk, the femora are orientated caudolaterally at an angle of $\sim 60^{\circ}$ (Figure 3). The metapodial and digital elements are slightly curved posteriorly. The curvature is stronger in the front than in the hind flippers. The incomplete right front flipper shows the strongest curvature of all four (Figure 3). Adjacent to the posterodistal corner of the left humerus there are two disk-shaped bones, possibly parts of the interclavicles (Figure 9).

The soft tissue has a reddish-brown color and is preserved along the right side of the postorbital part of the skull, and from there it continues along the right side of the neck (Figure 3). On the left side of the neck the soft tissue is restricted to the cervicothoracic transition (Figure 15). On both sides of the trunk, soft tissue is preserved at the shoulder girdle and the flanks with a width of between $50 \mathrm{~mm}$ and $70 \mathrm{~mm}$. It continues along the pelvic girdle without any constriction onto the tail base (Figures 3, 8). Here, the soft tissue reaches a maximum thickness of $170 \mathrm{~mm}$ immediately posterior to the ischiadic plates and from there gradually converges towards the end of the tail. Patches of a grey matter, which are apparently related to the soft tissue, are preserved along the right side of the body and at both sides of the tail. Wrinkled dark coating, which likely represents the visceral skin surface or the peritoneum, is visible between the ribs and the central elements of the gastralia (Figure 14). Soft tissue is also preserved along the flipper (Figures 3, 16). The humerus and proximal podials of both front flippers are surrounded by the reddish-brown substance. The soft tissue at the left front flipper expands posteriorly to about one fourth of the width of the flipper and terminates at about in the mid-length of the manus. There is soft tissue preserved that extends to the tip of the IVth digit of the right hind flipper, and is one third the width of the flipper (Figures 3, 12).

\section{Systematic paleontology}

\author{
Plesiosauria de Blainville, 1835 \\ Plesiosauroidea Welles, 1943 \\ Leptocleidia Ketchum and Benson, 2010 \\ Polycotylidae Williston, 1908 \\ Mauriciosaurus gen. nov \\ Mauriciosaurus fernandezi sp. nov.
}

Derivation of name: Genus and species name in honor of Mauricio Fernández Garza, who not only made the specimen accessible for scientific research, but also secures all future work in the quarry area at Vallecillo and supports public education in Earth- and biological sciences predominantly in the state of Nuevo León.

Holotype: A nearly complete and articulated skeleton with extensive soft tissue preservation (Figure 3) with the INAH (Instituto Nacional de Antropología e Historia) registration number CPC RFG 2544 P.F.1. The specimen is housed and on display in the Museo Papalote Verde, Monterrey. Type locality: Vallecillo (26³9'N 9959’W), western quarry field (Figure 1)

Type horizon: Vallecillo Member of the Aguas Nuevas Formation (Early Turonian, Late Cretaceous).

The specimen is referred to Polycotylidae according to the following combination of features:

Family: Polycotylidae (Albright III et al., 2007a; Benson et al., 2013; O’Keefe, 2001; Schumacher et al., 2016; Williston, 1908)

1. Pterygoids with anterior processes emerging from the middle of the anterior pterygoid body (Figure 4).

2. Pterygoid body with a shallow oval depression (“dished" according to O’Keefe, 2001) lateral 
to posterior interpterygoid vacuities meeting posterior to the posterior interpterygoidal vacuities (Figure 4).

3. Mandibular symphysis long (measuring at least one fourth of the entire mandibular length; Table 1; Figure 4).

4. Number of cervical vertebrae reduced (when compared with other Leptocleidia).

5. Humerus shorter but posterodistally slightly more expanded than femur (Figures 10, 12).

6. Shaft of humerus with subtle sigmoid curvature (Figure 12).

7. Supernumerary ossifications in epipodial rows (Figures 10 - 12).

8. Phalange digits one through four interlocking (Figures $10-12$ ).

9. Pterygoids meet atop the parasphenoid closing the posterior interpterygoideal vacuities (Figure 4).

\subsection{DIAGNOSIS FOR THE GENUS AND SPEGIES}

1. Dish-like depression restricted to the anterior half of the pterygoideal plates. The depression is posteriorly open, merging with a relief of prominent ridges that are arranged in a $\mathrm{W}$-configuration covering the posterior half of the pterygoideal corpus (Figure 4). This relief is perfectly preserved in three dimensions and it resembles that of Polycotylus (Schumacher et al., 2016), but is more complex in Mauriciosaurus.

2. Anterior pterygoid rods expand at union with the vomers to three times the width of the basal third of the processes (Figure 4).

3. Parasphenoid with a deeply concave ventral face and concave lateral margins in the middle part of the bone; anterior process bifurcated (Figure 4) without any trace of a median protuberance.

4. Posterior interpterygoidal vacuities narrow, longitudinally oval with a slight anterior expansion (Figure 4).

5. At least 42 tooth positions on either side of the upper jaw.

6. No posterior or medial perforations in the
Table 1. Mauriciosaurus fernandezi INAH CPC RFG 2544 P.F.1; measurements of the skull in $\mathrm{mm}$.

\begin{tabular}{|l|r|}
\hline Measurements of the skull in mm & \\
\hline Length of left mandibular ramus & 420 \\
\hline Length of right mandibular ramus & 425 \\
\hline Length of symphysis & 175 \\
\hline \begin{tabular}{l|} 
Mandibular width at caudal end of \\
symphysis
\end{tabular} & 70 \\
\hline Ratio mandibular/symphyseal length & approx. $45 \%$ \\
\hline
\end{tabular}

coracoids (Figure 8). This could be due to the juvenile stage of the specimen, but given the fact that this animal probably had at least half the length of an adult, one should expect at least to the a trace of such perforations.

7. Average length/width ratio of phalanges of digit III is 1.77. The polycotylid standard would be 1.5 (Table 5; Albright III et al., 2007a).

8. Gastralia converging medially, forming a median plate-like structure (Figure 9). A similar structure has been described for Cryptoclidus (Brown, 1981), but not for any polycotylid.

\subsection{NOMENGLATURAL ACTS}

The electronic edition of this article conforms to the requirements of the amended International Code of Zoological Nomenclature, and hence the new names contained herein are available under that Code from the electronic edition of this article. This published work and the nomenclatural acts it contains have been registered in ZooBank, the online registration system for the ICZN. The ZooBank LSIDs (Life Science Identifiers) can be resolved and the associated information viewed through any standard web browser by appending the LSID to the prefix "http://zoobank.org/" (International Commission on Zoological Nomenclature, ICZN, 2017). The LSID for this publication is: urn:lsid:zoobank.org:act:DF54BB6D-73DE4BEG-8723-A9B7B4A888B9 for the genus and urn:lsid:zoobank.org:act:8D331E82-25B54E81-98F8-AFE7086E7693 for the species.. 
The electronic edition of this work was published in a journal with an ISSN, and has been archived and is available from the following digital repositories: PubMed Central, LOCKSS urn:lsid:zoobank.org:pub:2B 15EAB5-96884DF3-8149-77217E598238.

\section{Osteology}

\section{SKULL (FIGURE 4)}

Both mandibular rami overlie the ventral surface of the skull, which is slightly twisted to the left side around its long axis in a way that the skull is visible in ventrolateral view. The mandible remains in articulation but has been sheared to the left in anterior direction. Therefore, the entire alveolar flange of the right premaxillomaxillary complex is exposed, whereby most of the medial part of the left premaxilla is only preserved as an external mould (Figure $4 \mathrm{~A}$ ). Of the left maxilla only fragments of the mid part of the alveolar margin are visible. The tip of the rostrum is missing. Due to compaction many of the bones are crushed, which makes the reconstruction of their outline difficult or impossible.

\section{MANDIBLE (FIGURE 4; TABLE 1)}

Dentary: With the exception of its anterior terminus, the right dentary is preserved for its entire length, while the left one is only half preserved. The right dentary terminates at the level of the posterior margin of the pterygoideal corpus. The dentaries converge at an angle of $\sim 10^{\circ}$ towards the dentary symphysis, which forms about $50 \%$ of the mandibular symphysis that posteriorly terminates at the twelfth maxillary tooth position. The dentary part of the symphysis measures one sixth of the dentary length. At the symphysis the lateral margin of the dentary is slightly convex anteriorly terminating in an acute anterior tip. Posterior to the dentary symphysis the lateral margin of the bone is slightly concave, and levels with the posterior terminus of the maxilla. Ultimately, it becomes convex again paralleling the squamosal. The medial margin of the dentary parallels the lateral margin. The bone surface of the dentaries appears slightly sculptured with irregular shallow longitudinal striae, but much of the surface structure of the bones has been scratched away during preparation.

Splenial: Both splenials are preserved over their entire length. The right one is seen in ventrolateral and the left one in ventromedial view due to the slight torsion of the skull (Figure 4). The splenial symphysis forms the posterior $50 \%$ of the mandibular symphysis with an apertural angle of about $10^{\circ}$ at the anterolateral margin and about $15^{\circ}$ at the anteromedial one. The splenial symphysis measures about one fifth of the longitudinal expansion of each bone. The lateral margins of the splenials lie in articulation with the medial margin of the dentaries following their curvature. The ventral face of each splenial slightly converges in posterior direction with the medial margin running sub-parallel to the lateral one. The ventrolateral part of each splenial terminates at level of the middle of the maxillary arches $15 \mathrm{~mm}$ anterior to the posterior margin of the pterygoid where it forms a posteriorly directed U-shaped suture with the angular. The medial flange of the splenial is only visible on the left mandibular ramus, but appears to terminate at the level of the anterior base of the jugal and contacts the surangular with a sigmoidal suture. A faint striation of the bone surface has been partially destroyed by unprofessional preparation.

Angular: Both angulars are preserved (Figure 4). The right one shows its lateral, the left one its medial aspect. The lateral face measures about one fourth of the length of the anteriorly adjacent splenial and is slightly laterally convex. The dorsal and ventral margins are parallel to each other. The anterior margin of the lateral face shows an anteriorly open U-shaped incision that matches its equivalent on the posterior margin of the splenial. The posterior terminus of the left splenial is slightly eroded but likely was evenly rounded as is seen on the right splenial. The medial face of 
each angular is concave. Each bone contacts a surangular with its regularly concave dorsal margin, which runs near parallel to the ventral one. The curvature of the angular gradually increases posteriorly. Each angular contacts the vertical posterior margin of the surangular in a posteriorly open V-shaped suture. At their anterior ends, the angulars appear to underlie the splenials for a few millimeters forming a squamate suture. Again the bone surface is badly scratched.

Surangular (Figure 4): The right surangular exposes its lateral, the left one its medial face. The lateral face of each bone has about two thirds the length of the lateral face of the angular, while its medial face has three times the length of the lateral face, covering the suture between angular and splenial medially. While the anterior two thirds of the medial flange of the surangulars are straight and parallel-sided, the posterior third of the bone curves medially, thereby slightly diverging in posterior direction. The surface of the bone appears smooth.

Articular (Figure 4): Only the left articular can be seen on the left mandibular ramus, where it is mostly overlain by the angular and surangular. Only the posterior-most terminus of the retroarticular process and the dorsomedial tip of the posterior cotylar process of the glenoid fossa are visible. The original shape of the bone cannot be determined.

\section{GRANIUM (FIGURE 4)}

Premaxilla: Only the lateral margin of the right premaxilla is preserved as a slender seam of bone, which is broken dorsally to the alveolar flange, which is now missing. Medial to the preserved remain of the premaxilla there is an internal mold of the internal surface of the alveolar flange, which is smooth and convex in all directions, with the transverse convexity being strongest. Posteriorly the lateral premaxillary wall overlaps the lateral margin of the maxilla reaching the level of the third visible maxillary alveolus. This overlap likely represents the lateral part of the suture with the maxilla, while the ventral part is missing. Howev- er, the damaged anterior margin of the alveolar flange of the maxilla suggests that the premaxillomaxillary suture was transverse at least in its lateral third. The remnants of three premaxillary teeth lie adjacent to the right premaxilla. Two teeth that are topographically referred to the left premaxilla are preserved to the left side of the left dentary. There were at least four widely spaced premaxillary teeth.

Maxilla: The entire alveolar flange of the right maxilla is preserved. Anteriorly the bone terminates at the level of the middle of the dentary symphysis, posteriorly it forms an obliquely directed suture with the jugal, and tapering to a pointed terminus. The maxillosquamosal suture covers about one third of the squamosal as exposed. Altogether 32 tooth positions are identified on the right maxilla. Alveolae numbers 5, 12 to 21, 23 and 30 to 32 contain slightly recurved conical teeth. Of the left maxilla, the posterior two thirds of the palatinal part are preserved, the posterior third of which are mostly overlain by the left splenial. A few fragments of the middle part of the lateral-most portion of the alveolar flange are visible adjacent to the lateral margin of the left dentary. The remnants of seven teeth from the left maxilla are preserved but they cannot be assigned to their respective tooth positions.

Vomer: Only two insignificant portions of the vomers are preserved between the medial margin of the palatinal part of the left maxilla and the right splenial. Neither the overall shape of the bone nor its posterior or anterior extension can be reliably reconstructed. As preserved the vomer terminates posteriorly at the level of maxillary tooth position 22 and separates the anterior processes of the pterygoids.

Palatine: Only fragments of the palatines are preserved. The left palatine preserves the entire transverse extent, but only the medial half is prepared and exposed. The lateral half of the right palatine is overlain by the right splenial. Most likely the palatines had sub-triangular outlines. Anteriorly they taper between the palatinal part of the maxilla and the anterior process of the pter- 
ygoid. The medial margin of the palatines forms a laterally convex loose contact with the anterior process of the pterygoids. Close to the posterior base of the anterior process of the pterygoid, the suture curves laterally and accommodates a low lateral process of the pterygoid. Two thirds of this suture is preserved on the right side. The lateral margins of the palatines contact the medial margin of the palatinal part of the maxillae. However, the middle two thirds of the palatinomaxillary suture on the left side of the cranium are obscured by matrix. The posterior margin of the palatines is poorly preserved and thus is difficult to reconstruct. Evidently they closely approached the ectopterygoids approximately in the middle of the posterior margin of the palatines, but the contact is not preserved. Medially and laterally there is a concavity that forms the anterior margin of the adductor chamber.

Pterygoid: The pterygoid consists of a rounded irregularly pentagonal corpus and an anterior process, which is one fifth longer than the corpus and anteriorly reaches the level of maxillary tooth position 18. The corpus expands anteriorly until the level of the maxillary tooth position 32 . The lateral margin of the corpus is sigmoidal being laterally convex in its anterior two thirds and concave in its posterior third. The caudolateral margin lies adjacent with the medial terminus of the squamosal and is inclined medially at an angle of $130^{\circ}$ with the lateral margin and it is straight. The posterior margin of the pterygoid is sigmoidal, about four times as wide as the caudolateral margin, and is one third the length of the corpus. The pterygoids meet in the median line posterior to the parasphenoid. The pterygoidoparasphenoidal suture is $\mathrm{W}$-shaped. The contact of the medial margin of the corpus of the pterygoid is sigmoidal between the posteromedial corner of the pterygoid and the foramen pterygoideum, the posterior half of the suture being laterally convex. The anterior one is laterally concave. Immediately anterior to the foramen pterygoideum there is a short triangular recess, which continues anteriorly in an elongate concavity confluent with the medial margin of the anterior processes of the pterygoids. It borders a large interpterygoideal vacuity. The anterior terminus of the parasphenoid marks the base of the anterior process of the pterygoid. The lateral and medial margins of this process are concave with the narrowest point lying in the basal third of the process. Further anteriorly the lateral and medial margins of the process diverge to about three times its minimum diameter. The lateral margin contacts the pars palatinalis of the maxilla, the anterior terminus borders the foramen incisivium and the medial one the vomer. The corpus of the pterygoid has a relief of prominent ridges arranged in a $\mathrm{W}$-configuration and opening anteriorly with a tubercle close to the posterior margin of the bone.

Parasphenoid: The parasphenoid is bottle-shaped with a $\mathrm{W}$-shaped posterior margin and the neck of the bottle lying between the expanded anterior third of the posterior interpterygoideal foramina facing anteriorly. The neck of the parasphenoid is about half as wide as the maximum width of its corpus. Its ventral face is deeply concave. Two short triangular processes form the parasphenoidal rostrum and protrude into the foramina pterygoidea. Further anteriorly the parasphenoid expands to a bifurcated process, which reaches the width of the corpus at its anterior terminus. The anterior margin of the parasphenoid is deeply concave forming the posterior margin of the interpterygoidal vacuity. The ventral face of the corpus of the parasphenoid is deeply concave in its posterior third and gradually shallows anteriorly.

Occipitals: The basioccipital and the otoccipitals are only identified by the topographical position of their fragments, which do not permit a confident reconstruction of these bones.

Postorbital: This boot-shaped postorbital is visible between the left palatine and the left jugal. The peduncle faces anteriorly and contacts the palatine. The corpus of the postorbital as preserved and contacts the jugal. This latter contact is three times the width of the peduncular contact with the palatine. The medial and lateral margins of 
the postorbital appear deeply concave, but from the state of preservation the outline of the bone remains uncertain.

Ectopterygoid: Both ectopterygoids are poorly preserved. The right one is visible in lateral, the left one in medial aspect. The ectopterygoid is trapezoidal in outline with the medial margin being about one third as long as the lateral visible one. The lateral-most part of the ectopterygoid is obscured by the right mandibular ramus. The anterior and posterior margins of the ectopterygoid are concave. The ectopterygoid contacts the pterygoid at the transition from the corpus to the anterior process. The suture is medially convex and even.

Squamosal: Both squamosals are present but badly preserved. Although none of the margins is complete, it is assumed in analogy to other plesiosaurs that each bone likely had a wide convex posterior margin and formed at least the posterior half of the roof of the adductor chamber. It is likely that the supratemporal fenestra was short and narrow.

Quadrate: A fragment of possibly the left quadrate is preserved. It contacts the right mandibular ramus where the jaw articulation should be. The possibility that this fragment represents a fragment of the right squamosal instead cannot be excluded because of the incomplete preservation. The margins of the fragment are too damaged to allow for a reconstruction of the bone outline.

\section{PALATAL VAGUITIES (FIGURE 4)}

Vomeral foramen [foramen incisivium according to Buchy et al., (2006), "internal naris" according to (O'Keefe, 2001)]: Only the left vomeral foramen is preserved. It has a longitudinal diameter of about $5 \mathrm{~mm}$ and is three times as long as it is wide. It is posteriorly bordered by the anterior terminus of the anterior pterygoidal process, laterally by the medial margin of the left maxilla and medially by the lateral margin of the vomer. The outline of the vomeral foramen was most likely an elongate oval. Anterior interpterygoidal vacuity: Anteriorly bordered by the vomer, laterally by the anteri- or pterygoideal processes and posteriorly by the parasphenoid, this long oval vacuity is by far the largest palatal aperture of the specimen. Its length is difficult to reconstruct because the posterior portion of the vomer is missing and likely covered the anterior processes of the pterygoids. It appears likely that this vacuity extended from maxillary tooth positions 23 through 32. Its maximum width level with tooth position 31 covers one third of the palate at the same level. It is hypothesized by some authors that this vacuity represents the choana (Buchy et al., 2006). Inside the interpterygoideal vacuity there are fragments of the skull roof that cannot be further identified. Presumably they come from the frontoparietal area.

Posterior interpterygoidal vacuities: The pterygoid foramina are laterally bordered by the pterygoid and medially by the parasphenoid. The vacuities are twice as long as they are wide and set off by raised margin. They are about one fourth the length of the parasphenoid.

\section{DENTITION (FIGURE 4)}

All preserved teeth show a height/width ratio of the crown of about 4:1 independent from their respective diameter. They have conical and moderately recurved pointed tips. A few crowns show coarsely striated enamel. However, due to the preparation scratch marks no details of the enamel sculpture remain. Because of the bad preservation and insufficient preparation, arrangement and size of the teeth are only assessable from an extrapolation based on the few teeth with preserved crowns, the diameter at the tooth cervix or the diameter of the alveoli.

The dentition is isodont, despite the smallest teeth being about one quarter the size of the largest (Figure $5 \mathrm{C}$ ). The badly preserved margin of the upper jaw indicates that the teeth in the anterior half of the preorbital rostrum are separated by an interalveolar space that is a little larger than the respective alveolar diameter. Only three small likely fragmentary teeth were identified there with certainty (tooth positions 1, 8, 11). The bulk of the small replacement teeth or tooth fragments occur 
in the posterior half of the preorbital part of the rostrum. The dental margin of the posterior third of the maxilla is very badly preserved and reconstruction would be too speculative. However the alveoli are visible in different stages of abrasion and the three posterior-most tooth positions appear widely spaced with interalveolar spaces that are three times the diameter of the respective alveoli.

Altogether there are at least 42 tooth positions in the upper jaw including the ones we reconstructed on minimum assumption. Because of the missing premaxillomaxillary suture any comment on the distribution of the teeth is impossible. That many of the teeth are spread out laterally suggests that the teeth from the upper and lower jaw interdigitated.

\section{AXIAL SKELETON (FIGURES 3, 5, 6; TABLE 2)}

The vertebral column is preserved in full articulation, but the trunk region is partially obscured by the bones of the girdles.

Cervical vertebrae: 21 cervical vertebrae are visible (Figures 3, 5). Although the atlas/axis system lies in a mass of broken bone, it is identified with confidence (Figure 5). The atlas is in articulation with the occiput and is posteriorly followed by the axis. All cervical vertebrae are slightly procoelous and have a length/width ratio of 2:3. Vertebrae XIII to XXI are visible in ventrolateral aspect because there that part of the cervical vertebral column has been twisted to the right. The centra of the cervical vertebrae I through XII are visible in ventral aspect, exposing the paired foramina, which are considered diagnostic for Sauropterygia (Rieppel, 1997). There is a blunt median keel between the foramina (Figure 6). From cervical vertebra XII to cervical vertebra XVIII, this keel abruptly changes into a median depression, flanked by a pair of sharp ridges. The depression is one-third the width of the respective centrum. Cervical vertebrae XVIII through XXI also have a blunt median ridge flanked by a paired of foramina. The diameter of the cervical vertebrae gradually increases by approximately one third from the anterior-most to the posterior-most. The cervical ribs are single headed and articulate at a long oval facet on the ventrolateral face of the centra. The articular facet has a length/width ratio of 2:1 and it extends over the posterior two thirds of the length of the respective cervical centrum.

The cervical neural arches are tilted laterally (Figures 5,6). This indicates that these neural arches are not fused to the cervical centra due to the juvenile stage of the animal. From cervical vertebra VI through XVII the neural spines including their respective peduncles are visible from the right side. The height of the first visible neural spine is onethird the width of the respective vertebral body. Posteriorly the height of the neural spines gradually increases with respect to the width of the vertebral body until a ratio of 1:1 is reached in cervical vertebra XVII. While the neural spines of the anterior-most cervical vertebrae are vertical with almost parallel anterior and posterior margins, those of vertebrae XII through XVII are inclined posteriorly. This inclination begins with about $3^{\circ}$ at vertebra XII and increases to about $15^{\circ}$ at vertebra XVII. In all inclined neural spines the anterior margin is convex and the posterior one concave, but both remain almost parallel. In the cervical vertebrae XIII through XVIII, there is a bulge at the base of the anterior margin that protrudes anteriorly between the postzygapophyses of the preceding cervical vertebra, suggesting the presence of a zygosphene / zygantrum articulation. The bulge covers the ventral half of the anterior margins of the respective neural spines and is tentatively identified as the base of a zygantrum (Figure 6). The dorsal margin of all the neural spines is very slightly convex and bears a sharp and low laterally facing ridge.

The postzygapophyses are visible on all preserved neural spines of the cervical vertebral column with the exception of vertebra XVII, where the postzygapophyses are missing. They arise from a blunt elevation beginning on the middle of the lateral face of the neural spines. The postzygapophyses extend posteriorly beyond the posterior margin of the respective neural spine for about 

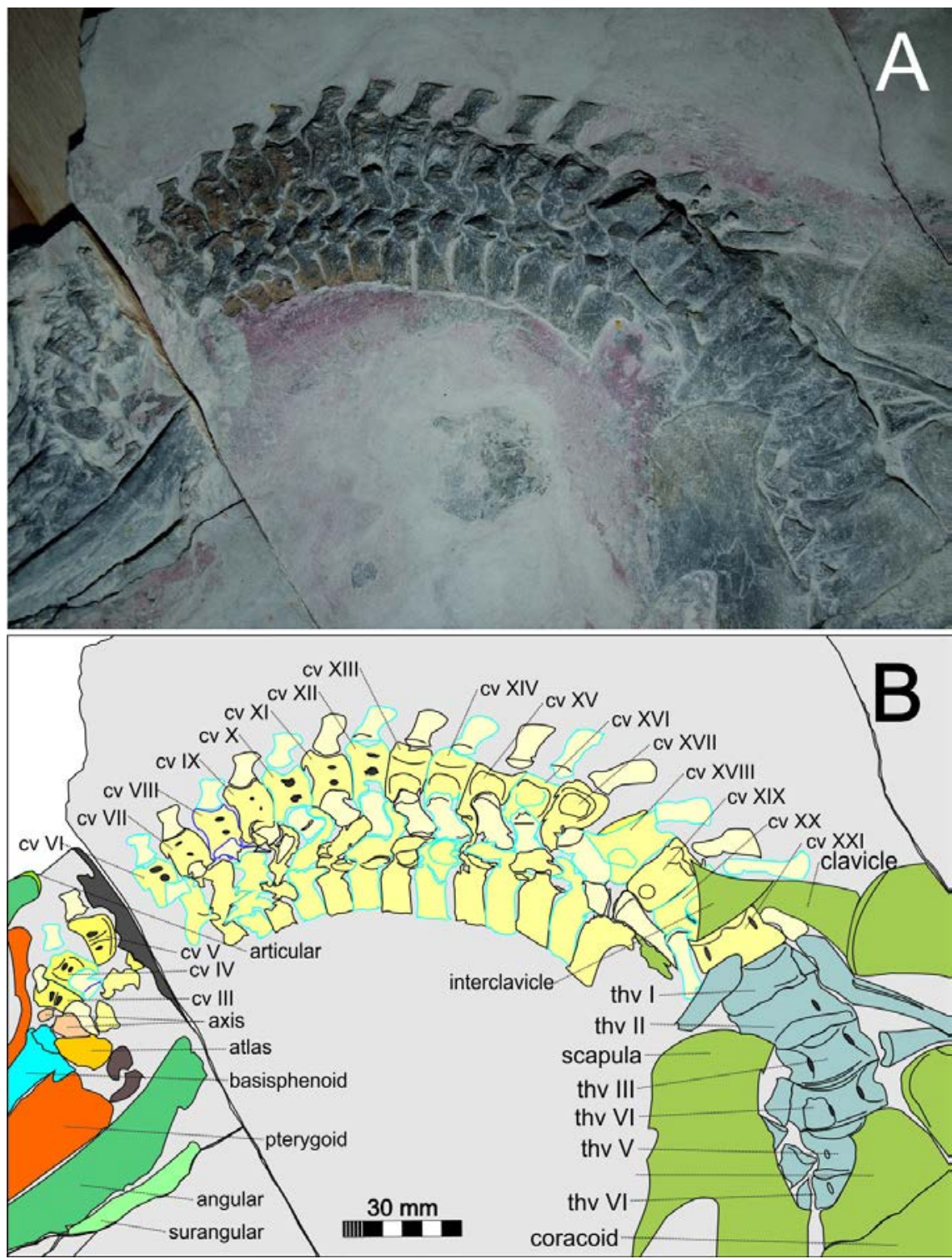

Figure 5 Mauriciosaurus fernandezi INAH CPC RFG 2544 P.F.1. Cervical vertebral column; A) photograph of the cervical vertebral column, B) interpretative line drawing.

one third the longitudinal extent of the respective neural spine, whereas the articular faces continue anteriorly over one half of the lateral face of the neural spines. The articular facets of the postzygapophyses are inclined slightly lateroventrally, and in cervical XVII slightly caudoventrally, too. Prezygapohyses are only visible in the cervicals $\mathrm{X}$, $\mathrm{XI}$, and XIV to XVI (Figures 5, 6). In the three latter vertebrae the prezygapophyses protrude beyond the anterior margin of the respective neural spine over the full length of its articular facet and terminate anteriorly in a notch on the lateral face of the possible zygosphene, which is only visible in cervical vertebrae VII and IX (Figure $5 \mathrm{~d}$ ). In cervicals $\mathrm{X}$ and $\mathrm{XI}$, the prezygapophyses overlie only the posterior two thirds of the preceding vertebra and do not terminate in a notch. In all others the prezygapophyses are at least partially covered by the cervical ribs. The same holds true for the peduncles of the neural arches of which only patches are seen. Otherwise the neural arches and spines would not have disarticulated from their respective 

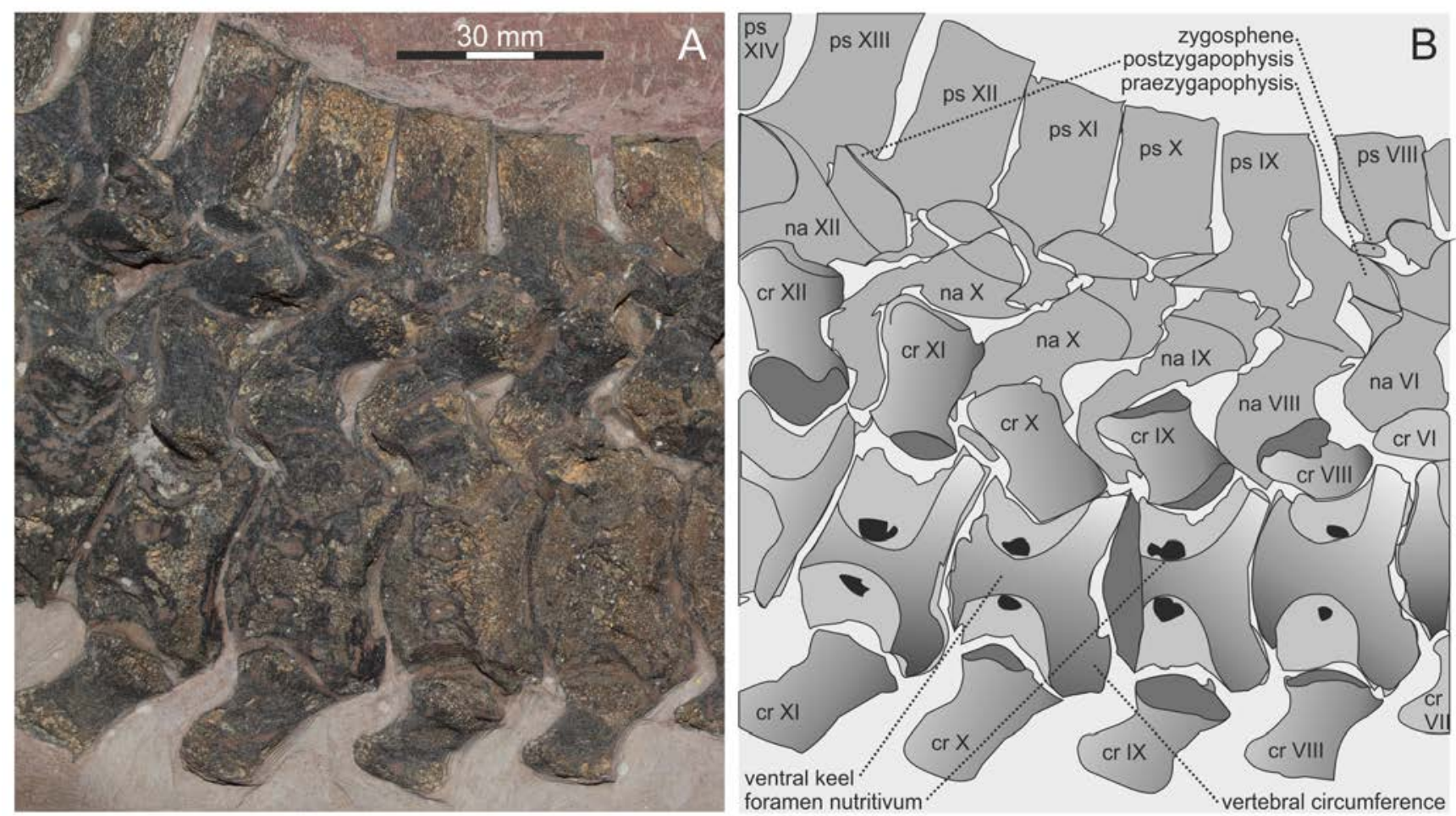

Figure 6 Mauriciosaurus fernandezi INAH CPC RFG 2544 P.F.1. Detail of cervical vertebral column, section from cervical vertebra VII through XII; A) photograph of the section, B) interpretative line drawing. Abbreviations: $\mathbf{n s}=$ neural spine, $\mathrm{na}=\mathbf{n e u r a l}$ arch, $\mathrm{cr}=\mathrm{cervica}$ rib.

centra in one line held together solely by the zygapophyseal articulations.

The articular heads of the cervical ribs II through XII have the same longitudinal diameter as the distal ends of the ribs. From vertebra XIII until XXI the lateral margin of the cervical ribs increases in length by about one third due to a posteriorly orientated process that terminates in a sharp point (Figure 5). The middle part of the rib is constricted, whereas the constriction is more expressed longitudinally with the exception of the posterior-most cervical rib. At the constriction, the longitudinal extension of the cervical ribs declines to about two thirds of the length of the articular facet. The aspect ratio of the cervical ribs changes from $1: 1$ in the most anterior ones to $1: 2$ in cervical vertebra $\mathrm{XX}$ (Figure 5). The cervical rib of vertebra $\mathrm{XX}$ is about five times longer than it is wide. This cervical is transitional to the thoracic vertebrae.

Thoracic vertebral column (Table 2): Only 17 tho- racic vertebrae are visible, because three are covered by the coracoids (Figure 8). Three vertebrae are covered by the ventral pelvic plates (Figures $3,8)$. One of these must represent a sacral from its position relative to the ilium. However, it is not clear which sacral it is. Thus the animal had at least 23 thoracic vertebrae. Thoracic vertebrae VII through XI are covered by the coracoids, and $\mathrm{XV}$ and XVI by the gastralia (Figures 3, 8). The outline of those vertebral bodies covered by the coracoids is visible through the latter bones (Figure 8). Like the cervicals the centra of the thoracic vertebrae have a length / width ratio of 2:3 (Table 2 , Figure 7 ). The thoracic vertebrae are platycoelous and show a pair of foramina on the ventral face. A pair of low but sharp ridges runs medial to the foramina in longitudinal direction. The anterior and posterior articular faces are ventrally surrounded by a sharp circumference, which merges with a shallow constriction that is the narrowest in about the middle of the vertebral centrum. Here, 
Table 2. Mauriciosaurus fernandezi INAH CPC RFG 2544 P.F.1. Counts and measurements of the vertebral column in millimetres; the numbering of the posteriors is Arabic, because posterior vertebra I cannot be identified with certainty (see also text). Note also that the number of thoracic vertebrae is at least 23. Because the height of the vertebrae cannot be measured for comparison the length/ width ratio is given here under the premise that in polycotylids the width of a centrum approximately equals its height (Schumacher et al., 2016).

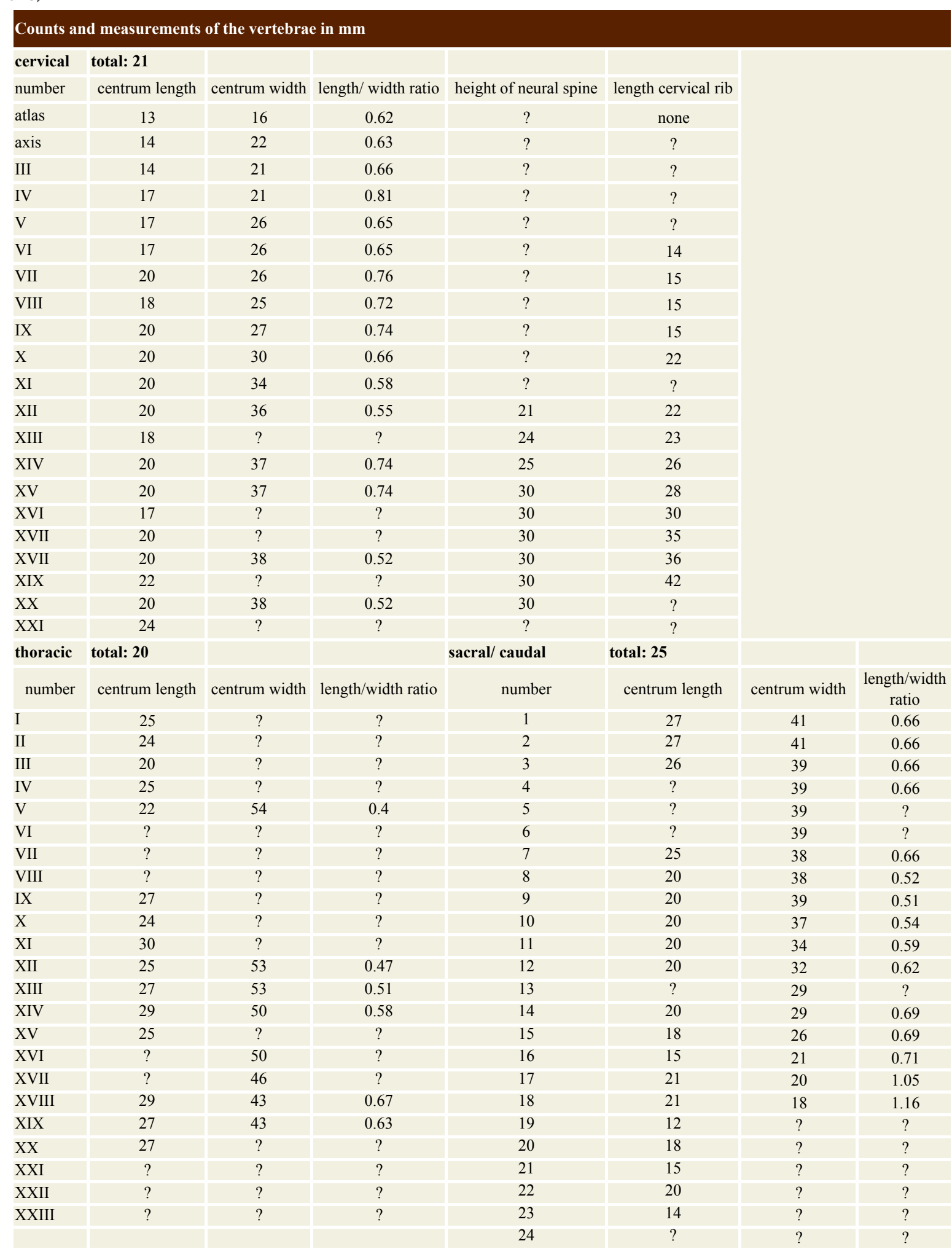


the centrum is about one fifth narrower than at the articular faces (Table 2, Figure 7). A pair of blunt ventrolateral longitudinal keels connects both articular circumferences and borders a ventral face, which is slightly concave in all directions and is two third the width of the centrum. Immediately medial to each ventrolateral keel there is a small, mostly long oval vertebral foramen nutritivum, which is only visible on those vertebrae that are exposed (Figure 8).

Sacral and caudal vertebral column (Table 2): The number of sacrals cannot be identified with certainty because they are covered by the ischia, and therefore, the exact border between the sacral and caudal vertebrae remains unclear. Consequently, the caudals have been designated Arabic numbers. The caudal vertebral column consists of at least 15 vertebrae, in which case there are three sacrals. The posterior six caudals lie along an oblique break and thus lack their left lateral faces. The number of missing caudals, can thus only be estimated to a maximum of ten, which coincides with other polycotylids. All caudal vertebrae are exposed in ventral aspect. The first vertebra posterior to the ischium is regarded as caudal 1 . With a length/width ratio of 1:3 this vertebra is one quarter shorter than the preceding one. The ventral margin of the posterior vertebral articulation facet of the first caudal is concave in the middle suggesting a slight opisthocoely. All following caudals have planar intervertebral articulations. While their length remains about constant, their width gradually decreases posteriorly. The posterior-most preserved vertebrae are twice as long as they are wide. Like the trunk vertebrae the basal six caudal vertebrae have a sharp, ridge-like circumference and a constriction around the middle of their centra, where the diameter of the vertebral bodies decreases to three fifths of the diameter at the anterior articular face. From caudal vertebrae 7 to 13 , the constrictions slightly deepen and the circumferences at the intervertebral articulations become more rounded. The articular facets for the hemal arches are limited to the anterior margin of the respective posterior vertebra. The facets are visible on caudals 2, 3 and 5 through 8 .

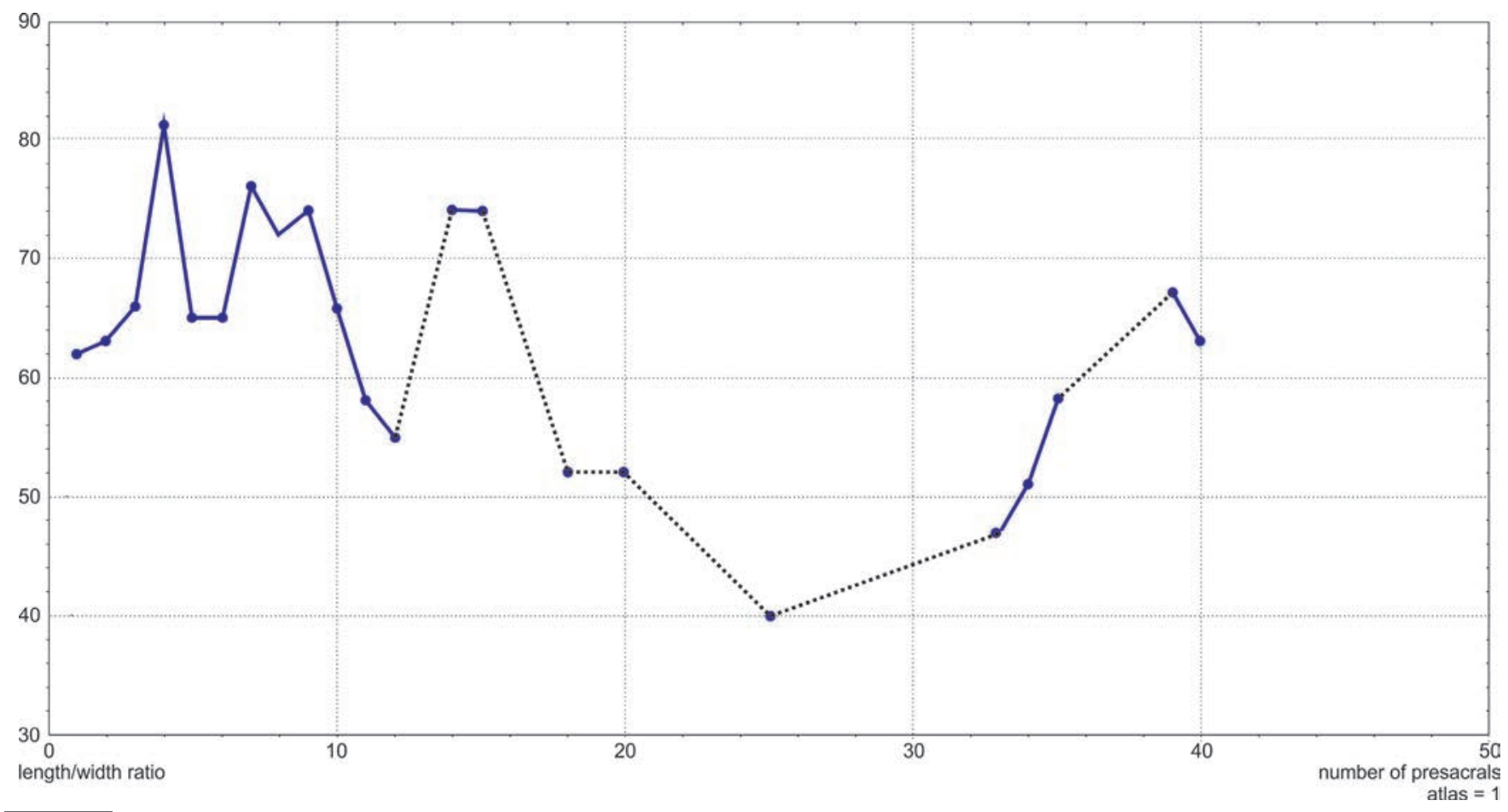

Figure 7 Mauriciosaurus fernandezi INAH CPC RFG 2544 P.F.1. The scatter plot of the length/width ratio indices of the vertebrae shows a typical polycotylid pattern (Schumacher et al., 2016). 

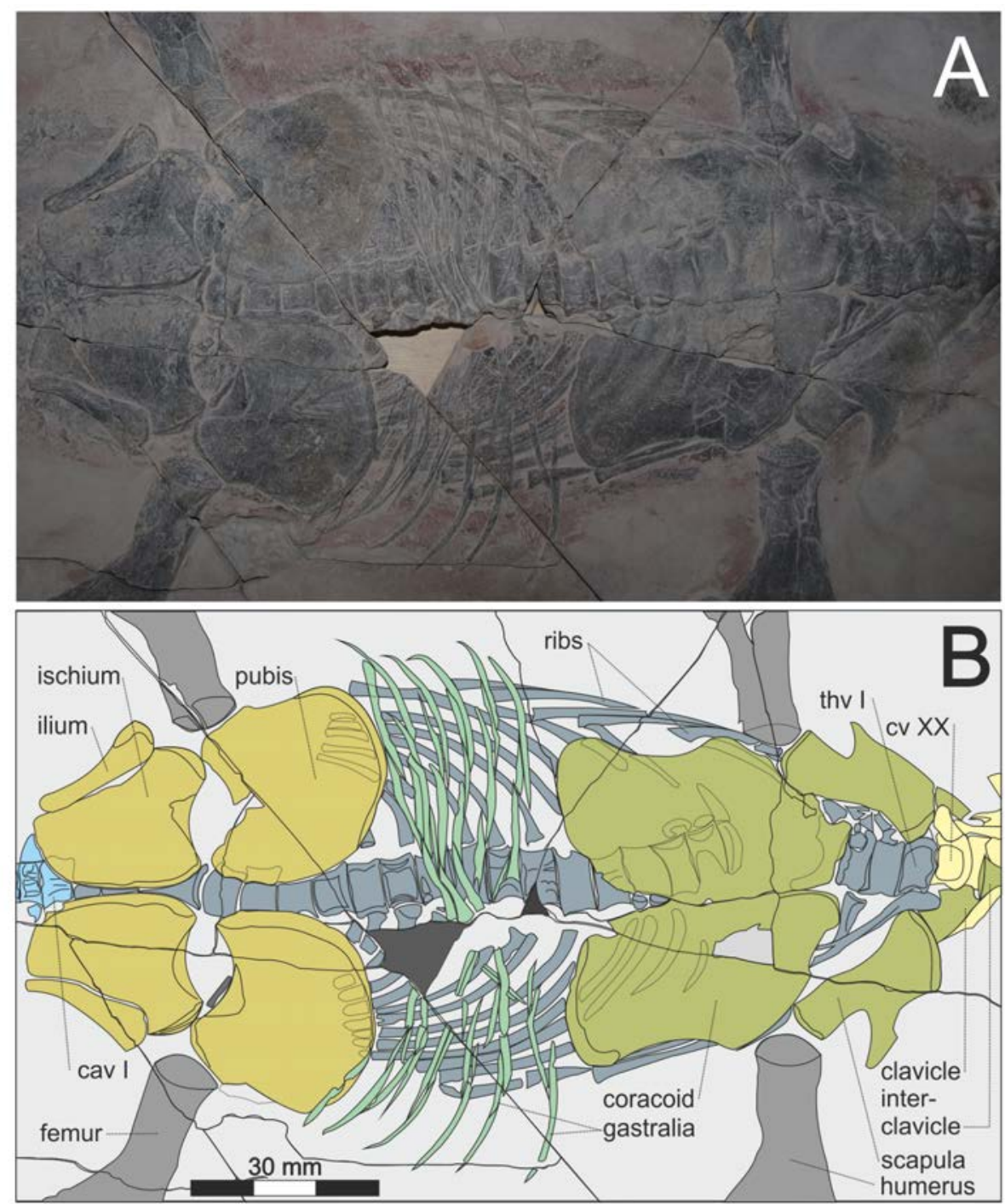

Figure 8 Mauriciosaurus fernandezi INAH CPC RFG 2544 P.F.1. Detail of the trunk including the girdles; A) photograph, B) interpretive line drawing; abbreviations: $\mathrm{cv}=$ cervical vertebra, thv $=$ thoracic vertebra, $\mathrm{cav}=$ caudal vertebra .

Thoracic ribs (Figure 8): 20 pairs of thoracic ribs are reconstructed by extrapolation from those ribs visible on either side of the thoracic vertebral column. With the exception of the first left thoracic rib, which is morphologically transitional between the cervical and the following thoracic ribs, none of the ribs is completely visible, because they are all overlain by the ventral girdle plates and the gastralia. With the exception of the ribs IV and V of the right side of the body all ribs are regularly curved posterodistally. The distal half of thoracic rib IV and the middle section of rib $\mathrm{V}$ are straight. The ribs gradually increase in length from thorac- ic segment I through IX, where they reach their maximum length. They remain of approximately equal size until thoracic segment XIII and then gradually decrease in length towards the sacral region, where they measure probably one fourth to one third the size of the longest thoracic ribs. The diameter of the thoracic ribs is largest in the third pair, the head of which is one third higher than that of the longest thoracic ribs. In all following visible ribs the diameter remains nearly constant. Those that are partially visible between the left pelvic plates are about one third thinner than the preceding ribs. 
In all ribs, the capitula and tubercula are confluent and together form single articular facets. Therefore, though invisible, the par- and diapophyses must be fused to synapophyses. The costal articular facet is slightly concave in the thoracic pairs of ribs III through XII. In the thoracic ribs I and II these facets are convex and posterior to thoracic segment XII the costal articular facets are flat where exposed. Thoracic rib III on the left side shows a sharply triangular cross-section at its articular head with a rounded internal face, a sharp external edge and a concave anterior face. This concavity may be due to compression and is not seen in any other rib with an articular head exposed.

In medial direction the corpus of the ribs diverges to an off-set ventrolaterally facing, transversely oval and concave articular facet for the vertebrocostal contact, which has twice the diameter of the corpus in the middle part of the shaft. Where the ribs are abraded, the medullary cavity is visible. This cavity, which is sharply separated from the compacta, has about half the diameter of the respective part of the rib shaft.

\section{GASTRALIA (FIGURES 8, 9)}

The gastralia basket is preserved mostly in situ (Figures 8,9). Deformation occurred when the gastral basket collapsed and was later crushed over the underlying bones during early diagenesis. There are six transversely oriented gastralia converging in medial direction. The widely $\mathrm{V}$-shaped unpaired medial gastral ossicles contact each other to form a medial plate. The anterior-most two are about one third wider than the posteriorly following three. Due to a gap in the slab (Figure 8) the medial parts of these gastral ossicles are missing; they were reconstructed according to the diameters at the medial fractures and mirrored. Laterally adjacent to the medial gastral ossicles, there is a transversely orientated series of lateral gastral ossicles. The arrangement of these lateral gastral ossicles is different in all gastralia.

The anterior-most gastrale has two medial ossicles opening anteriorly at a reconstructed angle of about $150^{\circ}$. The posterior of the two lies in close contact or overlaps the median gastral ossicle of gastral ribs II and III. Laterally adjacent to the anterior of the two follows a pair of spindle-shaped lateral gastral ossicles that are half as long as one arm of the respective medial gastral ossicle. Laterally, there is one more lateral gastral ossicle, which has three times the length of the spindle-shaped one but is the same thickness. It curves posteriorly and terminates in a sharply rounded caudolaterally facing tip.

Gastral ribs II and III share one medial gastral ossicle, which, like the next following two or three open posteriorly at a reconstructed angle of 120 to $140^{\circ}$. Gastrale III consists of four pairs of spindle-shaped lateral gastral ossicles that contact each other in a transversely directed suture. The suture between lateral gastral ossicles III and IV is inclined caudolaterally at an acute angle of about $20^{\circ}$. The lateral-most gastral ossicle is curved caudolaterally and terminates in a sharp caudolaterally facing tip. Gastral rib III also consists of four paired lateral gastral ossicles in a similar arrangement as in gastral rib II. However, lateral gastral ossicle III is half as wide as ossicles I and II and anteriorly overlapped by lateral gastral ossicle IV, which curves caudolaterally, ending in a sharp posteriorly facing tip. The medial face of lateral gastral ossicle IV articulates with the lateral face of lateral gastral ossicle II.

Gastral rib IV has the most massive medial gastral ossicle likely having been about twice as thick as the others. There are three pairs of lateral gastral ossicles. The medial two are spindle-shaped. The lateral of the two is one third shorter than the medial one. The third and lateral-most gastral ossicle of the gastral rib is only half as thick as the other two but about twice as long as the medially adjacent one. Lateral gastral ossicle III contacts the second along its entire anterior face. The medial terminus of the third lateral gastral ossicle contacts the lateral face of the first in an oblique suture. Lateral gastral ossicle III curves caudolaterally and terminates in a sharp tip.

Gastral ribs V and VI share one medial gastral 
ossicle. Likely, there was a second one posteriorly adjacent, which might have underlain the medial gastral ossicle. In this case the lateral gastral ossicles would have formed forming the base if the anterior edge of gastral rib five represented the lateral arms of medial gastral ossicle VI. However, the median part is missing.

Gastral rib V consists of a paired bundle of three basal lateral gastral spindle-shaped ossicles, the anterior of which, number one, might represent the lateral termini of medial gastral ossicle VI. The caudolaterally following lateral gastral ossicle II is twice as long as the first and laterally contacts lateral gastral ossicle IV. The third lateral gastral ossicle lies posteriorly adjacent to lateral gastral ossicle II and it measures four fifth of the latter. Lateral gastral ossicle III medially contacts medial gastral ossicle $\mathrm{V}$ and the first lateral gastral ossicle of gastrale VI. Lateral gastral ossicle IV is also spindle-shaped and has about the same length as the third. The lateral-most gastral ossicle, which is as long as the second, curves posteriorly and terminates in a sharp tip.

The sixth gastral rib has only two lateral gastral ossicles. The medial one is an elongating trapezoidal in outline and articulates with the caudolateral face of medial gastral ossicle $\mathrm{V}$. The lateral-most second gastral ossicle is one fifth longer than the first and sharply curves posteriorly in its distal fifth terminating in a slim and pointed posteriorly directed tip.

\section{GIRDLES (FIGURES 8, 10; TABLE 3)}

\section{SHOULDER GIRDLE (FIGURES 8, 10; TABLE 3)}

The shoulder girdle as preserved consists of a fragmentary interclavicle, a pair of scapulae and a pair of coracoids. The coracoid is three times the size of the scapula. Remnants of the clavicles are also preserved, but were damaged during collection and preparation. The preserved remains are barely ossified due to the immaturity of the animal. The outline of the bones can thus only be tentatively restored (Figures 8,10 ). The coracoid is trapezoidal in outline. Its maximum length is about twice the minimum width. The contralateral coracoids contact each other along their medial margin in a serrated suture, which diverges at the anterior-most terminus of the bones. The anterolateral margin of the coracoid is convex with the convexity strongest in the medial third of the anterolateral margin. In posterior direction this margin becomes almost straight, whereas the anterolateral margin forms an acute angle of approximately $50^{\circ}$ with the medial margin. The coracoidal part of the fossa glenoidea, which is barely visible, occupies the posterior-most fourth of the anterolateral margin of the coracoid. The lateral margin is concave. Anteriorly it is delimited by a small laterally facing protuberance that marks the posterior extension of the fossa glenoidea. Because of the juvenile status of the individual there are no further anterior extensions that interlock with the clavicles in adults. Posteriorly, the lateral margin of the coracoid turns medially at an angle of about $90^{\circ}$ and merges with the posterior margin, which is convex and set off by a low rim that commences on the lateral extremity of the posterior margin and terminates at the suture with the contralateral coracoid. The external surface of the coracoid is otherwise smooth. The angle between the posterior and the medial margins comprises about $120^{\circ}$.

These features may reflect the early ontogenetic status of the specimen. Parts of the clavicles and the interclavicle are now missing because of the crude method of collection.

The scapula is about half as long as the coracoid and has an evenly convex medial margin, which anteriorly expands into a low ventral process. The anterior margin of the scapula is strongly convex and angled sharply against the medial margin at about $90^{\circ}$. The anterior margin of the scapula is set off by a low ridge that probably demarcated a cartilaginous extension. The lateral margin of the scapula is slightly concave. In the middle third of this margin arises the dorsal scapular process, which most likely was orientated dorsolaterally during life. The dorsal scapular process is almost as wide as the corpus of the scapula in its middle 


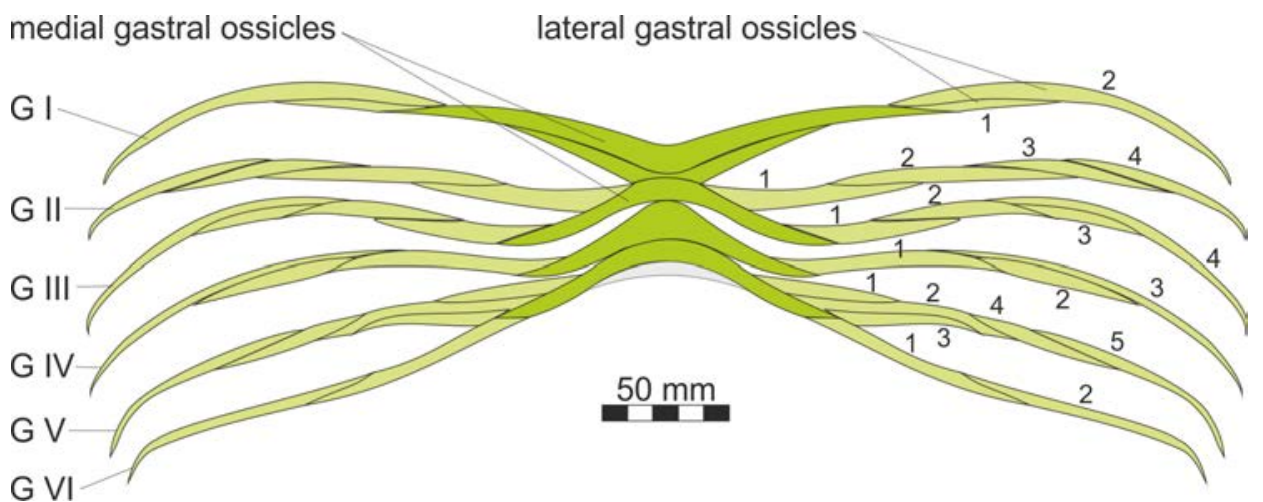

Figure 9 Mauriciosaurus fernandezi INAH CPC RFG 2544 P.F.1. Gastral basket reconstructed according to the best preserved elements. Because of the near in situ position of the lateral termini of the gastralia and the lining-up of the ossicles the median convergence is unlikely to be a taphonomic artefact a diagenetic artefact.

Table 3. Mauriciosaurus fernandezi INAH CPC RFG 2544 P.F.1. Measurements of the girdles in mm.

\begin{tabular}{|c|c|c|c|c|c|c|c|}
\hline \multicolumn{8}{|c|}{ Measurements of the girdles in $\mathrm{mm}$} \\
\hline shoulder girdle & & left & right & pelvic girdle & & left & right \\
\hline \multirow[t]{5}{*}{ scapula } & corpus length & 120 & 130 & ilium & shaft length & 103 & 103 \\
\hline & max. dorsal width & 53 & 65 & & acetabular width & 35 & 34 \\
\hline & width at glenoid fossa & 55 & $?$ & & spinal width & 10 & 10 \\
\hline & caudal margin & 95 & $?$ & ischium & length through shaft & 135 & 130 \\
\hline & depth of notch & 39 & $?$ & & acetabular width & 50 & 52 \\
\hline clavicle & no data & & & & $\begin{array}{l}\text { width of caudal } \\
\text { chord }\end{array}$ & 135 & 115 \\
\hline interclavicle & no data & & & pubis & length through shaft & 140 & 142 \\
\hline \multirow[t]{2}{*}{ coracoid } & max. length & 224 & 224 & & width at acetabulum & 52 & 55 \\
\hline & max. width & 125 & ? & & max. width of plate & 175 & 170 \\
\hline
\end{tabular}

part and is inclined posteriorly against the corpus of the scapula at an angle of about $45^{\circ}$. The slightly convex dorsal margin of the dorsal scapular process is about one third wider than the base of the process. Evidently this process was not yet fully mineralized. The posterior margin of the scapula is set of from the corpus by a low ridge, and is strongly convex in its middle third, but medially and laterally bares a shallow concavity. This medial concavity articulates with the proximal edge of the coracoid and the lateral one forms the scapu- lar part of the fossa glenoidea. The external face of the scapula shows a blunt straight ridge that reaches from the lateral third of the anterior margin of the bone to its caudolateral corner. Along this ridge the lateral part of the scapula with the dorsal process was angled against the medial part of the corpus. Because there is no break along the ridge either the bending angle was very shallow, or, more likely, the scapula suffered some plastic diagenetic deformation. Otherwise the external face of the scapula is smooth. 
Anteriorly adjacent to the left scapula there is a sub-rectangular bone likely representing the central part of the left clavicle. It articulates with the medial third of the craniomedial articulation face of the scapula. The medial margin of this fragment likely represents the original margin of the clavicle. The anterior margin of the fragment is irregularly broken while the lateral margin dips below the matrix. The original shape of the clavicle cannot be determined. Only an insignificant fragment, likely of the right clavicle, is identified, but it has no contact with the scapula, and thus might be part of the interclavicle.

\section{PELVIC GIRDLE (FIGURES 8, 10, TABLE 3)}

The elements of the pelvic girdle are almost preserved in their correct position, the ilia being crushed caudolaterally during diagenesis (Figure 8). The pubis is the largest of the pelvic elements being one third larger than the ischium and about six times larger than the ilium. The craniomedial margin of the pubic plate is semi-circular in outline and slightly expanded. A rim that parallels this margin suggests a cartilaginous extension of the bone in life, which explains the separation of contralateral pubic bones as preserved. The pubis becomes thickest close to its posteromedial corner. The posteromedial and caudolateral margins of the pubis are deeply concave and converge to a posteriorly facing peduncle that has one-fourth the width of the pubic plate. Anterior to the posteromedial margin there is a recess in the external surface that is boarded by a deeply concave, rounded step on the external surface of the bone. The medial third of the posterior margin of this peduncle is angled against the lateral two-thirds at about $130^{\circ}$. The medial part represents the contact surface with the ischium, the lateral part forms the pubic part of the acetabulum.

The plate of the ischium is orientated medially with a convex medial margin becoming laterally directed in its posterior third. In the anterior third the contralateral ischia diverge at an angle of about $10^{\circ}$. Posteriorly the divergent angle is approximately $45^{\circ}$. The medial articular facet of the ischia reaches its maximum thickness in the anterior third. The anterior and caudolateral margins of the ischium are concave, the concavity of the anterior margin being deeper than of that posterior one and only two thirds as long. In the middle third of the posteromedial margin of the ischium there is a slight convexity. Both anterior and posterior margins, in lateral direction, converge into a peduncle that is orientated at an angle of about $46^{\circ}$ anteriorly against the long axis of the animal. The anterolaterally facing articular facet of the peduncle has one-fourth the length of the medial margin of the ischum. The craniomedial third of the face articulates with the pubis, the lateral twothirds from the ischiadic part of the acetabulum. The ilium is elongate with a rounded triangular outline with the apex facing posteromedially. Its length is four times the width at its acetabular base, which is anteriorly convex. Both the lateral and medial margins converge posteriorly as preserved and merge with the posterior terminus of the ilium, which is sharply convex. The lateral margin of the ilium is gently convex. The medial margin is bipartite with the basal two thirds being slightly convex and the apical third being slightly concave. The anteriorly oriented basal part is the thickest and formed the roof of the acetabulum prior to a diagenetic collapse of the pelvic girdle.

\section{APPENDICULAR SKELETON (FIGURES 11 - 13; TABLE 4)}

\section{PEGTORAL LIMBS (FIGURE 11; TABLE 4)}

The reconstruction of the pectoral limbs is mainly based on the left forelimb, which is better preserved than the right.

Humerus: The slightly sigmoidally curved shaft of the humerus is longitudinally oval in cross-section with a length/ height ratio of approximately 1.6. Towards the caput humeri the shaft becomes almost circular in cross-section. The humeral head is low and regularly rounded with a finely wrinkled surface suggesting a cartilaginous coating in life. Immediately distal to the anterior margin of the humeral head there is a low and blunt deltoid tu- 
berosity that extends about one-seventh the length of the humerus. A low elevation on the posterior margin of the humeral shaft may represent the insertion tubercle for the $m$. coracobrachialis (Robinson, 1975). From the middle of the shaft in distal direction the anterior and posterior margins of the humerus diverge to about twice the longitudinal diameter. While the anterior supracotylar ridge only slightly curves anteriorly, the posterior one shows a deep convexity at its base. The posterior supracotylar ridge forms an angle of approximately $120^{\circ}$ with the humeral shaft and merges with the distal articular face in a regularly rounded flange. The distal articular face is flat and separated from the shaft by a blunt ridge that merges with the anterior and the posterior extremity of the humeral shaft. The articular facets for radius and ulna are separated by a very low interarticular rim that forms the distal-most extremity of the humerus. The articular facets for ulna and pisiform are confluent and together they are of equal size as that for the radius. Both articular faces include an angle of about $170^{\circ}$. While the articulation facet with the radius is straight, that of the ulna/ pisiform complex is slightly convex.

Radius and ulna: All articular facets of radius and ulna lie in articulation with their neighboring bones. However, there is a gap between radius, ulna and pisiform as well as the humerus.

The radius has a length/width ratio of 0.7 , is about twice the size of the ulna and roughly pentagonal in outline. The regularly convex proximal articular face with the humerus is the longest. The curvature of the proximal articular face of the radius does not match its humeral counterpart. However, the radial articular face of the humerus is still covered by matrix so that the actual shape of the facet cannot be reconstructed. The slightly convex anterior margin of the radius forms a right angle with the proximal articulation facet and includes an angle of about $100^{\circ}$ with the slightly concave articular facet with the radial one. The articular facet between radius and radial has three fourth the length of the radiohumeral one. Both articular facets run nearly parallel to each other. The

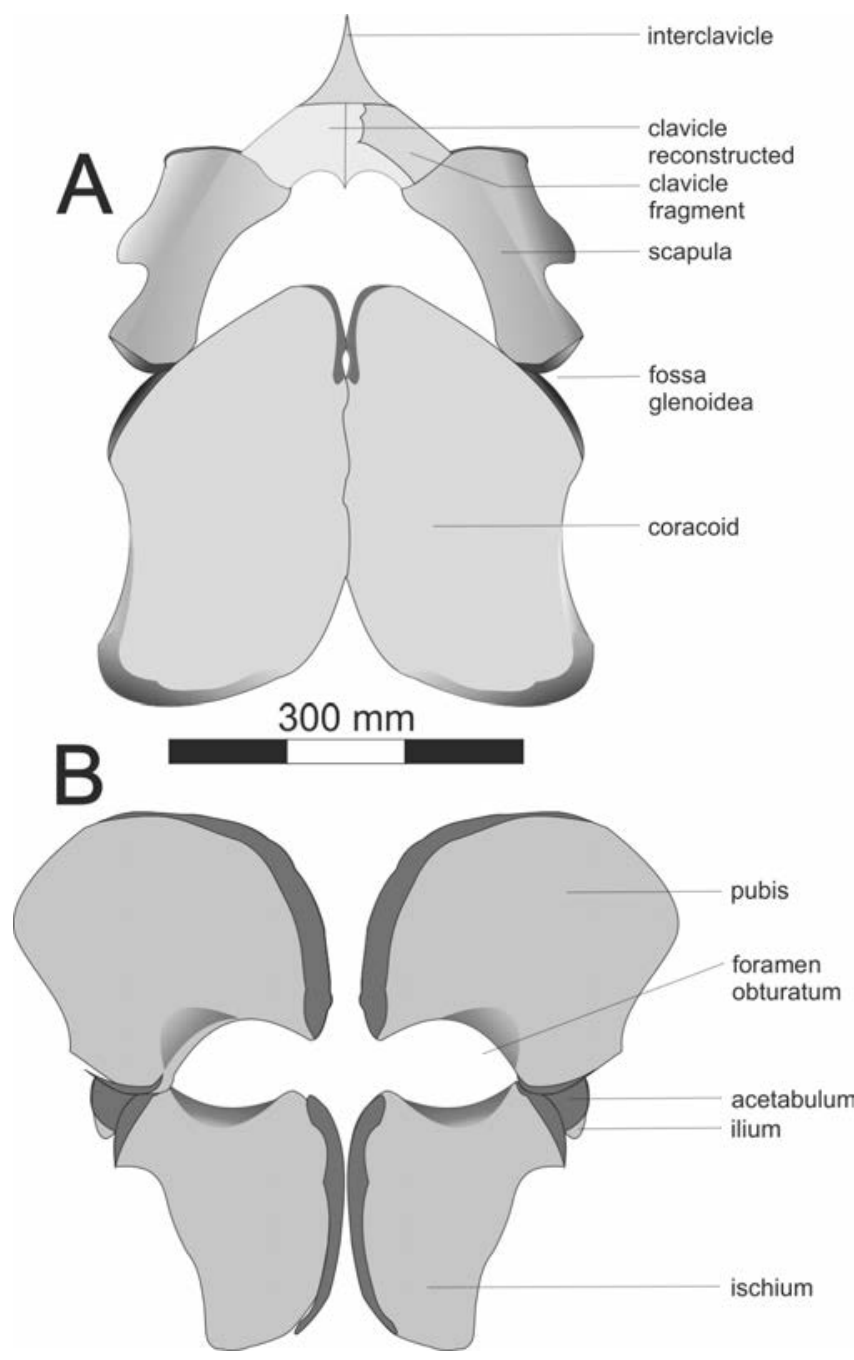

Figure 10 Mauriciosaurus fernandezi INAH CPC RFG 2544 P.F.1 Reconstruction of the girdles in ventral aspect; A) shoulder girdle with likely confluent coracoscapular foramina, B) pelvic girdle with likely large areas of cartilage that may have separated the contralateral obturator foramina; dotted lines and light grey = reconstructed. Note the ischia that are as long as they are wide, and the rounded pubic bones. These features may be aligned with the early ontogenetic status of the specimen. Parts of the clavicles and the interclavicle were lost during collection.

contact between radius and intermedium extends over one fourth of the longitudinal expansion of the radius, is slightly concave and forms an angle of $120^{\circ}$ with both the radioradial and the straight radioulnar articular facets, which are of equal length. The radioulnar articulation is slightly concave and over its entire length it contacts the ulna. The ulna has a length/width ratio of 0.83 , is 
roughly hexagonal in outline with the regularly convex ulnohumeral articulation face being the longest margin of the bone. The convex articular face is covered by wrinkles. The convexity matches the respective concavity of articulation facet of the humerus, but is separated from it by a gap. The ulnoradial facet forms a notch that accommodates the respective facet on the radius. It has one-third the length of the ulnohumeral facet. Both include an angle of about $110^{\circ}$. The articular facet with the intermedium is straight. It has two-thirds the length of the ulnohumeral facet and lies at an angle of $110^{\circ}$ to the ulnoradial facet and at an angle of $120^{\circ}$ with the slightly convex ulnoulnar facet, which is a little shorter than the ulnointermedial facet. The posterior margin of the ulna is formed by the tiny straight articular face with the fourth proximal carpal. This facet is half as long as the ulnointermedial facet and the two describe an angle of about $110^{\circ}$. The articular facet with the pisiform is straight, equals the length of the ulnointermedial facet and is orientated at an angle of $110^{\circ}$ against the posterior margin of the bone.

Carpalia: All carpalia lie in close contact to each other, suggesting that the articular facets were covered by a thin layer of cartilage during life.

The pisiform is trapezoidal with an almost straight articular facet with the posterior margin of the ulna. The posterior margin of the pisiform is also straight, and is the same length as the articular facet with the ulna. Both posterior and anterior margins of the bone converge distally at an angle of about $20^{\circ}$. The asymmetrically convex proximal margin of the pisiform is about one third
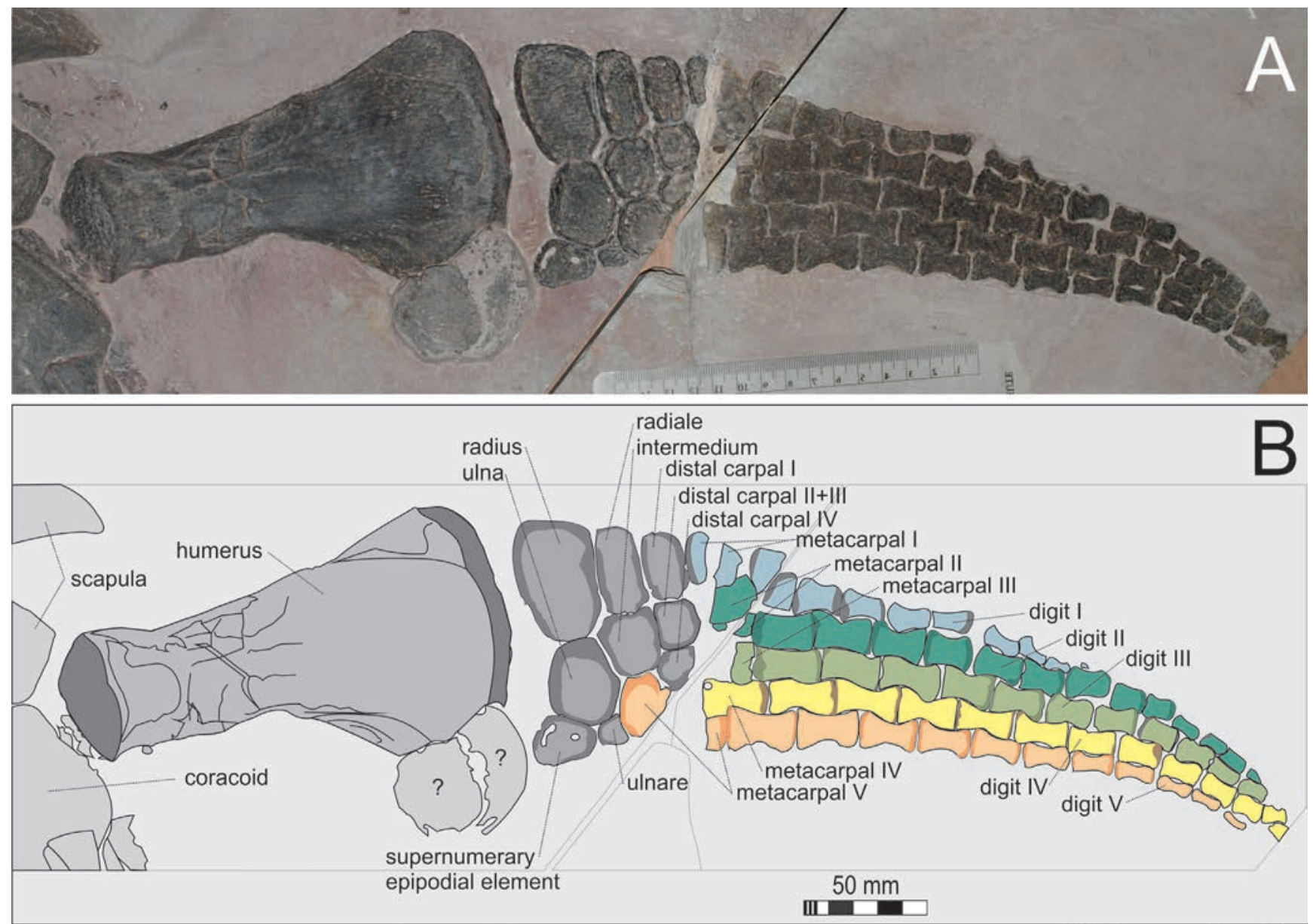

Figure 11 Mauriciosaurus fernandezi CPC RFG 2544 P.F.1. Left pectoral limb in ventral aspect; A) photograph, B) interpretative line drawing. 
Table 4. Mauriciosaurus fernandezi; measurements of the extremities in $\mathrm{mm}$; abbreviations: $\mathrm{dc}=\mathrm{distal}$ carpal, $\mathrm{dt}=\mathrm{distal}$ tarsal.

\section{Measurements of the extremities in $\mathrm{mm}$}

\section{front flipper}

\section{hind flipper}

\begin{tabular}{|c|c|c|c|c|c|c|c|}
\hline & & right & left & & & left & right \\
\hline \multirow[t]{3}{*}{ humerus } & shaft length & 170 & 180 & femur & shaft length & 185 & 180 \\
\hline & $\begin{array}{l}\text { max. width } \\
\text { humeral head }\end{array}$ & 48 & 55 & & $\begin{array}{l}\text { max. width } \\
\text { femoral head }\end{array}$ & 55 & 55 \\
\hline & max. distal width & 105 & $?$ & & max. distal with & 100 & 85 \\
\hline \multirow[t]{2}{*}{ ulna } & longitudinal & 35 & 45 & tibia & longitudinal & & 43 \\
\hline & proximodistal & 25 & 25 & & proximodistal & & 30 \\
\hline \multirow[t]{2}{*}{ radius } & longitudinal & 30 & 35 & fibula & longitudinal & & 42 \\
\hline & proximodistal & 25 & 25 & & proximodistal & & 30 \\
\hline \multirow[t]{6}{*}{$\begin{array}{l}\text { extrazeugo-podial } \\
\text { element }\end{array}$} & longitudinal & 15 & 20 & $\begin{array}{l}\text { extrazeugo-podial } \\
\text { element } 1\end{array}$ & longitudinal & 8 & 12 \\
\hline & proximodistal & 17 & 20 & & proximodistal & 10 & 14 \\
\hline & & & & $\begin{array}{l}\text { extrazeugo-podial } \\
\text { element } 2\end{array}$ & longitudinal & 20 & 22 \\
\hline & & & & & proximodistal & 23 & 20 \\
\hline & & & & $\begin{array}{l}\text { extrazeugo-podial } \\
\text { element } 3\end{array}$ & longitudinal & 9 & 15 \\
\hline & & & & & proximodistal & 13 & 10 \\
\hline \multirow[t]{2}{*}{ radiale } & longitudinal & $?$ & 35 & tibiale & longitudinal & 34 & 30 \\
\hline & proximodistal & $?$ & 15 & & proximodistal & 19 & 17 \\
\hline \multirow[t]{2}{*}{ intermedium } & longitudinal & $?$ & 25 & intermedium & longitudinal & 24 & 25 \\
\hline & proximodistal & $?$ & 20 & & proximodistal & 22 & 19 \\
\hline \multirow[t]{2}{*}{ ulnare } & longitudinal & $?$ & 24 & fibulare & longitudinal & 27 & 25 \\
\hline & proximodistal & $?$ & 20 & & proximodistal & 20 & 20 \\
\hline \multirow[t]{2}{*}{ dc I } & longitudinal & $?$ & 25 & dt I & longitudinal & 22 & 21 \\
\hline & proximodistal & $?$ & 15 & & proximodistal & 18 & 15 \\
\hline \multirow[t]{2}{*}{ dc II+III } & longitudinal & $?$ & 20 & $\mathrm{dt}$ II+III & longitudinal & 20 & 17 \\
\hline & proximodistal & $?$ & 15 & & proximodistal & 18 & 16 \\
\hline \multirow[t]{2}{*}{ dc IV } & longitudinal & $?$ & 18 & dt IV & longitudinal & 18 & 16 \\
\hline & proximodistal & $?$ & $?$ & & proximodistal & 21 & 18 \\
\hline total length & proximodistal & $?$ & 510 & & proximodistal & 505 & 510 \\
\hline manus length & proximodistal & $?$ & 300 & & proximodistal & 280 & 28 \\
\hline
\end{tabular}

longer than its evenly convex distal margin. The strongest convexity of the proximal margin of the pisiform lies in its anterior third.

The supernumerary carpal element is also trap- ezoidal. The articular face with the ulna consists of two low convexities that are separated from each other by a sharp notch. The anterior convexity merges with the proximal articular facet with 
the pisiform. The posterior half of the articular facet with the pisiform is slightly concave and terminates in a caudoproximally orientated tubercle. The sinusoidal proximal articular facet of the supernumerary element measures two thirds of the length of the sinusoidal posterior margin, in which the concavity lies in the proximal half of the bone. Posterior and anterior margins are of equal lengths and diverge distally at an angle of about $30^{\circ}$. The distal margin along which the supernumerary element articulates with the ulnare is about as long as its posterior margin. Where the supernumerary element contacts the ulnare, its margin is concave, whereas the posterior two thirds of the distal margin of the former are slightly convex. Along the convexity there is a posteriorly diverging articular gap. Both the proximal and distal margins parallel each other.

The radiale is longitudinally elongated pentagonal with a length/width ratio of about 0.4 . With its anterior margin the bone articulates with the radius, which is about three times as big as the radiale. The slightly convex anterior margin of the radiale is the longest of all margins of the bone and almost parallels the posterior margin, which is a little shorter than the anterior one and slightly concave along its contact with distal carpal I. The proximal fourth of the posterior margin of the radiale is straight and curves proximally against the concavity at an angle of about $7^{\circ}$. Distally the posterior margin of the radiale terminates in a blunt process that matches a respective notch on the anterior margin of distal carpal I. The anterior face of the radiale is regularly convex. The posterior face consists of two straight articular facets of equal length that include an angle of about $55^{\circ}$ with each other. The anterolaterally orientated facet of these two is angled in $55^{\circ}$ against the anterior margin of the radiale and articulates with the anterior face of the intermedium. The caudolaterally orientated part of the posterior margin bridges the gap between the anterior face of the intermedium and proximal face of distal carpal I.

The intermedium is hexagonal. The straight anteroproximally facing intermedioulnar articula- tion parallels the posterodistally facing margin of the ulna, leaving a small interarticular gap, inside which the dorsal margin of the intermedioradial articulation facet is visible. Thus the articular surface of the slightly compacted intermedioanterior articulation is exposed. The intermedioulnar articulation is about two-thirds the length of the intermedioradial articulation and describes an angle of about $70^{\circ}$ with the former and thus is facing proximoposteriorly. The intermedioulnar articulation faces posteriorly and is as large as the intermedioradial articulation.

The ulnare is longitudinally rounded in outline with a length/width ratio of 1.2. There are no clearly defined articular facets along its anterior, proximal and posterior margins. The anterior margin of the bone contacts the intermedium in a tiny section while the proximal margin of the ulnare matches the slightly concave posterodistal margin of the ulna.

Caudoproximally the pisiforme contacts the ulnare in a shallow concave craniodistally facing articular facet. The posterior and distal margins of the ulnare are slightly concave, the caudodorsal corner of the bone having been lost. The distal articular facet is about one third longer than the posterior one. Both facets include an angle of about $100^{\circ}$. The same angle is included between the posterior articular facet of the ulnare and its carniodistally facing margin. The distal concavity likely articulated with metacarpal (mc) V, but this area was destroyed while the slab was broken.

All three distal carpals (dc) are visible in the left pectoral limb. dc I is rounded rectangular in outline with a length/width ratio of 0.6 . The proximal, anterior and posterior margins of the bone are evenly convex, while the distal one is straight and about one sixth shorter than the proximal one. With its proximal margin dc I contacts both the accessory carpal element and the radiale; with its distal margin it contacts mc I and II/III. With its posterior margin dc I articulates with dc II/III, which is rounded quadrangular in outline with a length/width ratio of 0.75 . The proximodistal extension of dc II/III is a little larger than that of 
dc I, but cranioposteriorly it is about half as long. Like in dc II/III all margins meet approximately in right angle, with the proximal and posterior margins being concave and with the anterior and distal margins being convex. The distal margin shows the strongest convexity. The caudoproximal corner of dc II/III is marked by a short, straight facet that is one-fifth the length of the posterior facet of dc II/III. The proximal concavity of the bone precisely matches the distal convexity of the intermedium, while the posterior concavity fits the convex anterior margin of dc III. The convex anterior margin of dc II/III contacts the posterior margin of dc I in one point. Likely the distal margin of dc II/III articulated with mc II and III, but this contact is obscured by a fracture in the slab. With a size of about one third the size of dc I, dc IV is the smallest of the preserved distal carpals. As preserved the bone is irregularly pentagonal in outline. The proximal, anterior and posterior margins are slightly convex. The distal margin of dc IV, which has a length/width ratio of 0.75 , is situated on the edge of a crack and thus is slightly abraded. The proximal articular facet is about half as long as the anterior and posterior margins. With the anterior margin the proximal articular facet forms an angle of about $100^{\circ}$, with the posterior one an angle of about $120^{\circ}$. The distal margin has three times the length of the proximal margin, which contacts the distal margin of the intermedium in its posterior third. The anterior margin of dc IV articulates with the posterior margin of dc II/III. Distally, dc IV articulates with mc III and IV. Likely, there was a contact with the anterior margin of $\mathrm{mc} I V$, but the relevant area is destroyed.

Metacarpalia: With the exception of mc I the proximal ends of the metacarpalia are now missing as is much of their corpora. From what is preserved a length/width ratio of about 2 is reconstructed for all metacarpalia (Table 5). Nothing more can be said about their shape.

Phalanges: The phalangeal formula of the manus is 9-12-11 (preserved) -12 (preserved) - 11 with the incomplete digits II and IV being the longest. With the exception of the distal-most ones, the phalan- ges are uniformly hourglass-shaped with almost straight interphalangeal articulations. The length width ratio of the phalanges of all digits III is 1.77. In each phalanx, the minimum transverse section at the medial constriction is about two thirds of the extension of the proximal articular facet. The distal articular facet is about one fifth smaller than the proximal facet. The ultimate phalanges show a rounded tapering tip and a slightly convex proximal articular facet that does not precisely match its counterpart on the penultimate phalanx. The phalanges in the proximal half of the manus are arranged in oblique rows directed posterodistally. The interphalangeal articulations lie in the constriction of the posteriorly following phalanges. In distal direction, the interphalangeal articulation lines gradually line up with each other and in the distal fifth of the manus from a straight line.

\section{PELVIC LIMBS (FIGURES 12, 13)}

Femur: The femur resembles the humerus in outline with its longitudinally oval cross-section and a length/width ratio of approximately 1.8, but it is a little smaller in all dimensions and it has a straight shaft. At the caput femoris, the shaft becomes almost circular in cross-section. At the frill of the articular facet, the bone expands by about one fifth. The anatomical neck of the caput femoris is a shallow circumference distally adjacent to it. The third trochanter forms a shallow elevation on the posterior face of the femur. It commences distally to the anatomical neck and extends distally for about one third of the shaft. The caput femoris is low and regularly rounded. Its surface bears fine wrinkles, which during life were probably covered by a cartilaginous cap.

From the middle of the shaft the anterior and posterior margins of the femur gradually diverge distally. At the distal articular face the bone has about twice the longitudinal diameter of the midshaft. The posterior face of the femur is more convex than the anterior face. Therefore, the evenly rounded distal articular facet extends further posteriorly with respect to the long axis of the shaft than anteriorly. The posterior face of the femur in- 
Table 5. Mauriciosaurus fernandezi INAH CPC RFG 2544 P.F.1; measurements of metapodials and phalanges in mm. The average length/width ratio of the phalanges (ph) is 1.77 .

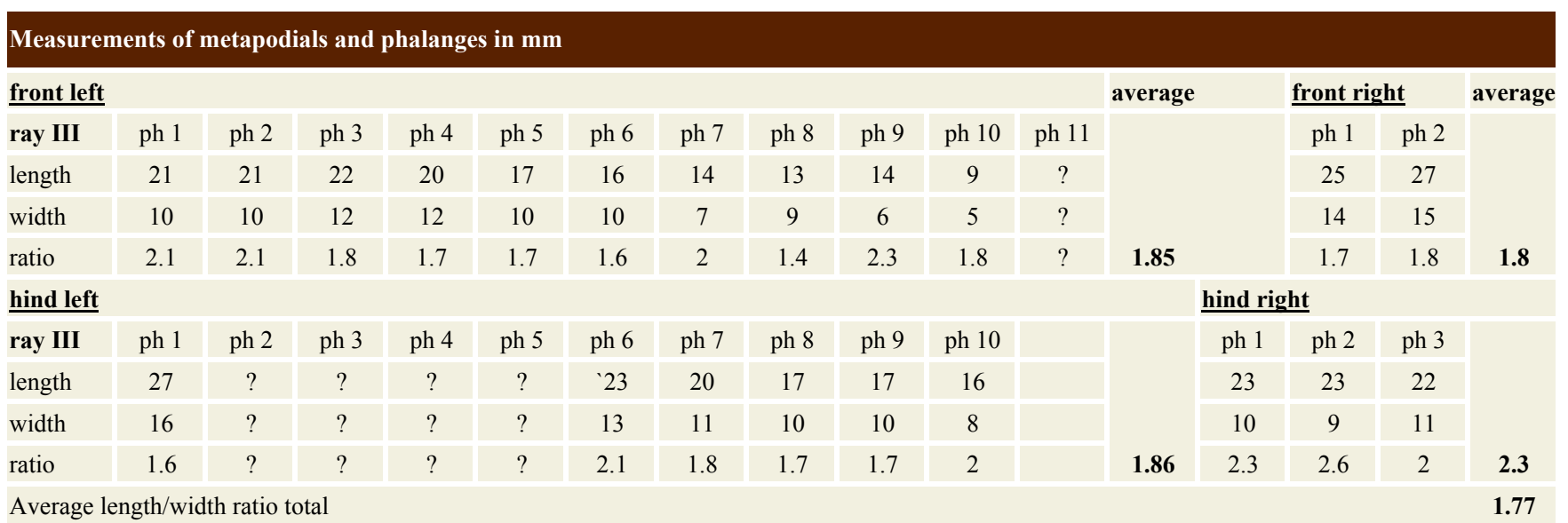
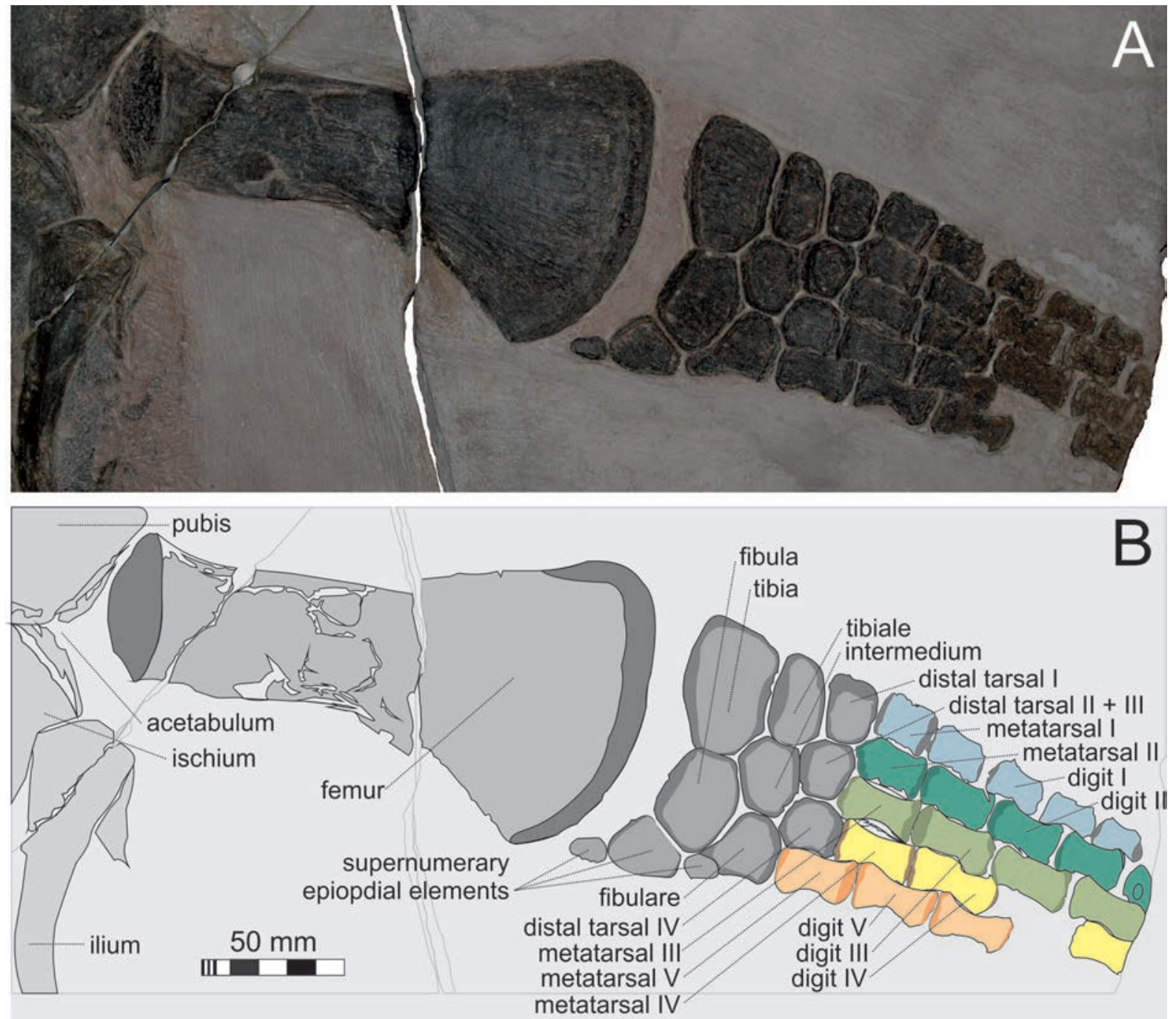

Figure 12 Mauriciosaurus fernandezi INAH CPC RFG 2544 P.F.1. Left pelvic limb in ventral aspect; A) photograph, B) interpretative line drawing. 
cludes an angle of about $120^{\circ}$ and merges with the distal articular face in a regularly rounded flange. A blunt ridge separates the flat distal articular face from the shaft. This ridge merges with the anterior and the posterior extremity of the femoral shaft. The articular facets for tibia and fibula are confluent with no trace of an intercondylar ridge. The femur is separated from the distal elements of the hind limb by a considerable gap containing a goethitic substance.

Tibia and fibula: The tibia is irregularly oval in outline with the anterior margin being about one third longer than the posterior ones. The length/ width ratio of the bone is about 0.7 . All facets are regularly convex and confluent. The tibia lies level with the anterior half of the distal femoral articular face, but it is separated from the latter by a gap that is half the proximodistal dimension of the tibia. With its posterior extremity the tibia contacts the anteroproximal half of the anterior convexity of the fibula. Distally, the tibia loosely articulates with tibiale and intermedium in one point.

The fibula is irregularly oval as well but has only a little more than half the longitudinal extension than the tibia (length/width ratio: 0.7). Like in the tibia all articular faces are convex and confluent. The fibula lies posteriorly adjacent to the tibia and like the latter is separated from the distal articular face of the femur by a gap. With its craniodistal convexity the fibula contacts the intermedium in one point, while the posterior two thirds of the distal convexity match a concavity on the proximal margin of the fibulare.

Supernumerary epipodial elements: Two sesamoidal supernumerary elements are preserved posterior to the fibula. The most anteriorly positioned of the two is rounded triangular in outline with the apex facing distally. The anterior and posterior margins are about on fourth longer than the proximal margin, which lies in line with that of the fibula. The anterior supernumerary element touches the posterior extremity of the fibula. With its caudoproximal corner the anterior supernumerary element contacts the posterior one, while its distal extremity touches yet another supernu- merary element, which lies posteriorly adjacent to the fibulare. The posterior supernumerary element is oval and one-third the size of the anterior supernumerary element. Its proximodistal diameter is twice the length of the cranioposterior. The bone articulates with the anterior supernumerary element with its distal extremity.

Tarsalia: Four elements form the proximal row of the tarsals: tibiale (= astragalus), intermedium, fibulare and a supernumerary element. The tibiale is an irregularly oval bone, which is twice as long longitudinally than transversely. All articular facets are convex, but the proximal one bears a tiny notch in its posterior third. Anteriorly, the tibiale extends over two thirds of the distal margin of the tibia and with its posterior extremity it contacts the intermedium. The distal convexity articulates with the anterior concave margin of $\mathrm{dt} \mathrm{I}$.

The intermedium is one third shorter than the tibiale but has the same proximodistal extension. All articular margins are convex and confluent giving the bone an oval outline, the proximal margin are more convex than the distal one. The proximal margin of the intermedium touches the posterodistal corner of the tibia and the craniodistal corner of the fibula, respectively. The posterior extremity of the intermedium articulates with the anterior one of the fibulare. Its distal margin touches the proximal convexities of dt II/III and IV.

The fibulare is the same size as the intermedium, but is roughly pentagonal in outline. Its anterior margin is concave and articulates with the posterior half of the distal margin of the fibula. The anteroproximal margin of the fibulare is almost straight and includes an angle of about $120^{\circ}$ with the anterior margin. At its anterior extremity the anteroproximal facet terminates in a sharply convex process that merges with the distal convexity at an angle of $90^{\circ}$. The posterior margin of the fibulare is one third longer than the anterior one and posteriorly merges with the shallowly convex posterior margin at an angle of about $90^{\circ}$. The caudoproximal facet of the fibulare is straight and meets with the posterior margin at an angle of about $120^{\circ}$. The posterior and the caudoproximal 
facets are of equal length and together they are as long as the anterior margin. With its distal margin, the fibulare contacts $\mathrm{dt} \mathrm{IV}$ and $\mathrm{mt} \mathrm{V}$ in one point, respectively. The caudoproximal margin of the bone articulates with the posterior margin of a supernumerary epipodial element that is trapezoidal in outline, it has one third the size of the fibulare and bridges the gap between the fibulare, the fibula and the anterior supernumerary element posterior to the fibula. The proximal margin of the tarsal supernumerary element is about half the size of the distal margin.

There are three distal tarsals, which are arranged in a row distally adjacent to the proximal row of tarsalia. Dt I is approximately trapezoidal and about one fourth smaller than the tibiale. The anterior margin of $\mathrm{dt} \mathrm{I}$ is the longest of all margins; it is concave and firmly articulates with the tibiale. The anterior, distal and posterior margins are all convex and confluent at the corners. The distal margin is about one third smaller than the proximal one. The anterior margin of $\mathrm{dt} \mathrm{I}$ is as long as the distal one with which it includes an angle of about $100^{\circ}$. The angle between the anterior margin and the proximal articular facet is about $80^{\circ}$. The posterior margin of $\mathrm{dt} \mathrm{I}$ is strongly convex and is half the length of the proximal margin. With its distal margin dt I contacts $\mathrm{mt} I$, with its posterodistal corner mt II. The posterior extremity of $\mathrm{dt} I$ articulates with the anterior margin of dt II/III, which is irregularly oval in outline and one fourth smaller than $\mathrm{dt}$ I. The proximal margin of dt II/III is convex and punctually contacts the distal convexities of tibiale and intermedium. The distal margin of the bone is divided into two facets of almost equal length. Both are convex and only separated by a slightly more convex part of the distal margin, which protrudes between the proximal articular faces of $\mathrm{mt}$ II and III. The posterior extremity of dt II/III contacts dt IV in a single point.

In longitudinal direction, dt IV is one third shorter than dt II/III, but a little larger proximodistally. The outline of dt IV is marked by slightly convex posterior and distal margins. The other margins are confluent and evenly convex, forming a nearly circular outline. The proximal margin of $\mathrm{dt} I \mathrm{~V}$ touches the intermedium and fibulare in a point, respectively. The posterior concavity, which equals the distal one in length, articulates with mt IV and the posterior one with the proximal two thirds of the anterior face of $\mathrm{mt} \mathrm{V}$.

Metatarsals: All five metatarsals are preserved in articulation. Mt I is the shortest being about one third shorter than mt III-V. In cranioposterior direction, $\mathrm{mt} \mathrm{I}$ is about one fourth shorter than in the proximodistal direction. The narrowest point of the shaft lies in the middle of the bone and is barely visible. Both the proximal and distal articular surfaces are slightly convex and articulate loosely with dt I proximally and with the basal phalanx of digit I distally. The posterior margin of $\mathrm{mt} \mathrm{I}$ lies in close contact with $\mathrm{mt}$ II. The latter bone is about one quarter longer proximodistally than $\mathrm{mt}$ I and shows a proximally orientated process that interdigitates with dt I and dt II/III. The circumference of the shaft is mostly obscured by matrix. The distal articular face is slightly convex. Mt II-V are approximately twice as long proximodistally as they are anteroposteriorly. The mid-shaft circumference has one-fourth the width of the proximal articular facet. The proximal articular faces of all metatarsalia are slightly convex as are the distal articular facets of $\mathrm{mt} \mathrm{I}$, II and V. Those of $\mathrm{mt}$ II and IV are slightly concave. The articulation surfaces between mt I-IV and the basal phalanges of the digits I-IV form a line which is inclined against the long axis of the body by about $5^{\circ}$. With one third of its anterior margin mt $\mathrm{V}$ contacts the proximal third of the posterior margin of mt IV.

Phalanges: The phalangeal formula of the pes is 6 (preserved) -12-14-14-11 with the digit IV being the longest. With the exception of the distal-most ones, the phalanges are hourglass-shaped with almost straight interphalangeal articulations, as in the manus. The length/width ratio of the phalanges of all digits III is 1.77 (Table 5). The minimum transverse section at constriction is about two thirds of the extension of the proximal articular facet and the distal articular facet is about one 
fifth smaller than the proximal one. The ultimate phalanges, where preserved, they show a rounded tapering tip and a slightly convex proximal articular facet that does not precisely match the distal articular face of the penultimate phalanx. The two proximal-most phalanges of the digits I-IV are arranged in oblique rows with a posterodistal direction, and with minimal overlap. An exception is digit $\mathrm{V}$, which overlaps the posterior margins of the phalanges in digit IV by one third of their posterior proximal face. Further distally the inclination of the line of the interphalangeal articulations gradually approaches the situation seen in the manus, where the interphalangeal articulation lies within the constriction of the posteriorly following phalanges. In distal direction, the interphalangeal articulation surfaces gradually line up with each other and in the distal fifth of the pes they form a straight line, as is the case in the manus, which is about one fourth larger than the pes.

\section{SOFT TISSUES (FIGURES 2, 14 - 18)}

There are five types of soft tissue preservation in the specimen: (1) a glossy black material that is restricted to the body cavity (Figure 14), (2) a dark grey material organized in transverse bars on the right side of the neck base (Figure 15), (3) an amorphous reddish substance along the neck and tail, as well as in the proximal areas of the flippers and along the posterior margin of the left hind limb (Figures 13, 15 - 18), (4) a reddish-grey material ornamented with shallow, but sharp transverse and longitudinal furrows along the trunk and the base of the left hind limb (Figures 15, 17), and (5) a light to dark grey glossy amorphous substance restricted to the tail base left and right hand side of the caudal vertebral column (Figure 18).

The amorphous to granular, sometimes finely striated glossy black material is restricted to the dorsal wall of the body cavity (Figures 2, 14). It coats the internal face of the dorsal half of the ribs, the space between them and the ventral face of the respective centra. Neither the gastralia nor the external faces of the ribs show such a coating. The material is especially well preserved on the right side of the body cavity. There are two taphonomic options that would explain this material: (1) it represents the bituminous remnants of the putrefied intestines that liquidized inside the body cavity under anoxic conditions that now coat the dorsal wall of the thorax. (2) The material represents the remains of a pigmented visceral peritoneum. In case of (1) it should be expected that the liquidized organic matter concentrates in the dorsal arcades of the ribcage along the thoracic vertebral column. However, the black substance is equally thin inside the entire body cavity including the medial sections of the ribs and the ventral faces of the centra; in places it shows a fibrous or wrinkled relief inconsistent with a liquid mass of organic matter. Therefore, it appears more likely that the black lining represents the visceral peritoneum that likely was heavily pigmented with melanocytes. A pigmented visceral peritoneum especially coating the dorsal part of the abdominal cavity is known from a variety of diurnal squamates that inhabit desert or high altitude habitats and is thought to screen solar radiation and block UV radiation from damaging the reproductive systems (Greer, 1989; Porter, 1967). However, a peritoneum pigmented with melanin also occurs in poultry (Wang et al., 2012), and a number of teleosts, where it even represents a diagnostic feature (e.g. Page and Burr, 2011). However, the function of a black peritoneum in chickens and teleosts is unknown. Plesiosaurs, at least those that preferably cruised close to the water surface were exposed to massive sun radiation and could have benefited from a melanistic visceral peritoneum especially in early ontogenetic stages.

In order to do a geochemical analysis, we were allowed to remove a very small piece from the substance. A test with EDAX probing yielded the typical absorption bands for Goethite $\mathrm{Fe}_{3} \mathrm{O}(\mathrm{OH})$, a mineral that preferably precipitates under dysoxic conditions and temperatures around $25^{\circ} \mathrm{C}$ (Schweitzer et al., 2013). For further investigations the sample was too small and further sampling was not permitted.

To the right hand side of the base of the cervical 


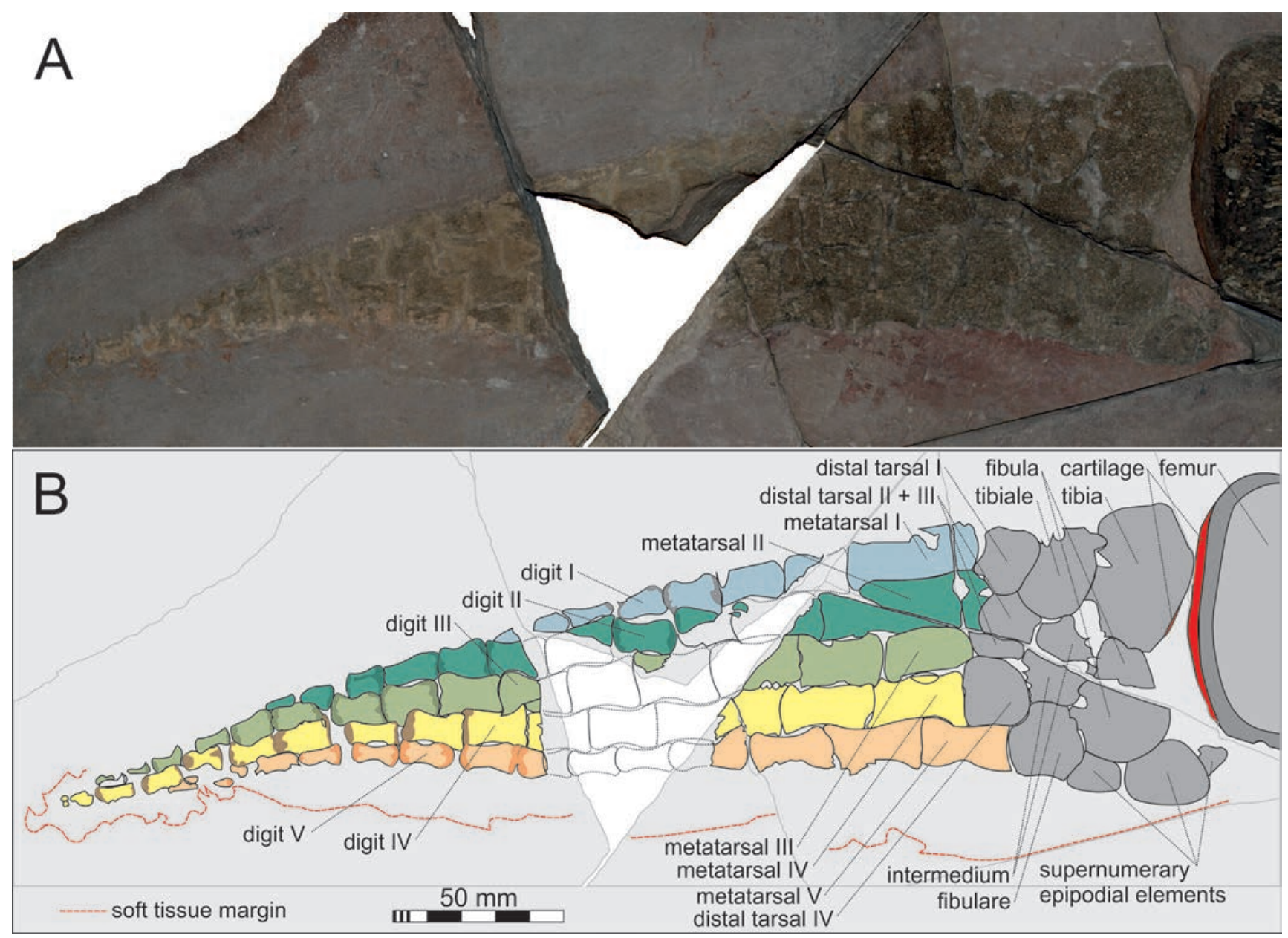

Figure 13 Mauriciosaurus fernandezi INAH CPC RFG 2544 P.F.1. Right pelvic limb in ventral aspect; A) photograph, B) interpretative line drawing.

vertebral column along the ventral termini of the left cervical ribs there is a sequence of approximately rectangular structures five to ten millimetres long by two mm wide preserved in a dark-grey substance. Rarely, they are square. Some are organized in transverse bands (Figure 15). Where preserved the structures are densely packed and organized in longitudinal rows. They are especially well preserved at the cervicothoracic transition, where they occur within a pale reddish substance. In places they are preserved as internal molds. Along the anterior margin of the scapula and lateral of the clavicle there are confluent patches of a light-grey mass. The transverse rectangular structures also occur along the body flanks, where they are either preserved in a dark-grey substance or as internal molds (Figure 16). In some places the rectangular structures are organized in almost parallel-sided longitudinal rows that are interrupted by areas of amorphous grey and red substance. In the space between the right femur and ilium similar rectangular structures occur in the same preservation styles, also interrupted by large areas with amorphous red and grey substances (Figure 17). Along the body wall, the structures are predominantly rectangular and measure about five millimeters transversely and one to two millimeters longitudinally. Many are arranged in oblique, parallel-sided rows extending from craniomedially to terminolaterally. Towards the external margin of the soft tissue the structures become circular or oval. In the angle between femur and ilium the 


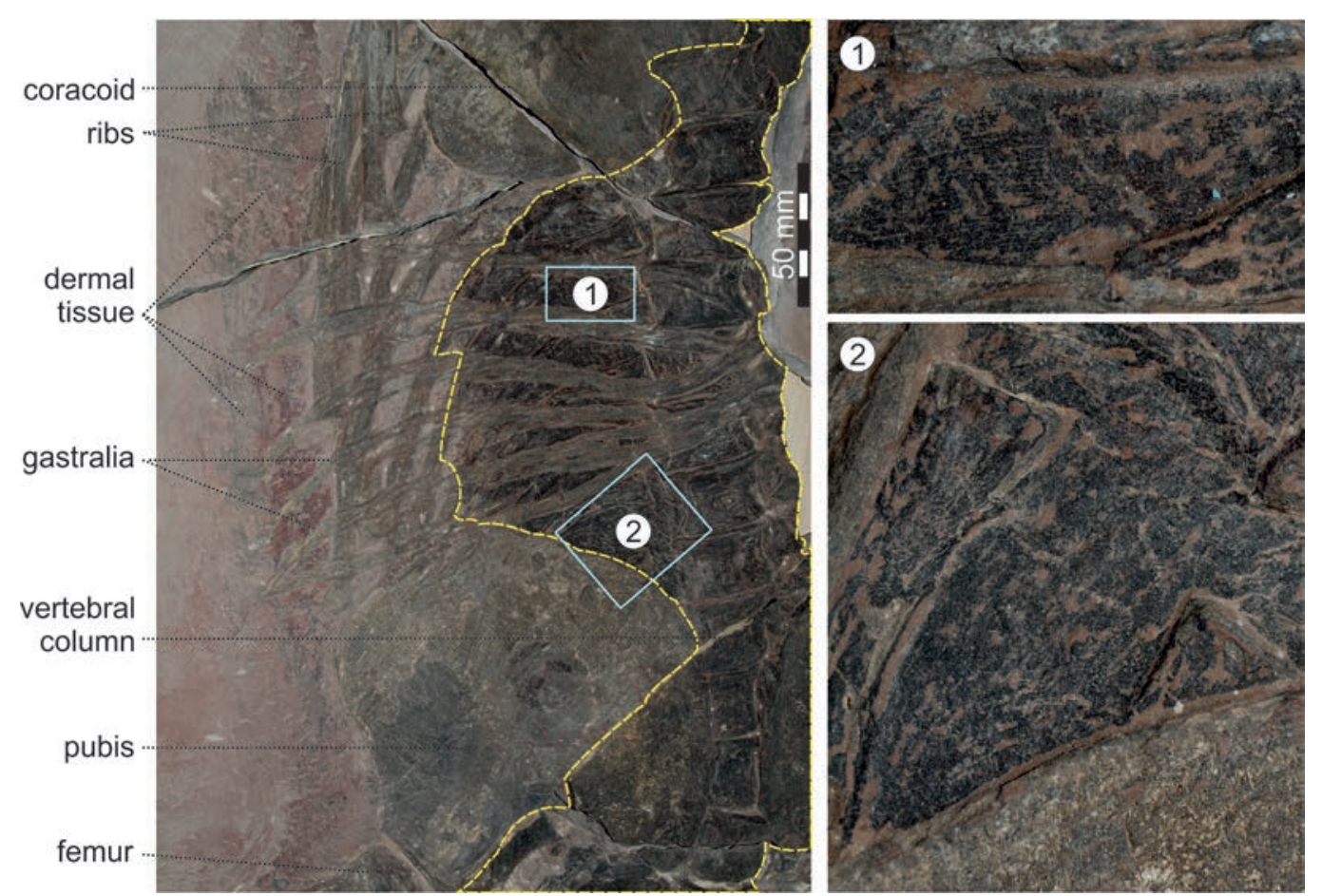

Figure 14 Mauriciosaurus fernandezi INAH CPC RFG 2544 P.F.1. Soft tissue preservation inside the body cavity; the yellow broken line outlines the black, glossy coating of the right thoracic cavity. Note that the internal faces of the ribs are covered by the substance but not the external faces of the gastralia.

lines bordering the structures become increasingly perpendicular to the trailing edge of hind flipper. In the transitional zone they diverge anteriorly and the structures preserved between the lines are trapezoidal reaching sizes up to $12 \times 14$ millimeters. In distal directions the longitudinal parallel lines become exceedingly finer and their distance decreases to about one millimeter or less. Lines of sub-circular structures are occasionally found between them. No such structures are visible in the tail. All soft tissue types detected here are amorphous.

The structures described above appear too regular to represent the results of taphonomic effects such as shrinking or autolysis. Artefacts of preparation can also be excluded. The structures can be interpreted as remnants of squamae mostly from the ventral and the lateral skin of neck and body. The regular squamation likely consisted of vaulted squamae, orientated transversely a size of about $12 \times 2$ millimeters. They were arranged in parallel-sided longitudinal rows that may have covered the entire belly. At the base of the flippers this pattern becomes radially arranged, forming a flexible folding zone. The trailing flap of the flippers was most likely covered by longitudinal rows of small, millimetric, sub-circular squamae giving the skin flexibility.

The amorphous reddish substance along neck and tail and as well in some patches along the sides of the trunk are approximately $100-150 \mathrm{~mm}$ wide with sharp lateral margins clearly set off from the surrounding sediment (Figures 3, 16). This material very likely is a decay product of skin and the subdermal tissue. The thickness of the substance suggests that either the skin of the ventral side of the body was still flexible and not particularly decomposed, when the gastral basket collapsed into the body cavity (Figure 19 B), or the subdermal tissue was thicker than in most extant reptiles, especially squamates. The subdermal tissue may have been rich in adipose tissue as is the case in many modern marine Mammalia where it streamlines the body. Possibly both factors contributed to the 

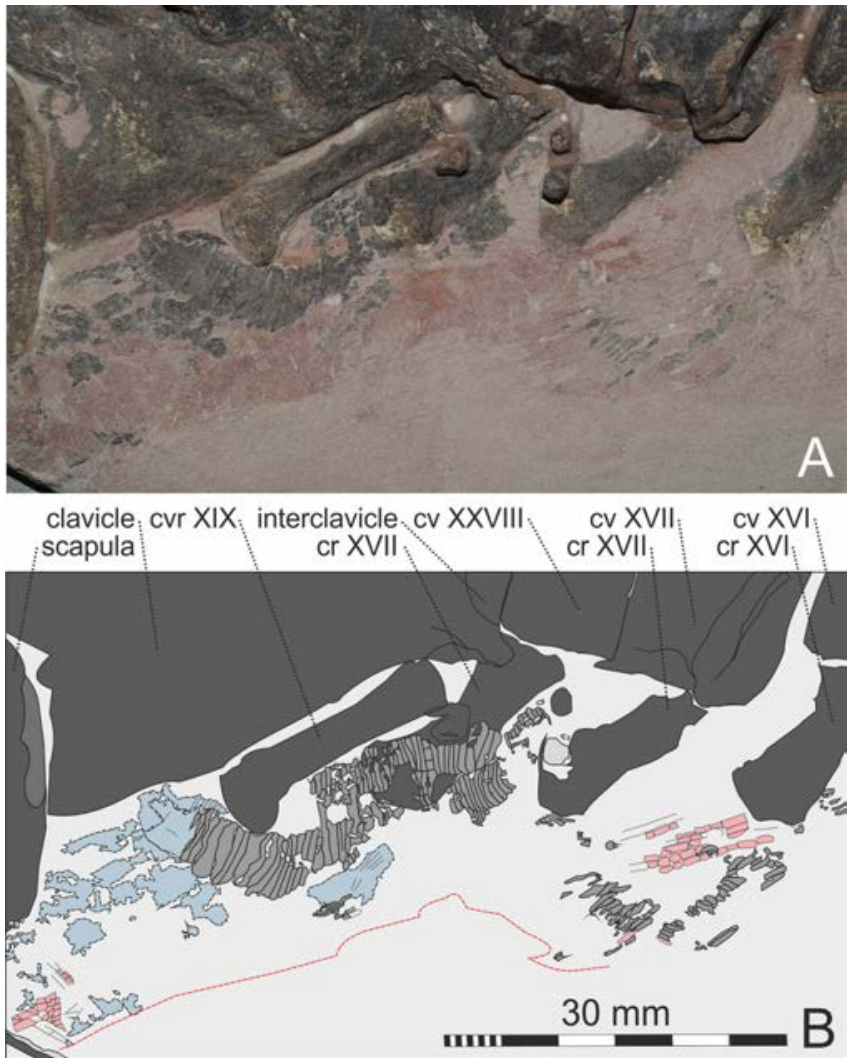

squamae in grey substance preservation

- internal moulds of squamae

grey substance without structure

- internal moulds of dermal furrows

- outline of the reddish soft tissue lining

Figure 15 Mauriciosaurus fernandezi INAH CPC RFG 2544 P.F.1. Soft tissue preservation at the left side of the neck base; A) photograph, B) interpretative line drawing; abbreviations: $\mathrm{cv}=$ cervical vertebra, $\mathrm{cr}=$ cervical rib.

preservation of the amorphous reddish substance as preserved. In the distal area of the flippers the amorphous reddish substance is not only visible between the bones but also as a patch at the posterior margin of the left humerus and as a seam along the posterior margin of the right hind flipper (Figures 3, $11 \mathrm{~A}, 13)$. This seam has one-third the depth of the bony core of the flipper and from the middle of the posterior margin of the femur curves into the lateral wall of the tail. This provides strong evidence for plesiosaur flippers having a flexible trailing edge and used as hydrofoils (Frey and Riess, 1982; Godfrey, 1984; Halstead, 1989; Lingham-Soliar, 2000; Robinson, 1975; Sanders et al., 2004; Taylor, 1981). Furthermore, the propo-

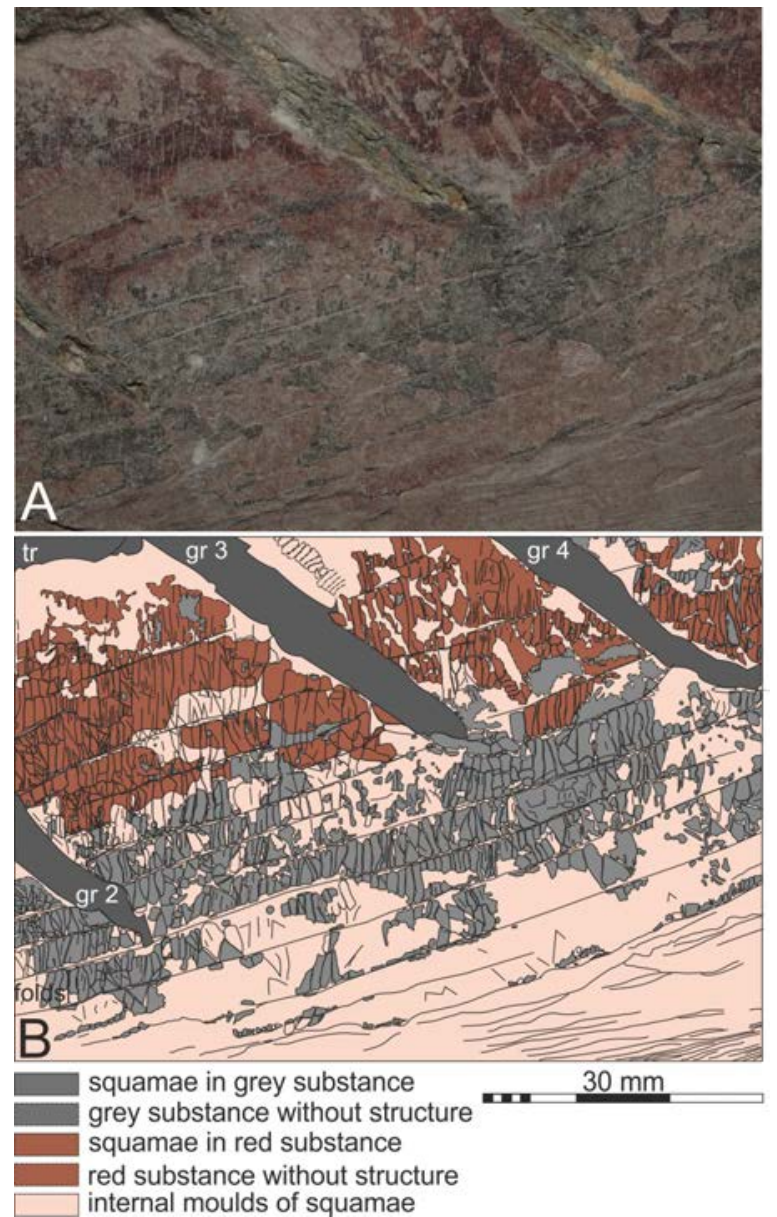

Figure 16 Mauriciosaurus fernandezi INAH CPC RFG 2544 P.F.1. Soft tissue preservation along the left side of the trunk; A) photograph, B) interpretative line drawing. Note the transversely rectangular squamae are arranged in longitudinal rows.

dials of the flippers were integrated in the body contour by a posterior skin fold that merged with the lateral body wall.

There are patches of a dark reddish or dark-grey substance that is thicker than the amorphous reddish substance, especially in the posterior third of the trunk, the base of the right hind flipper and the tail base. These areas are characterized by a pattern of fine crisscross running furrows that are mostly straight or slightly curved (Figure 18). The areas between the furrows are roughly rectangular or trapezoidal in outline with a smooth surface. Because these structures are preserved only on the external surface, they are assumed to be epidermal, but there is no evidence for scute-like 


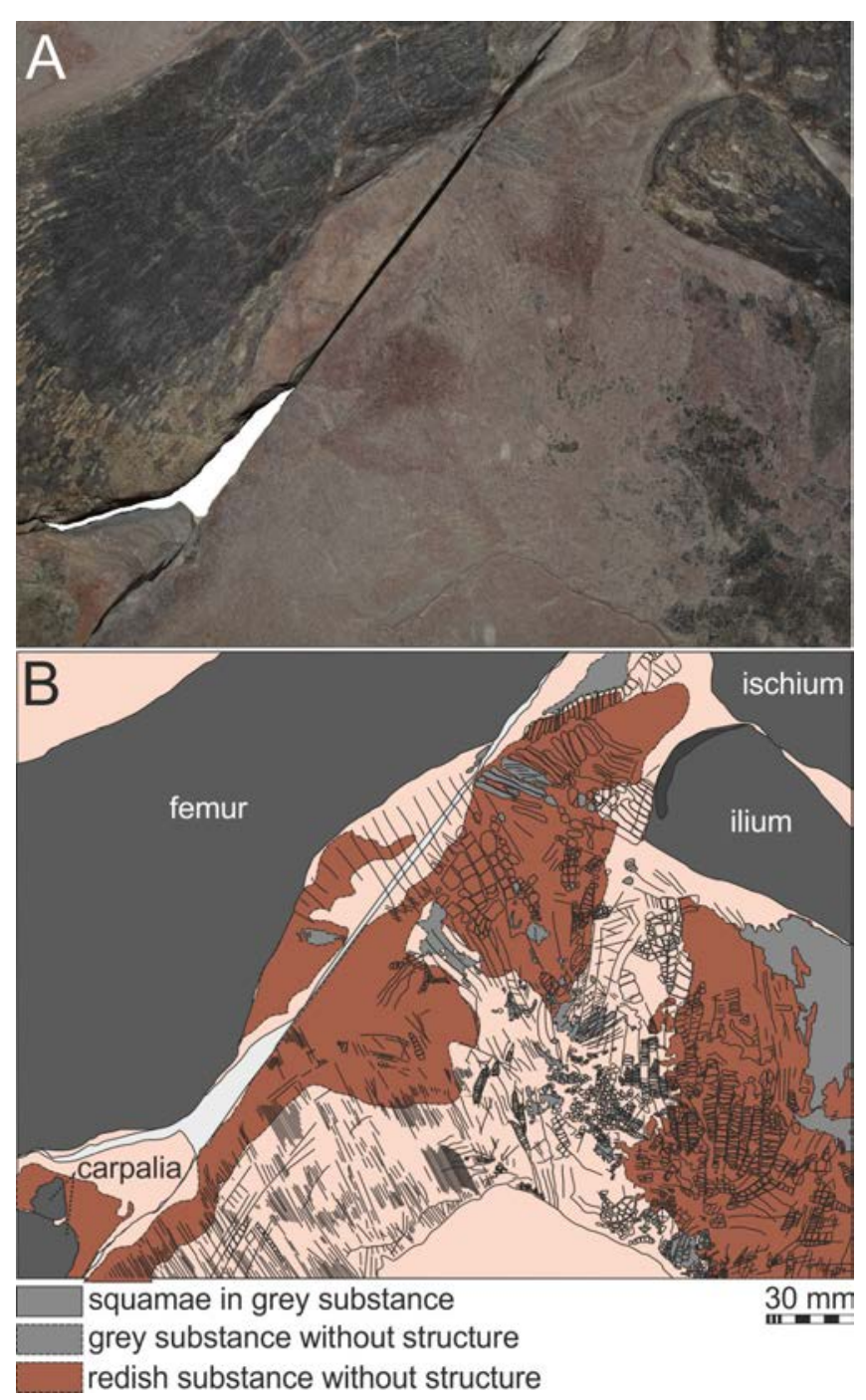

Figure 17 Mauriciosaurus fernandezi INAH CPC RFG 2544 P.F.1. Soft tissue preservation, at the posterior base of the right pelvic limb; A) photograph, B) interpretative line drawing. Note that the trailing flap continues on the tail base. Also note the fibrous structures perpendicular to the more distal part of the trailing edge.

structures.

A light to dark grey amorphous and glossy substance is preserved on both sides of the vertebral column of the tail, especially on the right side (Figure 18). It is bordered laterally by the above described amorphous reddish or dark-grey substance. Occasionally this substance shows an irregular fibrous texture and is evidently responsible for the conical shape of the tail and its massive base. In many lizards, e.g. the fat tailed geckos, the posterior adipose tissue is subdermal (Delome et al., 2012; Derickson, 1976). In crocodiles, the posterior adipose tissue is deposited in the tail base between the $\mathrm{m}$. ilioischiocaudalis and $\mathrm{m}$. caudofemoralis (Frey, 1988). Topographically these tissues in both groups of reptiles coincide with the grey masses preserved in the tail base of Mauriciosaurus. Provided these grey masses represent remains of adipose tissue, the deposit likely was subdermal, because the muscle masses of the tail are delimited by the dimensions of the transverse processes, the neural spines and the hemal arches, which are small in Mauriciosaurus, suggesting a weak muscularization of the tail. Therefore it appears plausible that the tail base of Mauriciosaurus was stabilized and shaped mainly by contour fat in a way that the outline of the trunk continued onto the tail.

\section{Comparative anatomy}

\subsection{GOEVAL POLYGOTYLIDS}

About seven genera of Polycotylidae are described and accepted (e.g. Albright III et al., 2007b, 2007c; Druckenmiller and Russell, 2009; Ketchum and Benson, 2011 , 2010).

According to Druckenmiller and Russell (2009), seven genera in eight species and two un-named taxa occur during the Late Cenomanian and Early Turonian, and thus are about coeval with Mauriciosaurus fernandezi. Two of these, Manemergus (Buchy et al., 2005) and Thililua (Bardet et al., 2003) have been found only in the Early Turonian of Morocco. The rostrum of Manemergus is dorsally concave, while that of Thililua is laterally compressed, with vertically festooned jaw margins and a convex ventral margin of the mandible level below the anterior margin of the orbit. In contrast, the rostrum of Mauriciosaurus is straight and rounded in cross-section, the jaw margins are straight and the ventral margin of the mandible is evenly convex. The dentition in both African species is anisodont. Furthermore, Mauriciosaurus has less than half as many cervical vertebrae as Thilitua. 

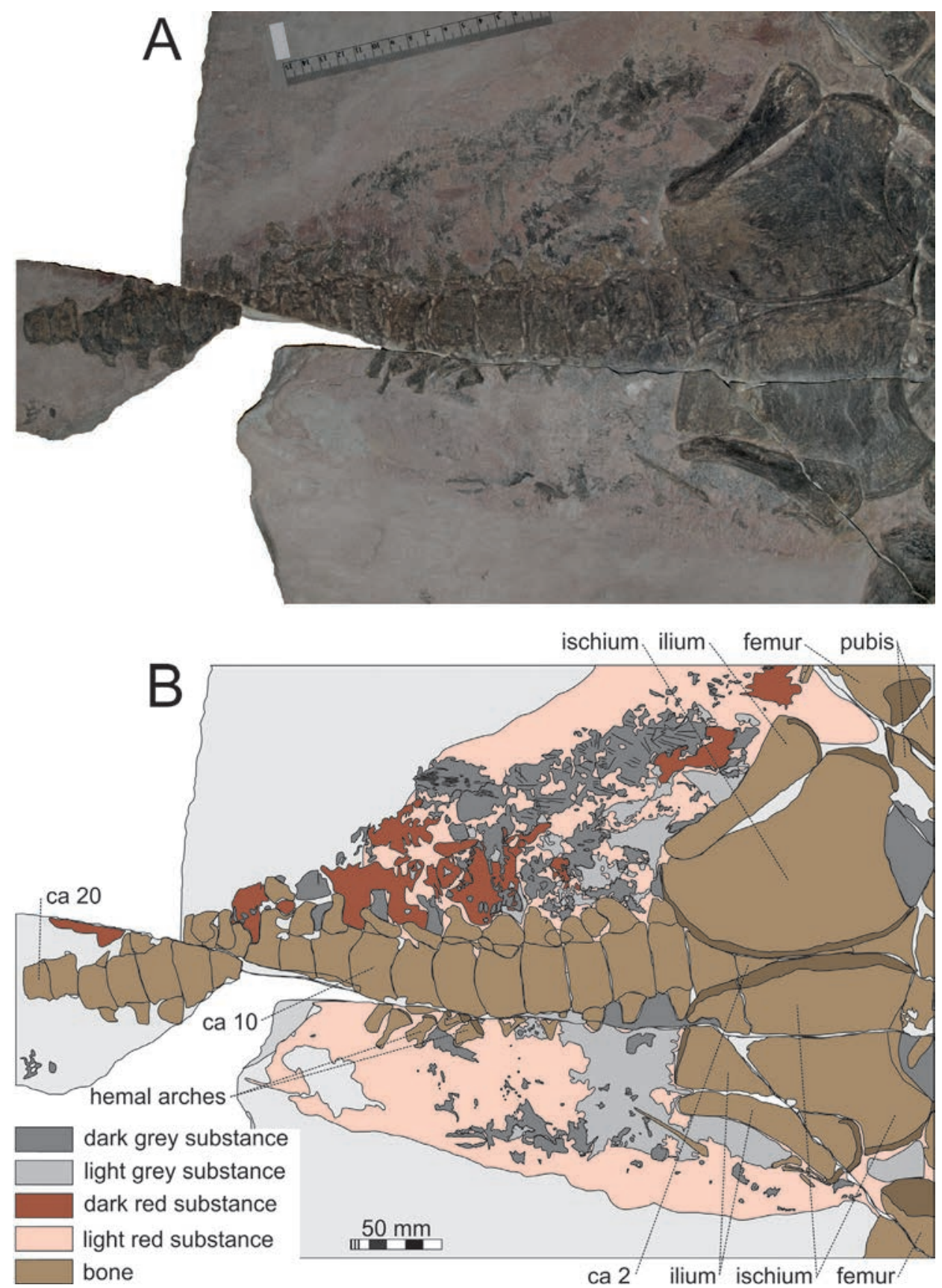

Figure 18 Mauriciosaurus fernandezi INAH CPC RFG 2544 P.F.1. Soft tissue preservation in the tail; A) photograph, B) interpretative line drawing. Note the massive tail base and the light-grey glossy substance on both sides of the vertebral column.

Palmulasaurus (Albright III et al., 2007c), previously described as Palmula (Albright III et al., 2007a) is reported with one species, P. quadratus, from the early Late Cenomanian of South Dakota (Schumacher and Bell, 1999; Von Loh and Bell, 1998) and the Late Cenomanian of Japan (Sato and Storrs, 2000). Pahaspasaurus haasi from the early late Ceno- manian of South Dakota is probably congeneric with Palmulasaurus (Schumacher et al., 2016). In Mauriciosaurus, the mandibular alveolae are invisible and it is therefore impossible to determine to which pair of alveoli the splenials extended anteriorly. However, when comparing the anterior extent of the splenials quantitatively, they appear to 
be significantly shorter and wider than in Palmulasaurus. Additionally, Mauriciosaurus has a straight lateral mandibular face, whereas the mandible of Palmulasaurus shows lateral interalveolar depressions. Palmulasaurus has 19 thoracic and 11 caudal vertebrae, each with a large nutritive foramen on the dorsolateral face of the centrum (Albright III et al., 2007a). Mauriciosaurus has 21 thoracic and at least 13 caudal vertebrae. In Mauriciosaurus there is no epipodial foramen between the rounded epiepipodials. For Palmulasaurus, isomorph polygonal epiepipodials are diagnostic and epipodial foramina are present. The average length/width ratio of 1.77 (Table 5) is smaller than that of Palmulasaurus, where this ratio is 1.9 [Figures 11-13; Table 3 (Albright III et al., 2007a)]. The morphological differences of the pelvic bones of Mauriciosaurus and Palmulasaurus are due to different ontogenetic stages.

A fourth species which to date is restricted to the Early Turonian of Utah (top-most Dakota Formation) is Eopolycotylus rankini (Albright III et al., 2007b). This species differs from Mauriciosaurus in the more massive teeth, the participation of the splenials in the ventral face of the mandibular symphysis, which is about $30 \%$ (Albright III et al., 2007b) instead of $50 \%$ in Mauriciosaurus, thoracic vertebrae that are about one fourth shorter than the cervical ones, a coracoid with a prominent anterior process and a number of foramina along its medial margin, foramina also in a scapula where the glenoid process is almost as wide as the lateral one. The curved ilium of Eopolycotylus has only about half the length of the ischium, while on the humerus there is a tuberosity, which is missing in Mauriciosaurus posterior to the caput.

The Turonian genus Trinacromerum and the Early Conacian genus Dolichorhynchops, which both are reported to reach the Campanian-Maastrichtian boundary, are also distinct from Mauriciosaurus.

The dish-like depression in the pterygoids of $\mathrm{Mau}^{-}$ riciosaurus is restricted to the anterior half of the ventral face of the corpus. They open posteriorly, merging with a relief of prominent ridges arranged in a $\mathrm{W}$-configuration covering the posterior half of the pterygoideal corpus, similar to Polycotylus (Figure 4). In Trinacromerum this depression is elongate ovoid (O'Keefe, 2004; Williston, 1908). In Trinacromerum the posterior fourth of the ventrolateral margins of the pterygoids rise to a sharp ridge that posteriorly terminates in an elongate process (O'Keefe, 2004; Williston, 1908). Mauriciosaurus bears a pair of prominent tubercles on the ventral face of the pterygoids adjacent to their posterior margins. The anterior pterygoid rods in Mauriciosaurus expand in their anterior halves to three times the width of the basal third of the processes. Similarly, in Trinacromerum, these rods expand to about twice the width of the basal third of the bone (O'Keefe, 2004; Williston, 1908). The pterygoids in Mauriciosaurus meet atop the parasphenoid, almost closing the posterior interpterygoidal vacuities (Figure 4). In Trinacromerum these vacuities are wide because of the concave lateral margins of the parasphenoid, which also lacks the ventral depression of this bone in Mauriciosaurus, and the concave medial margin of the caudal half of the pterygoids. Like the parasphenoid of Mauriciosaurus, that of Trinacromerum terminates in an anterior bifurcation (O'Keefe, 2004; Williston, 1908). With about 42 tooth positions, Mauriciosaurus has more premaxillomaxillary teeth than Trinacromerum with a premaxillomaxillary tooth count of about 30 in T. osborni and about 38 in T. willistoni (Riggs, 1944). The vertebral centra of Mauriciosaurus are laterally and ventrally constricted and not cylindrical as in Trinacromerum (Albright III et al., 2007a; Carpenter, 1997). The distal margin of the propodials of Mauriciosaurus is evenly rounded. In Trinacromerum they show a distinct articular facet for the anterior epipodial (Albright III et al., 2007b; Williston, 1908). The primary epipodials of Mauriciosaurus are distinctly wider than long and not as equidimensional as in Trinacromerum (Schumacher and Everhart, 2005). The average length/width ratio of the phalanges of Mauriciosaurus is 1.77 and thus similar to Trinacromerum (Schumacher and Everhart, 2005). Posterior and medial perforations of the coracoid are present in Trinacromerum (O'Keefe, 2004; Williston, 1908), but not in Mauriciosaurus. 
Dolichorhynchops differs from Mauriciosaurus in having a bean-shaped dish-like depression, which occupies the entire ventral face of the corpus of the pterygoids (O'Keefe, 2008, 2001; Sato et al., 2011). Dolichorhynchops lacks the prominent tubercles of Mauriciosaurus on the ventral face of the pterygoids adjacent to their caudal margins (O'Keefe, 2008, 2004, 2001; Sato et al., 2011). In Dolichorhynchops the anterior pterygoid rods taper anteriorly and slightly curve medially at their tips (O'Keefe, 2001, 2004, 2008; Sato et al., 2011), unlike the expanded pterygoid rods in Mauriciosaurus. The lateral margins of the parasphenoids of Dolichorhynchops are concave and border a wide posterior interpalatinal vacuity like in Trinacromerum. Similar to Mauriciosaurus the ventral face of the parasphenoid of Dolichorhynchops is concave, but to a lesser extent (O'Keefe, 2008). The parasphenoid of Dolichorhynchops anteriorly terminates in a blunt process, while that of Mauriciosaurus is bifurcated (O'Keefe, 2001, 2004, 2008; Sato et al., 2011). Mauriciosaurus has more teeth in the upper jaw than Dolichorhynchops, where the tooth count of the premaxillomaxillary complex ranges between 26 and 30 in adults and 26 or 27 in juveniles (O'Keefe, 2008; Sato, 2005). The caudal centra bear anterior and posterior articular faces for the heamal arches suggesting that they articulated with two caudals (Albright III et al., 2007a; Carpenter, 1997; Schumacher and Everhart, 2005). In Dolichorhynchops the distal margins of the propodials resemble those of Mauriciosaurus in being almost evenly rounded. The facets for the epipodials are faintly visible (O'Keefe, 2008). The average phalangeal length/width ratio of Dolichorhynchops is 1.45 (Schumacher et al., 2016). In Mauriciosaurus it is 1.77 , which could suggest a more primitive condition (Albright III et al., 2007a). In contrast to Mauriciosaurus, Dolichorhynchops possesses posterior and medial perforations of the coracoid. One outstanding feature of Mauriciosaurus is the gastralia basket with the gastralia converging to a center. A taphonomic effect is unlikely, because there is no displacement of bones in the abdominal area. Gastral baskets are rarely preserved in polycotylids, and when they are, mostly they are decayed e.g. (Carpenter et al., 2010; Schumacher et al., 2016). Therefore, little is known about the morphology of this structure. Most reconstructions are analogues to the gastralia arrangements in other plesiosaurs. For the moment, Mauriciosaurus is the only plesiosaur with this arrangement of gastralia, which could thus be regarded as diagnostic feature unique to Mauriciosaurus.

\subsection{GOMPARISON WITH NON-GOEVAL POLYCOTYLIDS}

Pahasapasaurus haasi (Schumacher, 2007) reported from the early Late Cenomanian Graneros Formation in western South Dakota differs from Mauriciosaurus in the following diagnostic features (Schumacher, 2007): it lacks an anterior interpterygoidal vacuity, the pterygoids have a common median suture anterior to the parasphenoid that bears a longitudinal ventral keel which is absent in Mauriciosaurus. The teeth are massive; the lateral margin of the anterior half of the jaws is undulating due to the laterally bulging tooth sockets. Furthermore, the alveolar margin is elevated. All epipodials have foramina. The distal margins of the propodials show three distinct facets and are not smoothly convex as in Mauriciosaurus.

Georgiasaurus penzensis (Ochev, 1977, 1976; Storrs et al., 2000) from the Santonian of the Penza region (the formation was not specified), about $700 \mathrm{~km}$ southeast of Moscow, differs from Mauriciosaurus in its massive teeth and the degree of participation of the splenials in forming just one tenth of the mandibular symphysis. Such a dentition and symphysis are also seen in a polycotylid described by Arkhangelsky et al. (2007) from the Campanian the middle Volga Region (SGU 104a/37, -38) and there stated to be closely related with Georgiasaurus. One single species of the genus Polycotylus, P. latipinnis, is known from the Early Campanian of North America, namely from the Niobrara Chalk of Kansas and the Moreville Chalk Formation of Alabama (Cope, 1869; O’Keefe, 2004; Schumacher et al., 2016). The cervical and trunk vertebrae of Late Cretaceous polycotylids referred to the 
genus Polycotylus (Trinacromerum) from the Late Cretaceous Russian districts Orenburg and Saratov (Bobolubow, 1912) are doubtful and thus not valid. Polycotylus differs from Mauriciosaurus in having 26 instead of 21 cervical vertebrae (Storrs, 1999).

The latest of the named polycotylids is Sulcusuchus erraini, Gasparini and Spalletti 1990 from the Late Campanian - Early Maastrichtian La Colonía Formation, Cerro Bosta, Southern Argentina. Despite the fact that the specimen consists only of a fragmentary skull and mandible, according to the emended diagnosis given by O'Gorman and Gasparini, 2013, it preserves the following unique diagnostic features that are not found in Mauriciosaurus: there are deep and wide anterior and mandibular grooves, the parasphenoid has a keel on its ventral side, the basioccipital tubercle protrudes posteriorly to the posterior terminus of the occipital condyle, and there is a wide notch on the posterior margin of the pterygoids. The anterior part of the body of the parasphenoid protrudes between the posteromedial margins of the wings of the pterygoids and together with them it forms a flat barely sculptured plate.

Mauriciosaurus fernandezi is identified as a polycotyline polycotylid based on its slightly sigmoidal humeri with a length/width ratio of 1.65 (Figure 11; Table 3), a missing antebrachial foramen (Figure 11), three distal tarsals (Figures 12, 13), primary epipodials which are distinctly wider than long (Figure 11; Table 3), and more than twenty trunk vertebrae (Figure 8) (Albright III et al., 2007a). Of all polycotylids, Mauriciosaurus most resembles Dolichorhynchops, but also shares many characters with Trinacromerum. The phalangeal length/width ratio appears more primitive than in Dolichorhynchops and Trinacromerum and more resembles that of Palmulasaurus. The enigmatic construction of the gastral basket may represent an autapomorphy of Mauriciosaurus fernandezi and is certainly not depending on the ontogenetic stage. We therefore consider it appropriate to erect a new genus for this enigmatic polycotylid that inhabited the $\mathrm{Pa}$ leogulf of Mexico.

\section{Discussion}

\subsection{TAPHONOMY}

The thick soft tissue in the trunk and tail region of Mauriciosaurus suggests the presence of a layer of subdermal adipose tissue, also known as contour fat (Figures 3, $16-18$ ). This adipose tissue, combined with a thin epidermis with thin keratinous scales, is probably the reason why dermal structures of plesiosaurs are so rarely preserved. The putrefaction process of the subdermal adipose tissue would rapidly lead to a delamination and disruption of the thin epidermis. In order to explain the excellent preservation of Mauriciosaurus the following scenario is proposed that is consistent with the preserved remains, the sediment and the depositional setting.

After death, Mauriciosaurus must have rapidly sunk into the soft water-soaked lime mud sediment, with its back first (Figure 19 A). This is concluded from the position of the ribs, which have rotated not laterally, but posteriorly in their vertebral articulations during the collapse of the body and subsequent compaction (Figure 4, 8). At least the dorsal half of the polycotylid must have been contained by sediment as is suggested by the thickness of the soft tissue (Figure 19 A). The immediate enclosure of the fresh carcass by soft water-soaked sediment formed a chemical reaction chamber in which the adipose tissue could become saponified into mortuary wax or adipocere (Figure $19 \mathrm{~B}$ ). Adipocere is a waxy substance that forms under anoxic conditions at temperatures of between 21 ${ }^{\circ} \mathrm{C}$ and $37^{\circ} \mathrm{C}$ and thus matches the palaeoenvironmental conditions reconstructed for the Vallecillo limestone (Ifrim et al., 2008; Topper et al., 2011). The adipocere likely helped to conserve the thin epidermis of the entire dorsal skin of the plesiosaurs and the contours of its body (Kahana et al., 1999). The belly, however, was exposed to the hostile oxygen-deficient bottom water (Figure 19 A). Therefore the exposed skin of the ventral face of the body decayed prior to the final embedding 


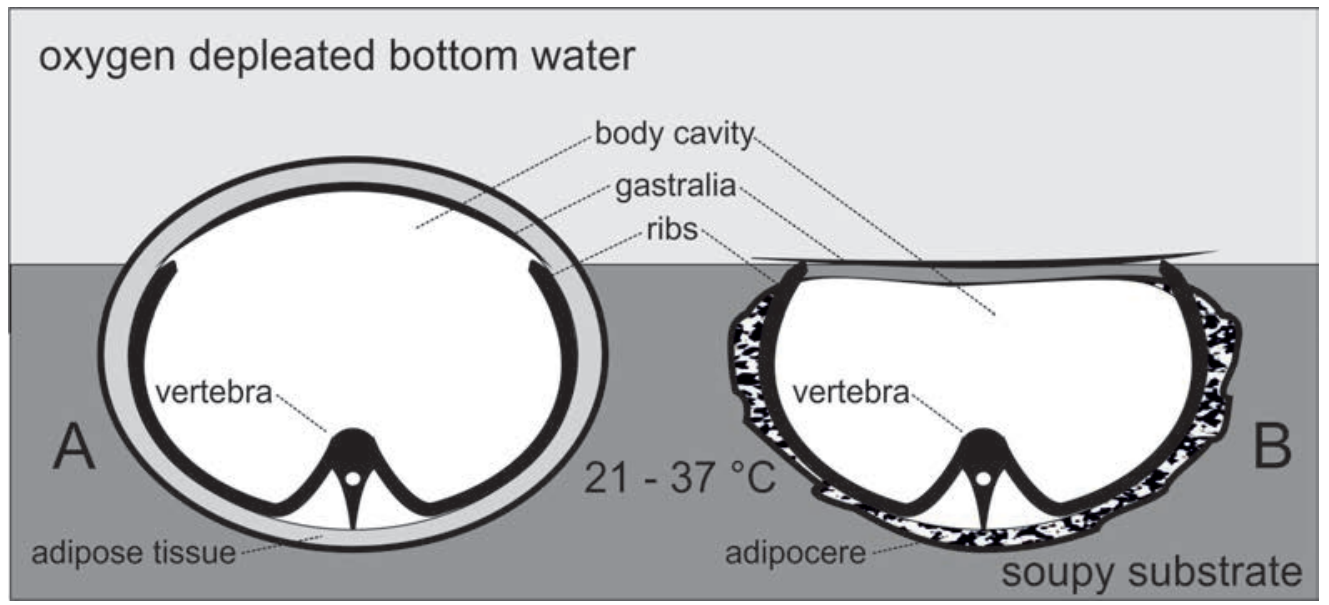

Figure 19 Mauriciosaurus fernandezi INAH CPC RFG 2544 P.F.1. ; model for the taphonomy: A) Schematic mid-trunk cross-section through the carcass in the embedding position after sinking into a soft, water-soaked substrate; note that the belly is not embedded with the gastralia. B) The part of the trunk exposed to the open water decayed and collapsed and the gastralia basket spread. The subdermal adipose tissue has transformed into adipocere preserving the delicate epidermal structures. In a third phase the ribs rotated posteriorly around their vertebral articulations due to the semi-consolidated surrounding sediment, as is seen in Figure 3 .

and thus left no trace on the skeleton (Figure 19 B). The preserved parts are all marginal or around the flippers. Due to early diagenetic compaction the previously vaulted gastralia basket was pressed flat in such a way that the lateral extremities of the gastralia now protrude laterally beyond the preserved soft tissue seam (Figures 8, 19 B).

The extensive soft tissue preservation of the Vallecillo polycotylid Mauriciosaurus fernandezi suggests that at least polycotylids, but probably all plesiosaurs, had a thin epidermis with an extremely low fossilization potential. The body appears to have been stream-lined by subdermal adipose tissue that was especially massive at the tail base. This adipose armor precluded a mobility of most of the weakly muscularised tail, probably excluding the very tip. This weak muscularization is evidenced by the low hemal arches and the short transverse processes that, in extant reptiles, mark the diameter of the hypaxial muscle masses. The neural spines which would yield a hint on the dimensions of the epaxial muscle mass are not visible. Apparently the tail was also mostly immobile especially at its base. Both tail and trunk formed a dropshaped, stream-lined unit that was propelled with the four flippers.

\subsection{INDIVIDUAL AGE}

Little is known about the ontogeny of plesiosaurs, especially polycotylids. The only fetal skeleton known is completely disarticulated (O'Keefe and Chiappe, 2011). Neonates and early ontogenetic stages of polycotylids are hitherto unknown, but there are some records of juveniles and subadults (Buchy et al., 2005; Schumacher et al., 2016). The following features suggest that Mauriciosaurus fernandezi must have died at an early ontogenetic stage:

1. The neurocentral sutures are unfused, as is visible in the cervicals (Albright III et al., 2007a).

2. The coracoids lack anterior clavicular extensions. They are simple in shape with little posterolateral and no posteromedial expansion (Figures 8, 10).

3. The ventral girdle bones are extremely thin.

4. The scapulae lack a dorsal process (O'Keefe and Byrd, 2012).

5. The ischia are short and only three times as long as they are wide (Figures 8, 10; Schumacher et al., 2016).

6. A wide gap between the propodials and epipodials suggests extensive cartilage (Figures 11-13). 
7. The small size of the specimen.

These immature features mostly concern the locomotor apparatus and are contrasted by densely packed carpals, tarsals and metapodials, as well as by the presence of a fourth supernumerary epipodial. There is also almost no space for cartilage between the interphalangeal joints (Figures 11-13). The palatinal roof is almost fully mineralized and thus shows features of a subadult. This pattern suggests that ontogenetic mineralization of the skull and distal elements of the limbs preceded that of the vertebral column (closing of the neurocentral suture (Albright III et al., 2007a). The rapid mineralization of the skull is best explained by the enhancement of bite force as early as possible during ontogeny, similar to pliosaurid plesiosaurs (Kear, 2007). The early mineralization of the epi-, meso-, meta- and acropodials suggests that the main thrust-generating structure was stabilized as soon as possible, prior to the mineralization of the elbow joint and that of the ventral girdle plates, where the locomotor muscles attached. This discrepancy may be explained by a high frequency and low amplitude of underwater flight that would require less power. The dimensional relationship of the flippers with respect to the body in Mauriciosaurus confirms the suggestion of $\mathrm{O}^{\prime}$ Keefe and Chiappe (2011) of an isometric growth of polycotylids. Mauriciosaurus died in the open sea about $500 \mathrm{~km}$ from the nearest shoreline. Other juvenile polycotylid are also reported from marine environments but shallow water coastal habitats (Buchy et al., 2005; Schumacher et al., 2016). Mauriciosaurus is the first juvenile polycotylid reported from a deep shelf offshore habitat.

\subsection{LOCOMOTION AND POSSIBLE DIET}

The limbs of Mauriciosaurus fernandezi had strongly muscularised propodials and a flexible trailing edge (Dames, 1895; McHenry et al., 2005) as concluded from the soft tissue adjacent to the posterior edge of the left pelvic limb. Hydrofoil locomotion models are therefore viable for all four limbs. Due to the immobile trunk and tail, all maneuvers could only have been provided by the limbs and neck. The latter was reinforced, as in all plesiosaurs, by a chain of overlapping cervical ribs that prevented extreme bending but allowed enough movement to seize prey, which in the case of Mauriciosaurus likely consisted of small items because of the slender rostrum and the small, pointed teeth. These anatomical features, and the fact that the thickest part of the trunk and tail unit lies in its anterior third, suggest swimming speeds comparable to that of modern sea turtles. Among these, the leatherback (Dermochelys coriacea), the fastest swimming sea turtle, travels at an average velocity of about $7 \mathrm{kph}$ (Eckert, 2002) and shows a hydrodynamic carapace, the outline of which strikingly resembles the body outline of Mauriciosaurus (Figure 20). This swimming speed falls within the range of swimming speeds reconstructed for Mesozoic marine reptiles (Massare, 1988). Nonetheless, the long and slim limbs that likely all participated in thrust generation, may have allowed for higher ve-
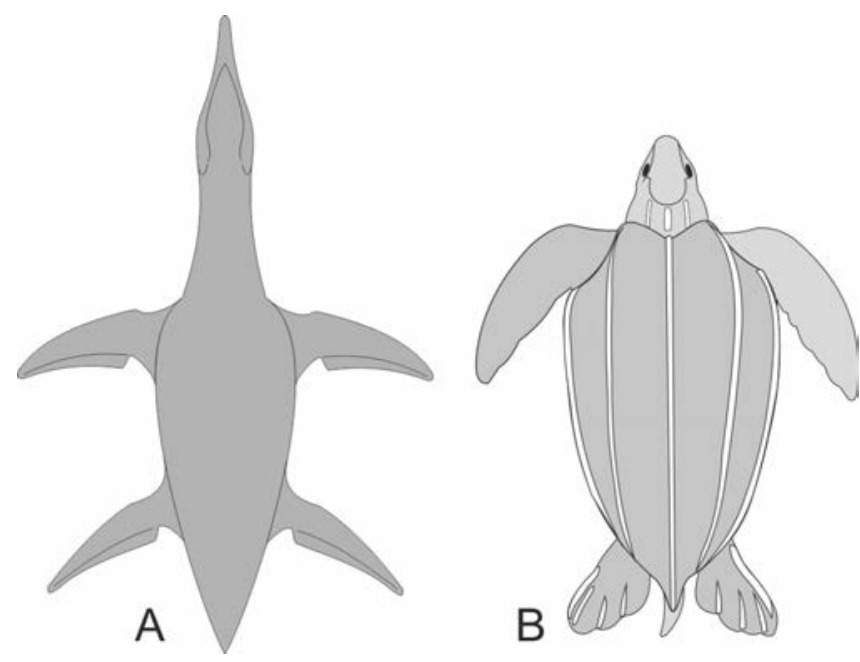

Figure 20 Comparison of the body outline of Mauriciosaurus fernandezi and Dermochelys coriacea. A) Schematic outline reconstruction of Mauriciosaurus fernandezi CPC RFG 2544 P.F.1. based on soft tissue evidence in ventral aspect. Note that trunk and tail form a functional unit with a drop-shaped outline with the thickest diameter lying anterior to the mid-section of the body. B) Outline sketch of a Leatherback Turtle (Dermochelys coriacea). Note that the drop-shaped outline of the carapace strikingly resembles the trunk-tail complex of Mauriciosaurus. The more slender body of the plesiosaur and the four-winged thrust system suggests a swimming speed greater than $7 \mathrm{~km} / \mathrm{h}$ $(1.9 \mathrm{~m} / \mathrm{s})$, which is the travel speed of a Leatherback Turtle. 
locities (Carpenter et al., 2010). According to the conservative body construction of Plesiosauria and the dimensions of the tail with respect to the body, it is reasonable to assume that Plesiosauria may have shared a drop-shaped body with a basically immobile fat tail that formed a functional unit with the trunk.

\section{Conclusions}

Mauriciosaurus fernandezi is an enigmatic polycotyline plesiosaur from the Paleogulf of Mexico. The species shows a mosaic of characters comprising diagnostic features from both Dolichorhynchops and Trinacromerum with a closer similarity to Dolichorhynchops, but also features of more basal polycotylids. Many of the enigmatic features are likely due to the early ontogenetic stage of the individual. Maturization of the cranial bones and the bones distal to the propodials preceded that of the axial skeleton and the vertebral column, resulting in an early enhancement of the feeding and locomotor apparatus. The extensive soft tissue preservation suggests a streamlined body contour with a fat tail base. The shape of the body thus resembles that of sea turtles. The soft tissue also allows for a reconstruction of the aspect ratio of the flippers of about 3.9, suggesting a high frequency - low amplitude stroke. This supports the assumption that polycotylids were the fastest swimming plesiosaurs (Carpenter et al., 2010; Massare, 1988). The body surface was covered with transversely orientated rectangular scutes arranged in transverse and longitudinal rows in the neck, body and tail. These structures could have helped to reduce drag at least at swimming speeds relevant for polycotylids (e.g. Dean and Bhushan, 2010; Saravi and Cheng, 2013; Supriadi et al., 2015) the body cavity was probably lined with a black peritoneum. Mauriciosaurus fernandezi is the best preserved 'soft tissue plesiosaur' worldwide and therefore contributes substantially to our knowledge on the anatomy and locomotion of plesiosaurs, especially considering that this young juvenile roamed the open sea more than $500 \mathrm{~km}$ away from the nearest shore.

\section{Acknowledgements}

Our special thanks go to Ing. Mauricio Fernández Garza for securing the specimen for the scientific community, allowing us to describe it, and donating it to the Museo Papalote Verde in Monterrey (Nuevo León). This publication would not have been possible without the support of the Deutsche Forschungsgemeinschaft (DFG). Dominik Schuster (Karlsruhe) assisted with the literature database and the measurement. We are very grateful to Bruce A. Schuhmacher (Hays Kansas), Bruce M. Rothschild (Rootstown, Ohio) R. Ewan Fordyce (Otago) and Robin O'Keefe (Huntington, West Virginia), who provided excellent reviews in an earlier version of this manuscript that substantially helped to improve the scientific content of the paper especially with respect to taxonomy. We cordially thank David M. Martill (Portsmouth) and Michael Maisch (Albstadt/Tailfingen) for their extremely constructive reviews of the final version of the papers. We also cordially thank Dr. Antoni Camprubí, Francisco Vega, Oscar Monzon and Sandra Ramos Amézquita (Mexico City) for their fantastic editing work.

\section{References}

Albright III, L.B., Gillette, D.D., Titus, A.L., 2007a, Plesiosaurs from the Upper Cretaceous (Cenomanian-Turonian) Tropic Shale of southern Utah, part 2: Polycotylidae: Journal of Vertebrate Paleontology, 27, 41-58.

Albright III, L.B., Gillette, D.D., Titus, A.L., 2007b, Plesiosaurs from the Upper Cretaceous (Cenomanian-Turonian) Tropic Shale of Southern Utah, part 2: Polycotylidae; replacement names for the preoccupied genus Palmula and the subfamily Palmulainae: Journal of Vertebrate Paleontology, 27, $41-58$. 
Albright III, L.B., Gillette, D.D., Titus, A.L., 2007c, Plesiosaurs from the Upper Cretaceous (Cenomanian-Turonian) Tropic Shale of southern Utah, part 1: New records of the pliosaur Brachauchenius lucasi: Journal of Vertebrate Paleontology, 27, 31-40.

Arkhangelsky, M.S., Averianov, A.O., Pervushov, E.M., 2007, Short-necked plesiosaurs of the Family Polycotylidae from the Campanian of the Saratov Region: Paleontological Journal, 41, 656-660.

Bardet, N., Pereda Suberbiola, X., Jalil, N-E., 2003, A new polycotylid plesiosaur from the Late Cretaceous (Turonian) of Morocco: Comptes Rendus Palevol, 2, 307-315.

Bhattacharya, J.P., MacEachern, J.A., 2009, Hyperpycnal Rivers and Prodeltaic Shelves in the Cretaceous Seaway of North America: Journal of Sedimentary Research, 79, 184-209.

Blanco-Piñón, A., Alvarado-Ortega, J., 2007, Review of Vallecillichthys multivertebratum (Teleostei: Ichthyodectiformes), a Late Cretaceous (early Turonian) "Bulldogfish" from northeastern Mexico: Revista Mexicana de Ciencias Geológicas, 24, 450-466.

Blanco-Piñón, A., Shimada, K., González-Barba, G., 2005, Lamnoid vertebrae from the Agua Nueva Formation (Upper Cretaceous: Lower Turonian), northeastern Mexico: Revista Mexicana de Ciencias Geológicas, 22, 19-23.

Blanco, A., Alvarado-Ortega, J., 2006. Rhynchodercetis regio sp. nov.; A dercetid fish (Teleostei:Aulopiformes) from Vallecillo, Nuevo León State, Northeastern Mexico: Journal of Vertebrate Paleontology, 26, 552-558.

Blanco, A., Cavin, L., 2003, New Teleostei from the Agua Nueva Formation (Turonian), Vallecillo (NE Mexico): Comptes Rendus Palevol 2, 299-306.

Bobolubow, N.N., 1912, The occurrence of Elasmosaurus and Polycotylusin Russian deposits: Annuaire Géologique et Minéralogique de la Russie, 14, 1-7.
Brown, B., 1904, Stomach stones and food of plesiosaurs: Science, 20, 184-185.

Brown, D.S., 1981, The English Late Jurassic Plesiosauroidea (Reptilia) and a review of the phylogeny and classification of the Plesiosauria; Bulletin of the British Museum (Natural History): Geology, 35, 253-347.

Buchy, M.C., Frey, E., Salisbury, S.W., Stinnesbeck, W., López-Oliva, J.G., Götte, M., 2006, An unusual pliosaur (Reptilia, Sauropterygia) from the Kimmeridgian (Upper Jurassic) of northeastern Mexico: Neues Jahrbuch für Geologie und Palaeontologie, 240, 241-270.

Buchy, M.C., Métayer, F., Frey, E., 2005, Osteology of Manemergus anguirostris n. gen. et sp., a new plesiosaur (Reptilia, Sauropterygia) from the Upper Cretaceous of Morocco: Palaeontographica Abteilung A: Palaozoologie-Stratigraphie, 272, 97-120. Buchy, M.-C., Smith, K.T., Ifrim, C., Giersch, S., 2007, Basal mosasauroids from the Turonian of Vallecillo, Nuevo León, Mexico, in Everhart, M.J. (ed.), Second Mosasaur Meeting May 2-6, Abstract Booklet, Fort Hays State University, Sternberg Museum of Natural History, 8.

Carpenter, K., 1997, Comparative cranial anatomy of two North American Cretaceous plesiosaurs, in Callaway, J.M., Nicholls, E.L. (eds.), Ancient Marine Reptiles: San Diego, Academic Press, 191-216.

Carpenter, K., Sanders, F., Reed, B., Reed, J., 2010, Plesiosaur swimming as interpreted from skeletal analysis and experimental results: Transactions of the Kansas Academy of Science, 113, 1-34.

Cicimurri, D.J., Everhart, M.J., 2001, An elasmosaur with stomach contents and gastroliths from the Pierre Shale (Late Cretaceous) of Kansas: Transactions of the Kansas Academy of Science, 104, 129-143.

Cope, E.D., 1869, On some reptilian remains: American Journal of Science, 2 48, 278.

Cope, E.D., 1872, Food of plesiosaurs: The American Naturalist, 6, 439. 
Dames, W., 1895, Die Plesiosaurier der Süddeutschen Liasformation: Abhandlungen der Königlich Preussischen Akademie der Wissenschaften zu Berlin, 1-83.

De Blainville, H.D., 1835, Description de quelques espèces de reptiles de la Californie, précédée de l'analyse d'un système général d'Erpétologie et d'Amphibiologie: Nouvelles annales du Muséum d'histoire naturelle, 4, 233-296.

De Gasparini, Z.B., de la Fuente, M., 2000, Tortugas y plesiosaurios de la Formación La Colonia (Cretácico Superior) de Patagonia, Argentina: Revista española de paleontología, 15, 23-35.

Dean, B., Bhushan, B., 2010, Shark-skin surfaces for fluid-drag reduction in turbulent flow: a review: Philosophical Transactions of the Royal Society A, 368, 4775-4806.

Delome, S.L., Lungu, I.M., Vickaryous, M.K., 2012, Scar-free wound healing and regeneration following tail loss in the leopard gecko, Eublepharis macularius: The Anatomical Record, 295, 1575-1595.

Derickson, W.K., 1976, Lipid storage and utilization in reptiles: American Zoologist, 16, 711-723.

Druckenmiller, P.S., Russell, A.P., 2008, A phylogeny of Plesiosauria (Sauropterygia) and its bearing on the systematic status of Leptocleidus Andrews: Zootaxa, 1863, 1-120.

Druckenmiller, P.S., Russell, M.J., 2009, The new plesiosaurian genus Nichollssaura from Alberta, Canada: replacement name for the preoccupied genus Nichollsia: Journal of Vertebrate Paleontology, 29 (1), 276.

Eckert, S.A., 2002, Swim speed and movement patterns of gravid leatherback sea turtles (Dermochelys coriacea) at St Croix, US Virgin Islands: Journal of Experimental Biology, 205, 3689-3697.

Ellis, R., 2003, Sea Dragons: Predators of the Prehistoric Oceans: U. S. A., University Press of Kansas, 326 p.
Fischer, A.G., Bottjer, D.J., 1995, Oxygen-depleted waters: a lost biotope and its role in ammonite and bivalve evolution: Neues Jahrbuch für Geologie und Paläontologie-Abhandlungen, 9, 133-146.

Frey, E., 1988, Anatomie des Körperstammes von Alligator mississippiensis Daudin: Stuttgarter Beiträge zur Naturkunde, Serie A (Biologie), $424,1-106$.

Frey, E., Riess, J., 1982, Considerations concerning plesiosaur locomotion: Neues Jahrbuch für Geologie und PaläontologieAbhandlungen, 164, 193-194.

Gasparini,Z.,Spalletti,L., 1990,Un nuevococodrilo en depósitos mareales maastrichtianos de la Patagonia noroccidental: Ameghiniana, 27: 141-150.

Giersch, S., 2014, Die Knochenfische der Oberkreidezeit in Nordostmexiko: Paläobiogeographie und Paläoökologie, $\mathrm{PhD}$ Thesis, University of Heidelberg, 275 p,.

Godfrey, S.J., 1984, Plesiosaur subaqueous locomotion: a reappraisal: Neues Jahrbuch für Geologie und Paläontologie, Monatshefte, 11, 661-672.

Goldhammer, R.K., Johnson, C.A., 2001, Middle Jurassic-Upper Cretaceous Paleogeographic Evolution and Sequence-stratigraphic framework of the Northwest Gulf of Mexico Rim, in The Western Gulf of Mexico Basin: Tectonics, Sedimentary Basins and Petroleum Systems: U.S.A., American Association of Petroleum Geologists, 45-82.

Greer, A.E., 1989, The biology and evolution of Australian lizards, Surrey Beatty and Sons, 264 p, Baulkham Hills, NSW, Australia.

Großmann, F., 2006, Taxonomy, phylogeny and paleoecology of the plesiosauroids (Sauropterygia, Reptilia) from the Posidonia shale (Toarcian, Lower Jurassic) of Holzmaden, south west Germany: $\mathrm{PhD}$ Thesis, University of Tübingen Germany, $135 \mathrm{p}$. 
Halstead, L.B., 1989, Plesiosaur locomotion: Geological Society, 146, 37-40.

Hampe, O., 1992, Ein großwüchsiger Pliosauride (Reptilia: Plesiosauria) aus der Unterkreide (oberes Aptium) von Kolumbien: Courier Forschungsinstitut Senckenberg, 145, 1-32.

Ifrim, C., 2006, The Fossil Lagerstätte at Vallecillo, North-Eastern Mexico: Pelagic Plattenkalks related to Cenomanian-Turonian Boundary Anoxia: $\mathrm{PhD}$ Thesis, University of Heidelberg, 151 p.

Ifrim, G., Frey, E., Stinnesbeck, W., Buchy, M.-C., González González, A.H., López Oliva, J.G., 2005, Fish assemblage in Lower Turonian carbonates at Vallecillo, N.L., México: Paleos Antiguo, 1, 43-51.

Ifrim, C., Stinnesbeck, W., 2008, CenomanianTuronian high-resolution biostratigraphy of north-eastern Mexico and its correlation with the GSSP and Europe: Cretaceus Research, 29, 943-956.

Ifrim, C., Vega, FJ., Stinnesbeck, W., 2011. Epizoic stramentid cirripeds on ammonites from Late Cretaceous platy limestones in Mexico: Journal of Paleontology, 85, 524-526.

Ifrim, C., Stinnesbeck, W., Frey, E., 2007, Upper Cretaceous (Cenomanian - Turonian and Turonian - Coniacian) open marine Plattenkalk-deposits in NE Mexico: Neues Jahrbuch für Geologie und Paläontologie, Abhandlungen, 245(1), 71-78.

International Commission on Zoological Nomenclature (ICZN), 2017, Lee Kong Chian Natural History Museum, National University of Singapore, available at ‘http:// zoobank.org. '

Kahana, T., Almog, J., Levy, J., Shmeltzer, E., Spier, Y., Hiss, J., 1999, Marine taphonomy: Adipocere formation in a series of bodies recovered from a single shipwreck: Forensic Science International, 44, 897-901.

Kear, B.P., 2006, Marine Reptiles from the lower Cretaceous of South Australia: Elements of a high-latitude cold-water assemblage: Paleontology, 49, 837-856.
Kear, B.P., 2007, A juvenile pliosauroid plesiosaur (Reptilia: Sauropterygia) from the Lower Cretaceous of South Australia: Journal of Paleontology, 81, 154-162.

Kear, B.P., Schroeder, N.I., Lee, M.S.Y., 2006, An archaic crested plesiosaur in opal from the Lower Cretaceous high latitude deposits of Australia: Biology Letters, 2, 615-619.

Ketchum, H.F., Benson, R.B.J., 2010: Global interrelationships of Plesiosauria (Reptilia, Sauropterygia) and the pivotal role of taxon sampling in determining the outcome of phylogenetic analyses: Biological Reviews, 85, 361-392.

Ketchum, H.F., Benson, R.B.J., 2011, The cranial anatomy and taxonomy of Peloneustes philarchus (Sauropterygia, Pliosauridae) from the Peterborough Member (Callovian,Middle Jurassic) of the UK: Paleontology 54, 639-665.

Lingham-Soliar, T., 2000, Plesiosaur locomotion: Is the four-wing problem real or merely an atheoretical exercise?: Neues Jahrbuch für Geologie und Paläontologie-Abhandlungen, 217, 45-87.

MacLeod, K.G., Hoppe, K.A., 1992, Evidence that inoceramid bivalves were benthic and harbored chemosynthetic symbionts: Geology, 20, 117-120.

Martill, D.M., 1992, Pliosaur stomach contents from the Oxford Clay: Mercian Geologist, 13(7), 37-42.

Massare, J.A., 1988, Swimming capabilities of mesozoic marine reptiles: Implications for method of predation: Paleobiology, 14, 187-205.

McHenry, C., Cook, A.G., Wroe, S., 2005, Bottom-feeding plesiosaurs: Science, 310, 75.

Muir, J.M., 1936, Geology of the Tampico region, Mexico: American Association of Petroleum Geologists Bulletin, 20, 1134-1141.

Noé, L., 1999, The Callovian pliosaurs of the Oxford Clay - Evidence and implications for the consumption of marine invertebrates, in Hoch, E., Brantsen, A.K. (eds.), Secondary 
Adaptation of Life to Water/La Réadaptation $\mathrm{Au}$ Milieu Aquatique. Proceedings of a Conference Held at the Geologisk Museum: Copenhagen, University of Copenhagen, 38-39.

O’Gorman, J.-P., de Gasparini, Z.B., 2013, Revision of Sulcusuchus erraini (Sauropterygia, Polycotylidae) from the Upper Cretaceous of Patagonia, Argentina. Alcheringa An Australasian Journal of Paleontology, 37 (2), 163-176.

O'Keefe, F.R., 2001, A cladistic analysis and taxonomic revision of the Plesiosauria (Reptilia: Sauropterygia): Acta Zoologica Fennica, 2001, 1-63.

O'Keefe, F.R., 2004, On the cranial anatomy of the polycotylid plesiosaurs, including new material of Polycotylus latipinnis, Cope, from Alabama: Journal of Vertebrate Paleontology, 24, 326-340.

O'Keefe, F.R., 2008, Cranial anatomy and taxonomy of Dolichorhynchops bonneri new combination, a polycotylid (Sauropterygia: Plesiosauria) from the Pierre Shale of Wyoming and South Dakota: Journal of Vertebrate Paleontology, 28, 664-676.

O'Keefe, F.R., Carrano, M.T., 2005, Correlated trends in the evolution of the plesiosaur locomotor system: Paleobiology, 31, 656-675.

O'Keefe, F.R., Chiappe, L.M., 2011, Viviparity and K-selected life history in a Mesozoic marine plesiosaur (Reptilia, Sauropterygia): Science, 333, 870-873.

O'Keefe , F. R., Byrd, C., 2012, Ontogeny of the shoulder in Polycotylus latipinnus (Plesiosauria: Polycotylidae) and its bearing on plesiosaur viviparity: Paludicola 9, 21-31.

Ochev, V.G., 1977, A substitution of the preoccupied name Georgia penzensis: Paleontologicheskii Zhurnal, 1977, 118.

Ochev, V.G., 1976, A new pliosaur from the Upper Cretaceous of Penza Province: Paleontologicheskii Zhurnal, 2, 135-138.

Page, L.M., Burr, B.M., 2011, Peterson Field Guide to Freshwater Fishes of North
America North of Mexico, 2nd edition, 663 p, Houghton Mifflin Harcourt, Boston.

Porter, W.P., 1967, Solar radiation through the living body walls of vertebrates with emphasis on desert reptiles: Ecological Monographs, 37, 273-296.

Rieppel, O., 1997, Sauropterygia. Introduction, in Callaway, J.M., Nicholls, E.L. (eds.), Ancient Marine Reptiles: San Diego, Academic Press, 107-120.

Riggs, E.S., 1944, A new polycotylid plesiosaur: Kansas University science bulletin, 30, 77-87.

Robinson, J.A., 1975, The locomotion of plesiosaurs. Neues Jahrbuch für Geologie und Paläontologie-Abhandlungen, 149, 286-332.

Sanders, F., Carpenter, K., Reed, B., Reed, J., 2004, Plesiosaur swimming reconstructed from skeletal analysis and experimental results: Journal of Vertebrate Paleontology, 24, 108A-109A.

Saravi, S.S., Cheng, K., 2013, A review of drag reduction by riblets and micro-textures in the turbulent boundary layers: European Scientific Journal, 9, 62-81.

Sato, T., 2005, A new Polycotylid Plesiosaur (Reptilia: Sauropterygia) From the Upper Cretaceous Bearpaw Formation in Saskatchewan, Canada: Journal of Paleontology, 79, 969-980.

Sato, T., Storrs, G.W., 2000, An early polycotylid plesiosaur (Reptilia: Sauropterygia) from the Cretaceous of Hokkaido, Japan: Journal of Paleontology, 74, 907-914.

Sato, T., Wu, X., Tirabasso, A., Bloskie, P., Sato, T., Wu, X., Tirab, A., 2011, Braincase of a polycotylid plesiosaur (Reptilia: Sauropterygia) from the Upper Cretaceous of Manitoba: Journal of Paleontology, 31, 313-329.

Schlanger, S.O., Jenkyns, H.C., 1976, Cretaceous oceanic anoxic events: causes and consequences: Geologie en Mijnbouw, 55, 179-184. 
Schumacher, B.A., 2007, A new polycotylid plesiosaur (Reptilia; Sauropterygia) from the Greenhorn Limestone (Upper Cretaceous; lower upper Cenomanian), Black Hills, South Dakota: Geological Society of America, 427, 133-146.

Schumacher, B.A., Bell, G.L., 1999, A new pliosauroid from the Greenhorn Limestone (Cenomanian), South Dakota, and its bearing on plesiosaur phylogeny: Journal of Vertebrate Paleontology, 3, 74A.

Schumacher, B.A., Everhart, M.J., 2005, A stratigraphic and taxonomic review of plesiosaurs from the old "Fort Benton Group" of central Kansas: a new assessment of old records: Paludicola, 5, 33-54.

Schumacher, B.A., Martin, J.E., 2016, Polycotylus latipinnis Cope (Plesiosauria, Polycotylidae), a nearly complete skeleton from the Niobrara Formation (early Campanian) of southwestern South Dakota: Journal of Vertebrate Paleontology, 4634, 0-15.

Schweitzer, M.H., Zheng, W., Cleland, T.P., Goodwin, M.B., Boatman, E., Theil, E., Marcus, M.A., Fakra, S.C., Schweitzer, M.H., 2013, A role for iron and oxygen chemistry in preserving soft tissues, cells and molecules from deep time: Proceedings of the Royal Society B, 281, 10.

Sohl, N.F., Martinez, R.E., Salmerón-Ureña, P., Soto-Jaramillo, F., 1991, Upper Cretaceous, in Salvador, A. (Ed.), The Gulf of Mexico Basin. Boulder, Colorado: Geological Society of America, v. J, 205-215.

Stinnesbeck, W., Frey, E., 2014, Paleogeography and paleoenvironment of Mexico during the Mesozoic., in Rivera-Sylva Héctor E., Carpenter Kennth, F.E. (ed.), Dinosaurs and Other Reptiles from the Mesozoic of Mexico: U. S. A., Indiana University Press (Series Life of the past"),13-29.

Storrs, G.W., 1999, An examination of Plesiosauria (Diapsida: Sauropterygia) from the Niobrara Chalk (Upper Cretaceous) of Central North America: Paleontological Contributions,
University of Kansas, 11, 1-15.

Storrs, G.W., Archangelksi, M.S., Efimov, V.M., 2000, Mesozoic reptiles of Russia and other former Soviet republics, in Benton, M.J., Shishkin, M.A., Unwin, D.M. (eds.), The Age of Dinosaurs in Russia and Mongolia: Cambridge, Cambridge University Press, 187-210.

Supriadi, S., Gunawan, M.B., Yanuar, H., Budhi, H.S., 2015, The replication of micro-riblets on ship hulls for drag reduction applications: International Journal of Technology, 5, 983-989.

Taylor, M.A., 1993, Stomach stones for feeding or buoyancy? The occurrence and function of gastroliths in marine tetrapods: Philosophical Transactions of the Royal Society of London, Series B, 341, 163-175.

Taylor, M.A., 1986, Marine reptiles - lifestyle of plesiosaurs: Nature 319, 179.

Taylor, M.A., 1981, Plesiosaurs - rigging and ballasting: Nature 290, 628-629.

Topper, R.P.M., Trabucho-Alexandre, J., Tuenter, E., Meijer, P.T., 2011, A regional ocean circulation model for the mid-Cretaceous North Atlantic Basin: implications for black shale formation: Climate of the Past, 7, 277-297.

Von Loh, J.P., Bell, G.L., 1998, Fossil reptiles from the Late Cretaceous Greenhorn Formation (late Cenomanian-middle Turonian) of the Black Hills region, South Dakota: Dakoterra 5, 29-38.

Wang, J., Wang, Y., Qu, H., Shu, D., 2012, Accumulation of melanin in the peritoneum causes black abdomens in broilers: Poultry Science, 93 (3), 742-746.

Welles, S.P., 1943, Elasmosaurid plesiosaurs with a description of the new material from California and Colorado: Memoirs of the University of California, 13, 125-254.

Williston, S.W., 1908, North American plesiosaurs, Trinacromerum: Journal of Geology, 16, 615-735. 